Chapman University

Chapman University Digital Commons

Spring 5-2021

\title{
Systemic Functional Linguistics in the Community College Composition Class: A Multimodal Approach to Teaching Composition Using the Metalanguage of SFL
}

Jennifer James

Chapman University, jenjames@chapman.edu

Follow this and additional works at: https://digitalcommons.chapman.edu/education_dissertations

Part of the Accessibility Commons, Adult and Continuing Education Commons, Bilingual, Multilingual, and Multicultural Education Commons, Community College Leadership Commons, Curriculum and Instruction Commons, Curriculum and Social Inquiry Commons, Language and Literacy Education Commons, and the Scholarship of Teaching and Learning Commons

\section{Recommended Citation}

James, J. (2021). Systemic functional linguistics in the community college composition class: A multimodal approach to teaching composition using the metalanguage of SFL [Doctoral dissertation, Chapman University]. Chapman University Digital Commons. https://doi.org/10.36837/chapman.000232

This Dissertation is brought to you for free and open access by the Dissertations and Theses at Chapman University Digital Commons. It has been accepted for inclusion in Education (PhD) Dissertations by an authorized administrator of Chapman University Digital Commons. For more information, please contact laughtin@chapman.edu. 


\title{
Systemic Functional Linguistics in the Community College Composition
}

\section{Class: A Multimodal Approach to Teaching Composition Using the Metalanguage of SFL}

\author{
A Dissertation by \\ Jennifer James \\ Chapman University \\ Orange, CA \\ Attallah College of Educational Studies \\ Submitted in partial fulfillment of the requirements for the degree of \\ Doctor of Philosophy in Education
}

May 2021

Committee in charge:

Scot Danforth, Ph.D., Chair

Dawn Hunter, Ph.D.

Noah Asher Golden, Ph.D. 
The dissertation of Jennifer James is approved.

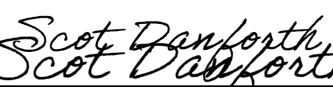

Scot Danforth, Ph.D., Chair

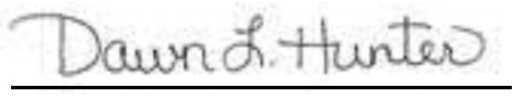

Dawn Hunter, Ph.D.

Noah Asher Golden

Noah Asher Golden, Ph.D.

February 2021 
Systemic Functional Linguistics in the Community College Composition Class: A Multimodal Approach to Teaching Composition Using the

\section{Metalanguage of SFL}

Copyright (C) 2021

by Jennifer James 


\section{DEDICATION}

To Will, Tommy, and Corinne - Always. 


\section{ACKNOWLEDGMENTS}

As I reach the end of my doctoral journey, I am filled with gratitude for the many people who supported me throughout the program. The achievement of this long-term goal was hardfought with many personal and professional obstacles that had to be overcome. I could not have reached the end without the encouragement, support, and guidance so many people provided. My students, mentors, friends, and family all played a vital role in helping me reach this milestone.

I need to start by acknowledging every student who has taken a composition class with me because they inspired me to go back to school and continued to inspire me to keep going throughout the program. Their voices and experiences informed and focused my research every step of the way. The joy in teaching comes from the relationships that develop through the classroom interactions and I am grateful students willingly shared their hopes and expectations with me. This research project could have never happened without the students who were so open to experiment with the art of composing along with me.

This dissertation also represents the faculty who challenged me in every class and informed my vision of inclusive curriculum filled with hope and opportunity. The faculty who served on my committee —Drs. Scot Danforth, Dawn Hunter, and Noah Asher Golden—were an invaluable asset from the conception to the completion of my dissertation. The idea for my dissertation came from an independent study with Dr. Golden. I am grateful for the space Dr. Golden created that allowed me to freely share my experiences with teaching writing. Dr. Golden somehow always had just the right reading to offer that would validate my experience and challenge me to find solutions. Most importantly, Dr. Golden held me to a high standard that always improved my work. Dr. Danforth also held me to high standards through challenging me in every disability studies class. His Introduction to Disability Studies class was the first class I 
took in the doctoral program, and he showed me what it means to be a disability studies scholar. As my dissertation chair, he believed in me when I did not believe in myself. His words of encouragement moved me through blocks and propelled me forward when I doubted myself. Dr. Hunter was an ever-present source of support and motivation throughout the program. Dr. Hunter was the first faculty member I met when I was thinking about pursuing a PhD. Her words of wisdom inspired me to enter the doctoral program and continued to guide me through the dissertation process. Her moral support and feedback strengthened my dissertation from design to completion.

The best part of the doctoral program has been the bond formed with my cohort, especially the Women of Mass Discussion. Betty, Anne, Elise, Sneha, Shayne, and Mackenzie have become my closest friends and confidants as we have gone through this experience together. Our group texts, coffee chats, dinners, and class discussions will always be the happiest memories from this time in my life. We saw each other through the program from the first class to the defense, and we left no one behind.

Outside of school, I could not have achieved this goal without the support of my tight network of friends: Mona Chung, Angel Vega Jordan, Shannon Sanchez, and Kathy Long. I truly felt loved, cared for, and supported throughout the program by my friends. From text messages, cards, care packages, phone calls, and words of encouragement, my friends continually reminded me I could accomplish this feat and kept me motivated to finish.

Of course, I need to thank my parents - Steve and Gwen James — who have always been supportive of every goal I set out to achieve. They were there for me to help with the kids when I took the GRE, needed time to study, had class, or went to conferences. The practical considerations of maintaining life while in graduate school would not have been possible without 
their help. They kept me grounded and helped me manage life so I could add the demands of graduate school. Their unconditional love and support have always made me feel capable of accomplishing any goal. I am so happy to share this degree with them.

I also share this degree with my children: Will, Tommy, and Corinne. A faculty member said to me at the beginning of my journey that the doctoral program represents sacrifice. As I reach the end of the program, those words resonate with me, and I know my children have also had to make sacrifices for me to finish. As a single mother, going through the doctoral program was hard and filled with doubt over whether I was making the right decision to go back to school with kids. I missed games, school events, and social experiences with my kids to study. They had to help each other with homework and pitch in with housework to keep the family moving. They have seen me breakdown in tears over feeling overwhelmed and have seen me filled with joy at the end of each semester. This has really been a family project from the beginning. I am so grateful for their love and support every step of the way. 


\section{ABSTRACT \\ Systemic Functional Linguistics in the Community College Composition Class: A Multimodal Approach to Teaching Composition Using the Metalanguage of SFL}

by Jennifer James

This qualitative research study sought to understand the affordances and limitations of a systemic functional linguistics (SFL) approach to teaching composition at the community college level. The study took place over the course of a semester in two developmental college composition classes using the language of SFL to teach writing through multimodal assignments. The study was developed in response to the increasing diversity in writing skills and educational goals of students in the community college composition class. The increase in diversity is a result of legislation in California that restructures developmental class offerings and affects placement in the transfer-level composition class. The findings of the study support that the sociocultural focus of SFL can empower students while also providing tangible instructional benefits for instructors. SFL supports equality in curriculum and fosters authentic, student-centered writing that prepares students for future writing situations. SFL also supports instruction by providing structured writing support, challenging students to expand writing skills, and preparing students to write for different disciplines in higher education. The central limitation to using an SFL framework to teach college composition is that SFL is not widely used in higher education in the United States. SFL as a framework for instruction has the potential to narrow the gap in writing skills among students, establish a shared language to discuss texts, and support 21 st writing 
demands. More research into the applications of SFL in higher education contexts is needed to support the inclusion of SFL in curriculum. 


\section{TABLE OF CONTENTS}

$\underline{\text { Page }}$

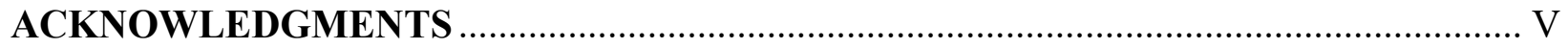

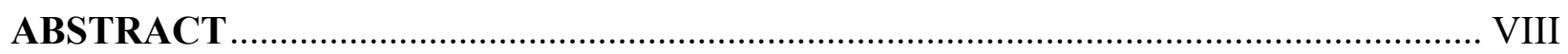

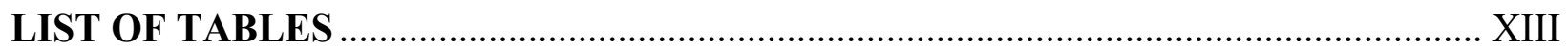

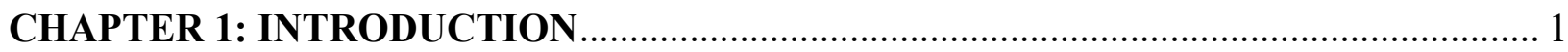

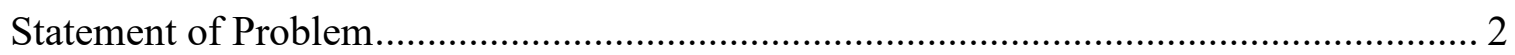

State Legislation in the Classroom ............................................................................. 3

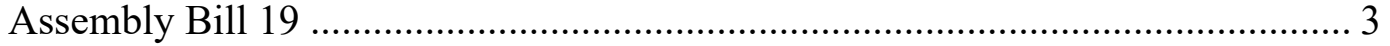

Assembly Bill 540 ...................................................................................... 4

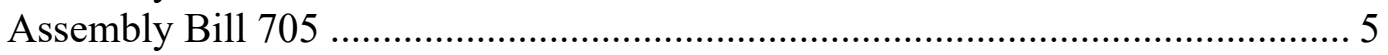

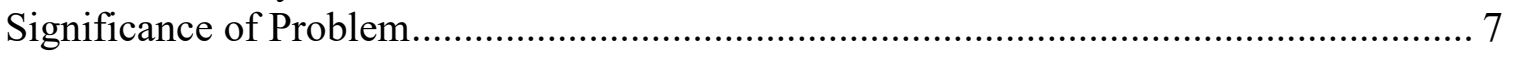

College Composition as Gatekeeper ...................................................................... 7

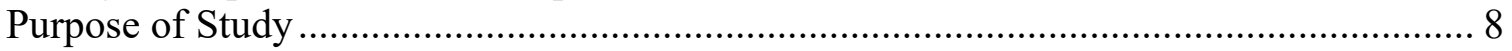

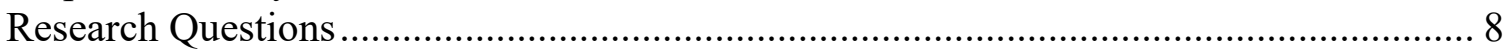

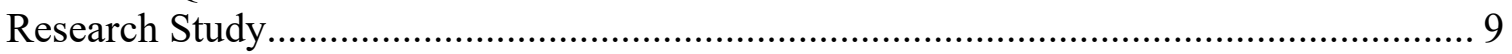

Framework: Systemic Functional Linguistics ……………......................................... 10

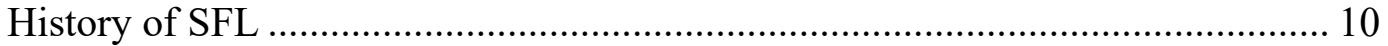

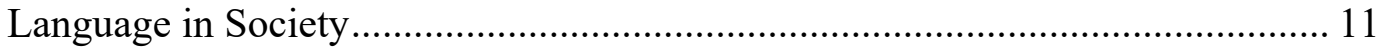

Language as Functional System...................................................................... 11

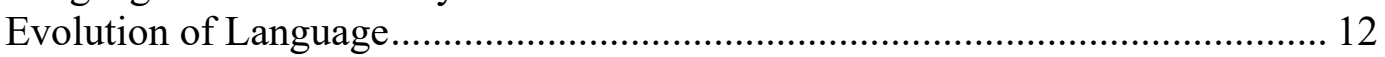

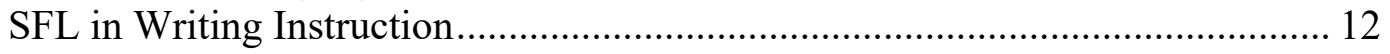

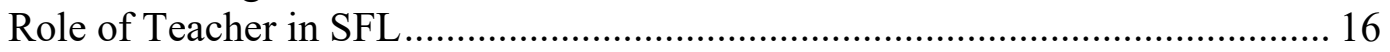

Composition Studies and SFL ...................................................................... 16

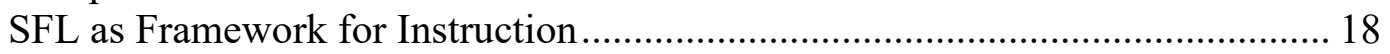

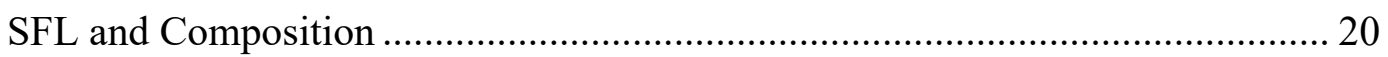

SFL and Democratic Agency........................................................................ 22

SFL Applied to Composition Classes for Research Study ................................... 23

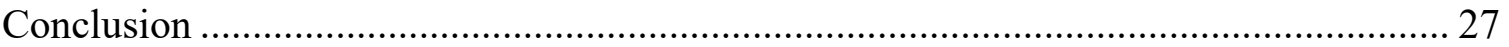

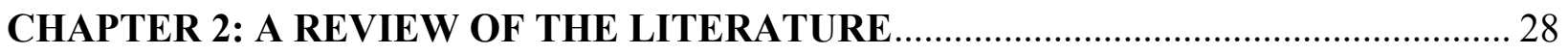

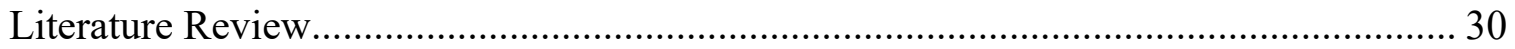

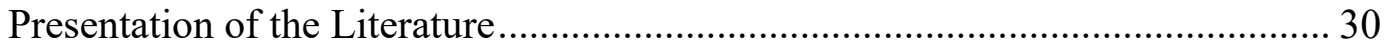

Affordances of SFL in Instruction ................................................................... 32

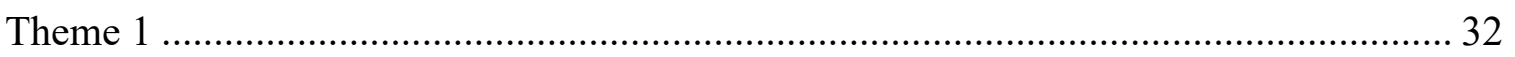

Shared Language for Writing Instruction ....................................................... 33

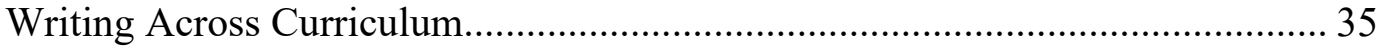

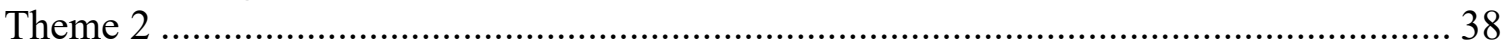

Tool to Develop Critical Reading Skills ............................................................. 39

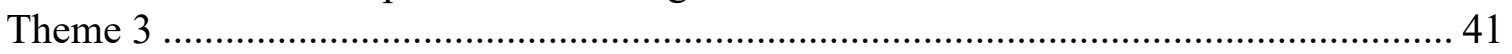


Theme 4

Instructional Support to Students From Marginalized Communities .................. 42

Shared Language for Instructional Discussions................................................ 48

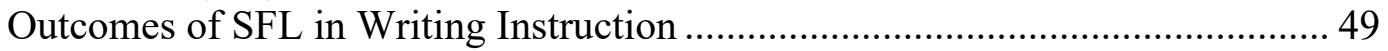

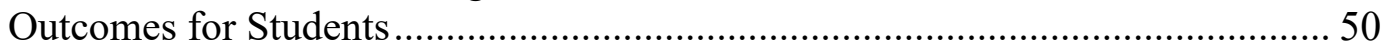

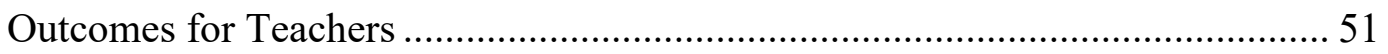

Limitations of SFL in Writing Instruction ..................................................... 52

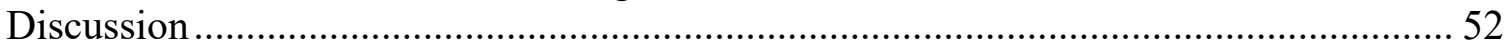

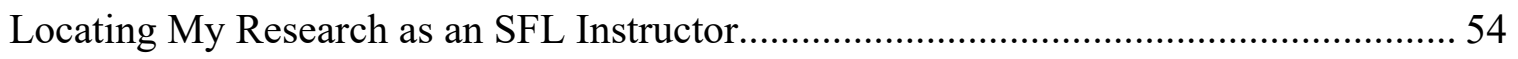

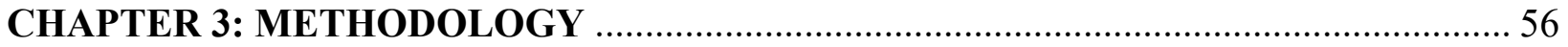

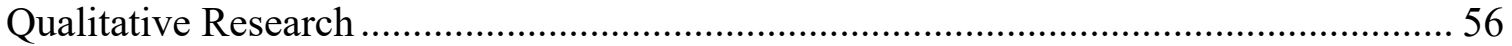

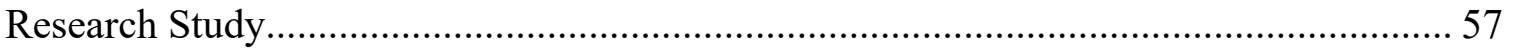

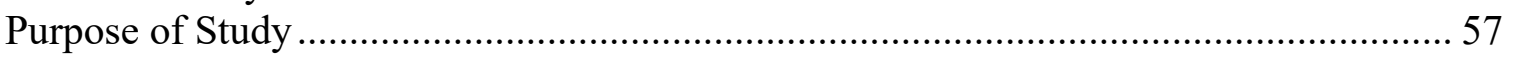

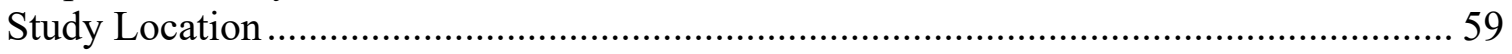

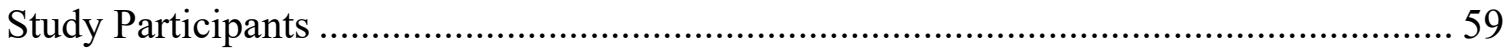

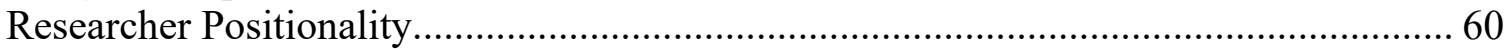

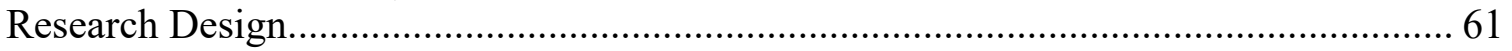

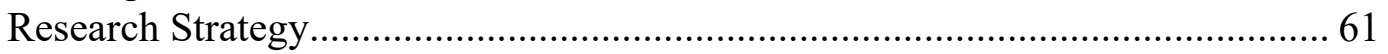

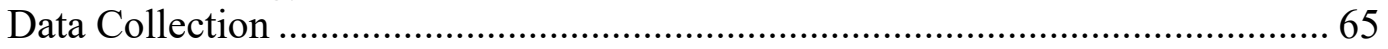

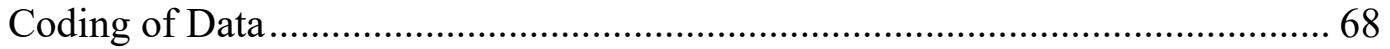

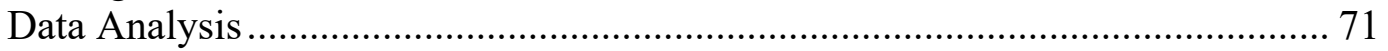

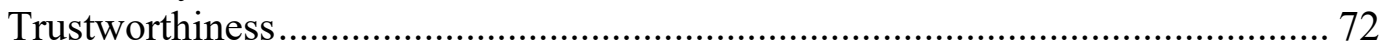

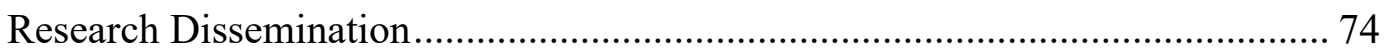

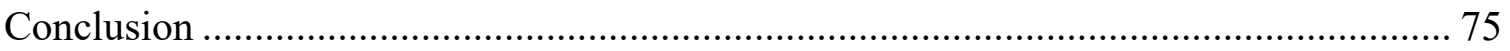

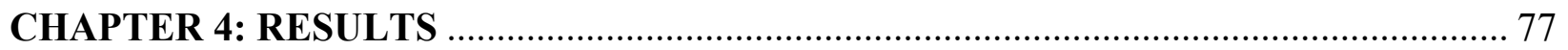

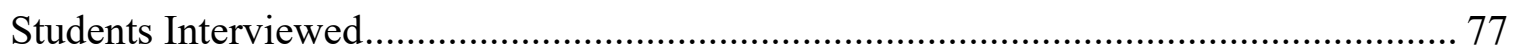

Description of Students Interviewed ........................................................ 78

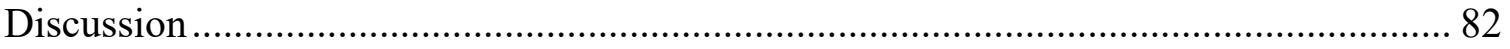

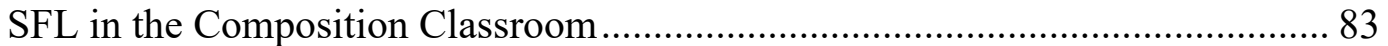

Register Level of SFL ............................................................................ 83

Affordances of the Register Level of SFL in the Composition Classroom .......... 84

Limitations of the Register Level of SFL in the Composition Classroom ........... 93

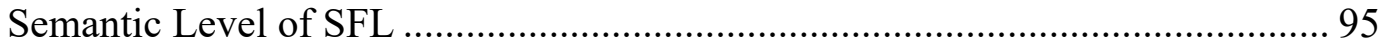

Affordances of the Semantic Level in the Composition Classroom.................... 95

Limitations of the Semantic Level in the Composition Classroom ................... 109

Lexicogrammar Level of SFL ................................................................... 110

Affordances of the Lexicogrammar Level in the Composition Classroom ........ 110

Limitations of the Lexicogrammar Level in the Composition Classroom ......... 118

End-of-Semester Reflection on SFL .............................................................. 118

Overall Affordances of SFL in the College Composition Classroom ................ 119

Overall Limitations of SFL in the College Composition Classroom................. 124

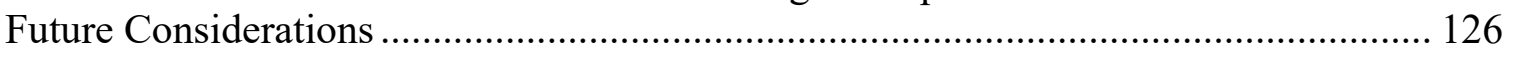

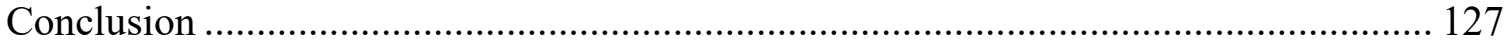




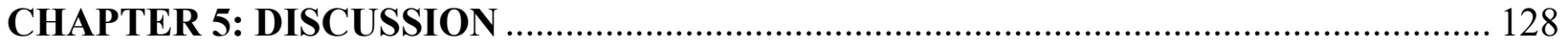

Discussion of Findings........................................................................................... 130

SFL Framework Empowering for Students .................................................. 130

SFL Framework Provides Instructional Support for Instructors.......................... 136

Students Develop Skills to Write Across College Curricula ................................. 139

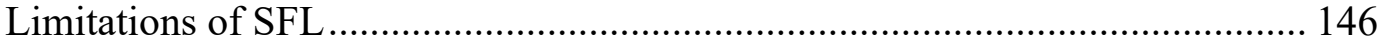

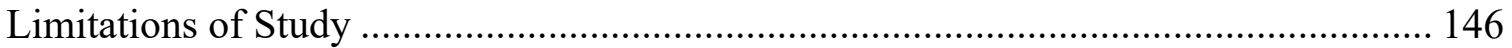

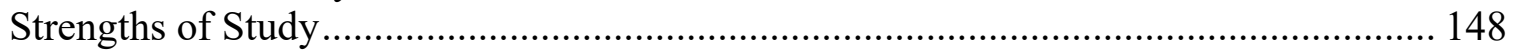

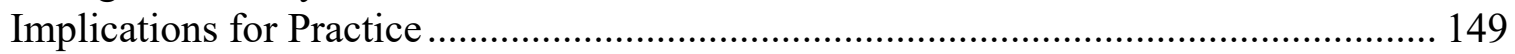

Bridge the Skills Divide................................................................................ 150

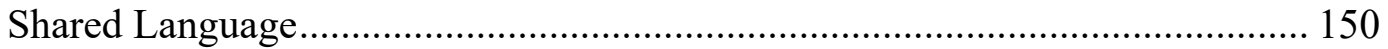

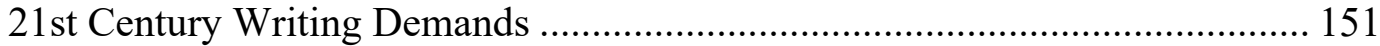

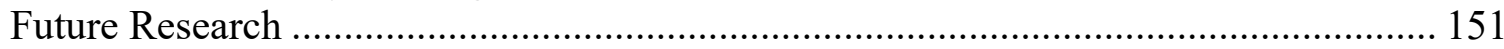

Develop Curriculum for Diversity in Abilities ............................................. 152

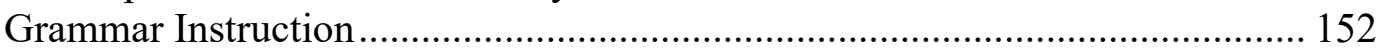

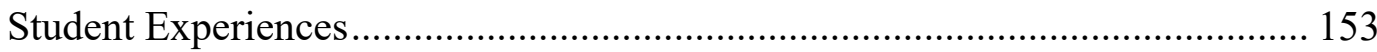

Interdisciplinary Research ........................................................................ 154

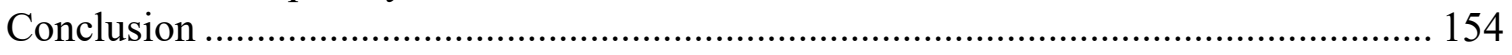

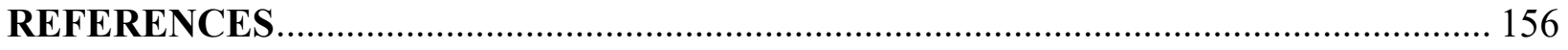




\section{LIST OF TABLES}

$\underline{\text { Page }}$

Table 1. Articles Included in Review of Literature ................................................................. 31 


\section{CHAPTER 1: INTRODUCTION}

Toward the end of the Spring 2018 semester, I asked students in my Friday

developmental college composition class to write everything they dislike about writing classes. Then I asked for them to write down everything they like about writing classes. Finally, I asked them to write whether they view composition as a skill that is necessary in life outside of the classroom or if it is just another step in a long line of classes. I selected my Friday class because it is representative of a typical community college classroom. There were students representing all ages, cultures, and socioeconomic classes. I wanted to get a feel for what is working and what is not from a student point of view. The responses to the free-write questions were as varied as the community college classroom. A few students wanted to have structured assignments with plenty of examples as guides. A few other students did not like the structured approach to writing; they wanted more freedom in writing by not having to follow a rhetorical mode and choosing what they write about. English language learners (ELL) students wanted a greater emphasis on grammar, and native English speakers reported finding grammar instruction boring. The problem with teaching in a community college classroom is the same aspect that makes the teaching experience so rewarding - diversity. This is a daunting task for many community college teachers.

As a community college teacher for 9 years, I posed the questions to my class because I was struggling with creating engaging activities and assignments that would reach each student. Many students seemed to be going through the motions of developing pat academic essays that fulfilled a model they had been taught to follow throughout their education. Other students would wait after class and ask me to tell them exactly how I wanted the assignment to be completed. I felt students wanted to complete the assignment to my satisfaction, without 
understanding the why behind the assignment. While grading essays, I began to question the confines of the composition class essay. The often formulaic writing produced in the composition class did not seem to allow for the diversity in student experiences to come through.

\section{Statement of Problem}

Although the diversity found on community college campuses throughout California can create a dynamic environment for rich class discussions, it can also be difficult for instructors to teach to such diversity in age, socioeconomic brackets, languages, ethnicities, and abilities. The largest age demographic is between $20-24$ years of age at $31.67 \%$, and students ages 35 and over represent $20.7 \%$ of enrollees (California Community Colleges Chancellor's Office [CCCCO], 2021). In addition, "three out of every 10 Californians ages 18-24 are enrolled in a community college" (Foundation for California Community College [FCCC], 2021, para. 1) with a total enrollment of 2.1 million. As for ethnicities, over $69 \%$ "of California community college students are people of diverse ethnic backgrounds" (FCCC, 2021, para. 1) with Hispanics the largest ethnicity at $43.61 \%$. Students with disabilities are another significant demographic. During the 2016-2017 academic year, 124,328 community college students were registered with Disabled Students Programs and Services (CCCCO, 2021). There is also diversity in students' reasons for attending community college. Students can pursue a career technical certificate, an associate degree, personal enrichment, or admission into a university (California Community Colleges, 2021). The diversity is supported by community college's broad enrollment requirements. California community colleges are required to admit any resident or nonresident with a high school diploma or equivalent. Anyone over 18 without a high school diploma can enroll if they are judged to be "capable of profiting from the instruction offered" (California Community Colleges, 2021, para. 1). High school students can also enroll in community college 
through dual enrollment programs. The diversity in backgrounds, abilities, and goals can make finding commonality among students difficult for instructors.

\section{State Legislation in the Classroom}

The State of California has recently passed a series of assembly bills that aim to support students in pursuing higher education. Although the goal of the assembly bills is to reduce the barriers students in college face, the changes may affect the composition of the classroom leading to greater diversity in student readiness and purpose.

\section{Assembly Bill 19}

Assembly Bill 19 (AB19) has the potential to increase the diversity on community college campuses throughout California. AB 19, the California College Promise (CCP) was signed into law by Governor Jerry Brown in the fall of 2017 (Zinshteyn, 2017). There are clearly defined goals for the CCP: (a) increase the number of high school students who enroll in college prepared for college-level coursework, (b) increase the number of students who earn associate degrees or career technical certificates, and (c) increase the number of students who transfer to a California State University or University of California campus. Most significantly, the CCP has a goal to reduce and eliminate

regional achievement gaps and achievement gaps for students from groups that are underrepresented at the California Community Colleges, including, but not limited to, underrepresented students, low-income students, students who are current or former foster youth, students with disabilities, formerly incarcerated students, undocumented and AB 540 students, and students who are veterans. (California State Legislative Information, A.B. 19, 2017, sec. 76396.1) 
Collectively, these goals are designed to increase affordability and support services for underrepresented students. Funding to accomplish the goals of CCP will be provided through the CCCCO. Each individual community college can decide how they will use the funds from CCP to address the needs of their specific community. Although colleges can use the funds from CCP to provide support services, like on-campus childcare or dual enrollment to high school students, colleges can also use the funds to offer free or reduced tuition to first-time community college students enrolled full time. The emphasis on community outreach to increase enrollment, coupled with additional support and reduced or free tuition, has the potential to increase the diversity in the community college classroom.

\section{Assembly Bill 540}

Additionally, in the fall of 2017, Governor Jerry Brown signed into law Assembly Bill 540 (AB 540) - Community Colleges Student Success and Support Program Funding (CCCCO, 2017). The goal of AB 540 is to develop a standard methodology to evaluate access, retention, degree, and certificate completion for underrepresented students. This law is designed to support the Seymour-Campbell Student Success Act of 2012, which required each community college district to develop a student equity plan (California Legislative Information, A.B. 705, 2017). Specifically, "this bill would require that Student Success and Support Program funding be used to support the implementation of student equity plan goals and the coordination of services for the targeted student population through evidence-based practices" (California Legislative Information, A.B. 504, Ch. 742). AB 1081 was signed along with AB 504 to add three additional categories to be included in the equity plan: homeless students and lesbian, gay, bisexual, or transgender students (2017). AB 1081 also enables the governing boards of each community college district to add additional categories of underrepresented students. AB 504 and AB 1081 
show that the State of California is not only trying to increase enrollment of underrepresented students, but that the state is also committed to monitoring whether the needs of underrepresented students are being met to improve retention and completion. The diversity in the community college classroom needs to be supported, evaluated, and monitored.

In addition to recent laws that strive to increase enrollment of underrepresented students and decrease tuition for these students, Gavin Newsom, the governor of California, included a promise of free community college tuition for all as part of his education reform platform (Savidge, 2018). Free community college is widely supported by Californians as well. A poll by the Public Policy Institute of California (2019) found 53\% of residents want free tuition for community college to be a top priority for the governor. The funds for free community college will come from the estimated $\$ 14.9$ billion revenue surplus Newsom inherited when he took office (Savidge, 2018). Offering free tuition may be in the distant future or may not even transpire, but this does show the governor and residents of California are in support of making community college affordable for all. Free tuition has the potential to remove the financial burden that keeps many people from pursuing higher education, which will increase enrollment and diversity even more.

\section{Assembly Bill 705}

The task of meeting the needs of students in composition courses may become even more challenging with changes in how community colleges structure composition course offerings. The 116 community colleges in California have changed their approach to testing for college readiness and how remedial courses are offered to students. Changes to the community college system are a result of the California Acceleration Project and Assembly Bill 705. The California Acceleration Project (2021) is a community college faculty-led organization that was created in 
2010 to "transform remediation to increase student completion and equity" (p. 1). Through professional development and advocating for policy change, the organization strives to eliminate high-stakes standardized placement tests to determine college readiness and reduce the number of remedial courses a student must take before enrolling in college-level coursework. AB 705, which was signed by Governor Brown on October 13, 2017, requires a community college district or college to maximize the probability that the student will enter and complete transfer-level coursework in English and mathematics within a one-year timeframe, and use, in the placement of students into English and mathematics courses in order to achieve this goal, one or more of the following: high school coursework, high school grades, and high school grade point average. (California Legislative Information, A.B. 705, 2017, sec. 78213)

In addition, Title 5 of California Code 55002 moves basic skills coursework in math, writing, and reading from the community college to adult education as noncredit, open-entry classes.

Although many educators in higher education in California herald these changes to remediation as a positive step in the right direction, other educators have spoken out against the new direction of remediation in college. Those who support the changes assert removing standardized tests as an assessment for college readiness will improve access and graduation rates for students (Xia, 2017). Eloy Ortiz Oakley, California Community Colleges chancellor, asserted in an interview with The Los Angeles Times, "We have ... been placing many students in remedial courses that really didn't belong in those remedial courses—and in doing so have made it harder for them to complete their college educations" (as cited in Xia, 2017, para. 18). Conversely, the Academic Senate for California Community Colleges (ASCC) wrote a letter to Benjamin Allen, senate education committee chair, in opposition to AB 705. The letter, dated 
June 27, 2017, conveyed the Academic Senate's concern the bill would not "recognize and respond to the needs of the diverse student populations" (ASCC, 2017, para. 1) the California community colleges serve.

\section{Significance of Problem}

Community colleges were created to provide postsecondary education to a wider demographic (Beach, 2010). Although the purpose of the community college system was to expand access and create equity in postsecondary education, "traditionally underserved populations, such as the economically disadvantaged and non-white ethnic/racial minorities, still struggle to achieve equality of opportunity in American society and its institutions of higher education" (Beach, 2010, p. xix). With half of first-time college students in the United States taking classes at a community college, access to higher education for many Americans is limited to the community college due to its affordability and open access. Although the majority of students enrolled in a community college plan to transfer to a university, most students will never earn a college degree. As community college is often the only postsecondary option for students from marginalized communities, "the structural outcomes of its mission are of great consequence to educators, policymakers, and citizens concerned with social justice and participatory democracy" (Ayers, 2005, p. 527).

\section{College Composition as Gatekeeper}

Students must pass transfer-level college composition with a grade of $\mathrm{C}$ or better to earn a career technical certificate, complete an Associate of Arts degree, or transfer to a university. The reading and writing skills learned in college composition are often necessary in other disciplines as well, so students may struggle to pass other classes without the skills taught in college composition. If a student does not learn college-level reading and writing skills, students 
risk not fulfilling academic, career, and personal goals. This can be detrimental because "the community college affords the disadvantaged an opportunity for employment, financial independence, and personal development" (Ayers, 2005, p. 527). If the community college is to fulfill its egalitarian purpose, then it must provide the opportunity for students from all backgrounds and abilities to fulfill their goals and potential.

\section{Purpose of Study}

In light of the differences in writing skills and educational goals among students in a community college composition class, a framework for teaching college composition that would support the diversity while challenging each student was researched. Systemic functional linguistics (SFL) as a sociocultural approach to literacy was discovered through research as a potential method for instruction. The purpose of this study was to gain insight into the affordances and limitations of using a SFL framework to teach composition. To carry out the purpose of the study, SFL was used as the framework for writing instruction in the community college composition class.

SFL is a language system that views all language as functioning within a system and as purposefully functioning according to the system. SFL consists of multiple levels that function together to create a language system. For this study, the SFL levels of register, semantics, and lexicogrammer were applied to the class curriculum. This sociocultural approach to language instruction was used to teach two sections of developmental college writing at Coastal California Community College (pseudonym) during the Spring 2019 semester.

\section{Research Questions}

The main question I researched for this study was: What are the affordances and limitations of a systemic functional linguistics approach to teaching college composition? In 
addition to the main research question, I researched several subquestions: Does SFL advance the writing skills of all students — both advanced and developmental? Can students apply the SFL framework to other disciplines in college? Does SFL enable students to write outside of academia for a variety of work and personal situations?

\section{Research Study}

For this study, I taught developmental college composition at Coastal California College using the SFL framework through multimodal assignments. The study intended to provide insight into the affordances and limitations of the SFL framework in teaching college composition to a diverse student body. SFL has the potential to bridge the educational gaps present in a community college class by providing access to how language functions and is structured in response to society. SFL can provide insight for students into how language is a resource that can be used to enrich a student's life academically, professionally, and personally. This approach to teaching may move students away from viewing the composition class as one more class to check off their degree requirements list.

The classes in which I used the SFL framework for instruction were my Friday class that met from 9:30 a.m.-1:50 p.m. and my Monday / Wednesday class that met from 7:20-9:20 a.m. These classes attracted the diverse demographic that is the hallmark of community college. I have taught at these times before, and it has been my experience that these class times attract students who are trying to fit classes in while working full time or juggling multiple responsibilities outside of school. 


\section{Framework: Systemic Functional Linguistics}

SFL is a comprehensive approach to studying how a language system functions to create meaning in society. This approach to studying language reveals the evolving nature of language as a meaning-making resource for users (Halliday \& Matthiessen, 2014).

\section{History of SFL}

Halliday developed SFL as "a semantic system of meaning which is distinguished from other semiotic systems by the fact it is grounded on grammar" (Webster, 2009, p. 5). Halliday created a practice through SFL that accounts for meaning in language as being constructed through social experiences and relationships (Webster, 2009). Halliday realized the need to account for meaning deriving from experiences and relationships when studying linguistics in China. Halliday was a language teacher who returned to school to pursue a $\mathrm{PhD}$ in linguistics at Cambridge University. While a graduate student, Halliday was in China to study the colloquial dialects of Cantonese. However, due to civil unrest in the villages, Halliday was unable to complete the research in the villages. Instead, Halliday had students from the villages who were attending the local university translate sentences from academic, formal Cantonese to the colloquial Cantonese used in their individual village. From this experience, Halliday realized a need to develop a "theory in how we actually use language to construe reality and enact social relationships" (as cited in Webster, 2009, p. 1). However, Halliday was reluctant to refer to the linguistic system they created as a theory because they did not see themselves as a theoretician. Halliday viewed SFL as a practice that used grammar as a resource for making meaning. Halliday's ideas were first published in a 1961 edition of the academic journal WORD under the title "Categories of the Theory of Grammar." Halliday continued to develop the framework and 
eventually developed their ideas into a book, Introduction to Functional Grammar, in 1985 (Matthiessen, 2014).

\section{Language in Society}

SFL provides a sociocultural approach to studying "language through semiosis - the making and understanding of meaning" (Halliday \& Matthiessen, 2014, p. 5). It is through both oral and written language that human experience is created and conveyed to others. However, the language that has evolved to communicate experience does not directly correspond to the tangible events and objects in the environment. As Halliday and Matthiessen (2014) explained, "Experience is remembered, imagined, abstracted, metaphorized and mythologized — the text has the power to create its own environment; but it has this power because of the way the system has evolved, by making meaning out of the environment as it was given" (p. 29).

The text that communicates experience is created when people write or speak and readers or listeners respond to the text. Text can be any medium of language as long as it can be interpreted by an audience who shares the same language. In this respect, language is a resource

for making meaning through text that is then communicated within a context. Text, when viewed as a social construct of people who share a language, can be critically analyzed to gain insight into why a text means what it does and why the text is valued in society. The text becomes an artifact of the linguistic system as a whole. The text cannot be analyzed in isolation of the linguistic system it comes from.

\section{Language as Functional System}

In SFL, the linguistic system that creates language can be broken down into grammatical categories that create meaning. These larger units of language contain smaller units, known as “constituency" (Halliday \& Matthiessen, 2014), and represent the compositional structure of 
language. Meaning is created through how the user chooses and combines these units of language: "A language is a resource for making meaning, and meaning resides in systemic patterns of choice" (Halliday \& Matthiessen, 2014, p. 23). The units of language are the resources that form a functional system to create and express meaning. The system of choices utilized by the user to create meaning reflects "a basic premise of systemic linguistics: that language use is purposeful behavior" (Eggins, 2004, p. 4). All language is created by the user to fulfill a purpose, either pragmatic or interpersonal. Although language consists of a system of choices that creates meaning, the system is also functional because it reveals how "people use language and how language is structured for use" (Eggins, 2004, p. 3).

\section{Evolution of Language}

A benefit of the systemic approach is the ability to see how language evolves along with society (Halliday \& Matthiessen, 2014). As language evolves, SFL provides insight into the new meanings created when language and social context intersect (Schleppegrell, 2004). New meanings are constantly created as "speakers and writers simultaneously present content, negotiate role relationships, and structure texts through particular grammatical choices which make a text the kind of text it is" (Schleppegrell, 2004, p. 18). Speakers and writers are active participants in the evolution of language as a result of responding to changing contexts. The evolving nature of language revealed through SFL "contributes to understanding how developing new ways of using language also leads to new ways of thinking" (Schleppegrell, 2004, p. 18).

\section{SFL in Writing Instruction}

The pedagogy of SFL relates language as a social process that can be communicated through writing by transforming experience and interaction into wording at the semantic and lexicogrammar levels (Halliday \& Matthiessen, 2014). 


\section{SFL Applied to Writing}

SFL can be used to analyze the discourse of any field - education, politics, science, law, etc. SFL deconstructs language for analysis by breaking down language into its constituent parts. These parts can then be analyzed within the linguistic system of the ideational and interpersonal levels to gain insight into how language is used and why it is valued (Zhang, 2019). This approach to breaking down language into parts can also be used to build language in a discourse community by making conscious choices in writing at each level of the language system. Halliday and Matthiessen (2014) asserted there is a "paradigmatic ordering in language" (p. 22) with system on one axis and structure on another axis. The system of language represents "patterns in what could go instead of what" and the structure of language reflects the patterns in language or "what goes together with what" (Halliday \& Matthiessen, 2014, p. 22). These two modes of meaning work together to provide a theory of human experience. SFL uses an ideational metalanguage to represent the semantic level of language that transforms experience and interaction into a system of meaning. In addition to the semantic level, the lexicogrammar level of language acts as a resource to further transform the meaning into words (Eggins, 2004). The lexicogrammar level corresponds with textual meaning by being concerned with how words combine to form meaning through sentences (Zhang, 2019).

\section{Semantic Level of Meaning}

Systemicists break the semantic level down into the genre and register of the text. The genre refers to a specific discourse type that serves a social purpose by enabling interaction and understanding between the writer and reader (Schleppegrell, 2004). Genre is a response to the cultural context of language by communicating purpose in writing through a socially expected structure (Eggins, 2004). For example, there are specific genres that are often associated with the 
writing expected in school contexts: "recount, narrative, procedure, report, account, explanations, exposition" (Schleppegrell, 2004, p. 83). Each context has "its own expectation for particular ways of using language" (Schleppegrell, 2004, p. 83), which writers must be aware of to construct meaning.

The register level of SFL "describes the impact of dimensions of the immediate context of situation of a language event on the way language is used" (Eggins, 2004, p. 9). The three dimensions of register in SFL are labeled as the ideational, interpersonal, and textual levels of meaning. These three dimensions provide a metalanguage to describe how language makes "real world meaning" (Eggins, 2004, p. 11) within a cultural context. Halliday and Matthiessen (2014) described the ideational metafunction as comprising "language as reflection" (p. 30), because we do not use language in isolation. The language we construct is interacting with the environment around us; therefore, our language choices are a reflection of our environment. At the same time, the interpersonal metafiction is construed as "language as action" (Halliday \& Matthiessen, 2014, p. 30), because our language choices are interacting with an audience. The textual metafiction reflects how we build discourse - through organization, cohesion, and continuity - to construe experiences and enact interpersonal relationships.

The ideational, interpersonal and textual metalanguage of SFL corresponds in practice to field, tenor, and mode (Eggins, 2004). The field corresponds to the "topic or focus of the activity" (Eggins, 2004, p.9, the tenor refers to the "role relations of power and solidarity" (p. 9), and the mode represents the "amount of feedback and role of language" (p. 9). In writing, the field relates to the topic or subject matter being written about, the tenor reflects the power dynamic between the writer and audience, and the mode represents the language choices used to construct the field and communicate the tenor (Halliday \& Matthiessen, 2014). These three 
components of the semantic level of meaning operate within a social system that organizes language as sets of choices (Eggins, 2004). The meaning constructed in writing is developed from choices made by the writer against a backdrop of all the other possible choices that were not made.

\section{Lexicogrammar Level of Meaning}

The next level of meaning in SFL is the lexicogrammar of a text. The lexicogrammar level is broken down into four ranks: sentence, subsentence (or clause), word, and letter (Halliday \& Matthiessen, 2014). This level is the "central processing unit of language, the powerhouse where meanings are created" (Halliday \& Matthiessen, 2014, p. 22). The lexicogrammar level of a text represents the systems of grammatical choice writers can use (Eggins, 2004). Language can convey ideational, interpersonal, and textual meanings because of grammatical resources available within the lexicogrammar level. The grammatical resources authors use in creating text are transitivity, clause complex, theme and mood. Transitivity refers to "the clausal realization of contextual choices [to] represent experience in a particular way" (Eggins, 2004, p. 253). The writer develops clauses through transitivity to create a coherent text that reflects an experience or interaction. The clause complex refers to two or more clause clusters in a sentence. A writer can create lexical density in a sentence by combining clauses. Theme is "the starting-point for the message: it is what the clause is going to be about" (Halliday \& Matthiessen, 2004, p. 64). A writer uses theme when referring to something that has already been written about in the text (Eggins, 2004). Finally, the mood structure refers to the "choices about the functional constituents such as subject, finite, predicator, complement, adjunct and their configurations" (Eggins, 2004, p. 184). The mood is how the writer constructs the clauses to enable interaction between the text and the audience. 


\section{Role of Teacher in SFL}

In the book, Language of Schooling: A Functional Linguistics Perspective, Schleppegrell (2004) asserted, "Learning in school is done primarily through language, yet the language of school tasks is seldom explicitly discussed or taught in schools" (p. 19). Employing an SFL approach to writing instruction allows teachers to make explicit how language functions to make meaning. SFL provides a visible framework for teachers to discuss choices available to a writer when constructing a text. The role of the teacher is not to lecture on the rules of writing but to explain how knowledge is constructed through conscious choices made in the semantic and lexicogrammar levels of language. SFL provides a framework to show the choices available in developing a text are based on the social context of the situation. With this approach, a student's social experience "can be explicitly acknowledged and incorporated into language development theory and pedagogy" (Schleppegrell, 2004, p. 9). Students have not had equal exposure to language instruction, so SFL enables the teacher to level improve equality in curriculum by using SFL to illustrate how language functions in creating meaning. In SFL, language is viewed as a coconstructed social force between student and teacher. Most importantly, SFL makes explicit that discourse style is a social construct that varies from group to group. As a result, SFL can enable "teachers to work more effectively with students with whom they do not share cultural or class membership in helping them understand those students' discourse styles and how they may be different from mainstream expectations" (Schleppegrell, 2004, p. 40). This insight can enable students to expand their linguistic ability to create meaning in all facets of life.

\section{Composition Studies and SFL}

There are two focal approaches in the teaching of composition: prescriptive and process. The rules-based focus of the prescriptive approach is represented by the text, The Elements of 
Style by Strunk and White (2009). This approach values adherence to grammatical rules and forwards the idea that "a basic structural design underlies every kind of writing" (Strunk \& White, 2009, p. 15). In the chapter on the principles of composition, Strunk and White (2009) asserted, "The first principle of composition ... is to foresee or determine the shape of what is to come and pursue that shape" (p. 15). The chapter then outlines 10 principles that function as rules to follow when writing a composition.

The foundational text of the process approach to composition is Elbow's (1998) Writing Without Teachers. The process approach follows an expressionist framework that believes writing comes from within oneself in an organic process through generative free writing and peer review (Elbow, 1998). As writing should be an organic experience, process pedagogy does not explicitly teach grammar or adhere to strict rules:

Class does not teach rules of grammar directly, it will help make these matters less a problem. By learning the reactions of real readers, you will learn the effects of different mistakes. (Elbow, 1998, p. 137)

Although some scholars argue the field is in a "post-modern, post-process period of composition studies" (Jones, 2002, p. 264), the categories still exist and are reflective of the textbooks currently used in composition classrooms.

As opposed to the prescriptive and process approach, SFL privileges the system over the structure; with SFL, the words form the basis of the structure and the structure is developed based on systemic choices (Martin, 2016). The SFL framework values language as a resource for meaning and not a list of rules that a writer must follow. According to Monbec (2020), "This represents a significant shift from a traditional approach to language which tends to prioritize sentence level issues and grammatical accuracy rather than a principled description of the way 
language is used to make meanings" (p. 3). The SFL perspective that language is a function of society may provide students with a broader appreciation of the role writing can play in their life both inside and outside of academia.

\section{SFL as Framework for Instruction}

SFL analyzes how language functions in society; therefore, the moves made in developing writing have a purpose. Wulandari (2017) described SFL as "a tangled network of complex semiotic system that consists of five levels top-down textural, semantic, lexicogrammar, phonetic and phonological. In this model, the speaker forms the meaning in texture by selecting available choices at each level" (p. 456). This approach to teaching composition is useful because students can use the levels of SFL to analyze the moves authors make in published writing and then apply the same SFL skills when creating their own writing. SFL also provides students with a skill set to critique the writing of others through peer review. This may make peer review more meaningful than it is currently practiced by many instructors as a worksheet with guided questions to help a student respond to another student's writing. As SFL consists of multiple layers, students can gradually be introduced to the SFL approach one layer at a time through scaffolding. SFL focuses on how language functions, and this may be the common denominator to bridge the diversity in writing ability in the community college classroom.

SFL is an approach to teaching writing that honors the language each student brings into the classroom and teaches the student through the levels of SFL how to gain a new language: the language of academic discourse. The Navy veteran has the language of the military and the language of seafarers. The legal secretary has the legal discourse used on the job and the native language used outside of work. The international student has the native language of Mandarin plus the formal English language instruction learned in China. The student with autism has their 
own approach to processing and using language. SFL is a unifying pedagogy that honors these native languages while introducing students to a new language. Halliday's (1961) emphasis on SFL as a practice emerged in response to the needs of students as higher education became more diverse. An SFL approach to literacy broadens the actors and activities seen as literate.

In contrast, composition in higher education places focus on the text because it was developed as a theory to compete with the sciences as higher education embraced a positivist approach to research. As a result of the theoretical approach to writing, academic journals and doctoral programs emerged in the 1970s for the freshman composition class that became foundational. SFL, on the other hand, developed at the same time to focus on academic literacy as a practice developed to analyze how texts and culture interact (Eggins, 2004). Language in SFL is viewed as a meaning-making resource by studying how people use language to interact with each other in society. Therefore, composition focuses on the texts while SFL focuses on the interaction between participants engaged in a text.

A text in SFL is defined as "authentic products of social interaction, considered in relation to the cultural and social context in which they are negotiated" (Eggins, 2004, p. 2). This sociosemantic approach to language is interested in understanding why a text means what it does and why is it valued in society. To understand how people use language to make meaning, language use must be viewed as functional, semantic, contextual and semiotic. SFL asserts language is a semiotic system organized by a series of choices that fuse together the ideational, interpersonal, and textual meanings of linguistic units. The priority in SFL is to understand the system that language is created within and then interpret how the structure emerges from systemic choices (Martin, 2016). 


\section{SFL and Composition}

By focusing on the system within which the language is created, SFL can offer a broader approach to addressing the student learning outcomes (SLOs) of both the developmental and transfer-level composition class. SLOs for the developmental, pretransfer level composition course require instructors to teach students how to apply the fundamentals of grammar, sentence structure, and precompositional techniques; read and analyze text using critical thinking skills; and write structurally varied and grammatically correct sentences, paragraphs, and essays. The transfer-level, freshman composition course requires instructors to teach students how to articulate clear, logical and adequately supported ideas in an essay that are effectively organized and satisfactorily edited.

SFL is a theory and analytical methodology that reveals how text are created as a result of social processes by analyzing language patterns (Eggins, 2004). By focusing on the choices made in creating a text, SFL can teach students how to critically analyze a text by deconstructing a text to find patterns of meaning. Patterns of meaning are a function of the society within which the text was created, and an SFL approach can enable students to tap into their funds of knowledge when engaging with the text. The analysis of language patterns in an SFL approach to composition would fulfill the SLO of writing structurally varied and grammatically correct texts by breaking down the elements of a sentence and showing how an author constructs units of meaning based on the function of text. Students can learn through SFL how "linguistic systems make meaning by ordering the world" (Eggins, 2004, p. 17). Once the ability to manage linguistic resources is developed, writers can proficiently convey meaning through oral and written communication (Schulze, 2015). This fulfills the overall purpose of the composition class to teach students how to write clear, organized, and supported text. 
The ability to write clear text using an SFL framework is the result of analyzing the relationship between language and context. Once students understand the relationship, predictions can be made regarding what language choices a writer will employ based on the context of the situation. SFL begins with studying the genre and register of a text. The genre is the context of culture in text and the register is the context of situation in a text. Critically reading texts for the linguistic patterns of genre and register enables students to examine how people use language to achieve goals, which in turn helps the student to develop their own text based on their purpose for writing. SFL makes the purpose behind language choices visible by creating and responding to context of genre and register at the same time (Schools, 2015). As an applied systemic approach to studying language, SFL can be used to respond to and write about both research and practical problems through the study of genre and register (Martin, 2016).

In addition to the context of culture and situation in text, SFL can fulfill the sentence structure and grammar SLOs of the composition class by examining the lexical choices within a text (Eggins, 2004). The lexical choices come from a grammatical system that functions as the basic organizing element in language. The analysis of the presence and ordering of the grammatical elements illustrate how the language system is prioritized over the structure. Language is organized according to function; therefore, in SFL the "strategy is to distinguish between function (the role an item plays in a structure) and class (what the item is) - and so between labels for functions (aka relations) and labels for classes (aka categories)" (Martin, 2016, p. 42). The fundamental units of language in SFL are broken down into three units of meaning: field, tenor, and mode (Schulze, 2015). The analysis of these elements strips the text down to the bare idea and reveals how the clauses added on to the idea construct meaning. This enables the student to see why grammatical choices in language are made instead of the 
traditional approach to grammar that tells students what to do based on rules. Through this approach to grammar, SFL can "model languages in cartographic terms as resources for meaning rather than as lists of rules and this goes a long way to explaining why SFL is both systemic and functional and what this affords" (Martin, 2016, p. 44).

\section{SFL and Democratic Agency}

In addition to providing a framework to introduce students to academic discourse, SFL has the potential to increase a student's democratic engagement through an SFL approach to reading and writing. There was only one area my students agreed upon in the free write I assigned about composition class. They all agreed the composition class is a steppingstone to the next class and to their overall goal. Students did not view the composition class as having a purpose outside of the college classroom. They viewed the class as enabling them to become better college students but not better people. This was disheartening for me as I try to show application of the skills learned in class to life outside of class. It is possible students are so focused on passing to check off the class that they do not recognize the greater benefits of learning how to critically read and write. A composition class focused on the sociocultural component of writing and communication with an SFL framework may show students how reading and writing can increase their ability to critically engage in the democratic process. This would be an added benefit to using SFL as an approach to bridging native language with academic language.

SFL can increase a student's ability to engage in the democratic process because of the focus on examining the language choices users make to engage with others. These choices reveal language can be used to negotiate power relationships (Shulze, 2015). The context of culture and situation in a text will always "be influenced by our ideological positions: the values we hold 
(consciously or unconsciously), the perspectives acquired through our particular path through the culture" (Eggins, 2004, p. 10). As power relationships are revealed through language, SFL provides a way for students to talk about how power is used and enables students to challenge the power structures around them. More than just learning how to write an essay, an SFL approach to composition provides students with the ability to see how their view of the world is constructed through language. Language as a cultural emblem can be used to forward "social reproduction and social stratification" (Flores \& Rose, 2015, p. 151); therefore, it is important for this system to be revealed to students so they have a shared language to discuss the power dynamic at play in society.

Beyond addressing the SLOs of the college composition class, an SFL framework for teaching composition may provide students with the tools necessary to increase their democratic engagement in society. With an SFL approach to composition, students have the potential to view the creation of text as more than a requirement to move on to the next class. Students may come to view the social interaction of language as helpful and useful in daily life outside of the college classroom.

\section{SFL Applied to Composition Classes for Research Study}

For this study, I used SFL as the framework to teach developmental college composition by creating a syllabus that introduces each of the three main levels of SFL: register, semantics, and lexicogrammar. After an initial writing assignment that served as an assessment, the rest of the semester was broken into three units with an SFL level and the corresponding components of the level taught in each unit. Each unit built upon the previous unit; for example, the level of register was reinforced throughout the instruction of the semantics level and then register and semantics were both reinforced throughout the instruction of the lexicogrammar level. With this 
method, each level is reinforced and built upon with the instruction of the next SFL level. The language of SFL can be cumbersome and complicated, so the scaffolding of the SFL levels can provide students with repeat exposure to the language of SFL, along with time to experiment with using the concepts.

For each unit, students were assigned historical and current events to see how the concepts of SFL work in practice. For the first unit that informed an audience about an issue affecting a community, students read primary source documents of newspaper articles, letter to the editor, and opinion pieces from the Greensboro lunch-counter sit-ins. The current event students read about was the water crisis in Flint, Michigan. In addition to learning about the issue through newspaper articles, the class also watched documentaries and Flint city council meetings to see how people were informing a variety of audiences about the issue. In the second unit, which was the genre of argument regarding an issue that affects the State of California, students were assigned to read primary source texts about the Delano grape boycott and strike. Students specifically analyzed the reading to see how the United Farm Workers argued for the boycotting of grapes. In addition, students were assigned current academic articles from different disciplines that addressed the grape boycott. The current issue students learned about was immigration in California. The final unit, which was the genre of cause and effect, had students read about the war on drugs in the 1980s as the historical issue and the opioid crisis in the United States as the current issue. For this issue, we listened to and analyzed music of each period along with newspaper and journal articles.

The historical issue provided hindsight insight into how the culture of the society during the time period affected the texts and the current event provided current perspective about how culture of society is affecting text. The historical event provided a detached lens for student 
examination of the historical texts and then students could place themselves within the current event during analysis of the texts. The SFL concepts were also applied to a wide variety of texts to illustrate how the concepts function. Students could use the levels and components of SFL to analyze how the values and perspectives of each time period shaped the language choices used by the authors to reach an intended audience.

In addition to reading and analyzing a variety of texts, students also conducted extensive research for each unit. Students were provided the opportunity to employ the primary research techniques of interview, survey, and observation to understand the issue and the audience for their text in each unit. This is important because every level of SFL addresses audience awareness, particularly the power dynamic between the writer and audience. Students can use primary research methods as a way to gain intimate insight into the audience, which will help students select the best mode for the assignment and help in the development of the text. Students also used the concepts of SFL to guide and direct their secondary research process by narrowing research terms down based on the field and tenor of the register level of SFL. Research was incorporated throughout the development of each unit, which helped students develop each component of the SFL level.

For each of the three units, students selected an issue to address for their formal writing assignment. The genre for the first unit that developed the SFL concept of register was informative, and students had to select an issue that affected a community to which they belonged. Students had to select and audience that was either part of or outside of the community the issue affected. The genre for the second unit, which developed the SFL concept of semantics, was argumentative, and students had to select an issue that affected the State of California. For the final unit that developed the SFL, students had to select an audience that was in a position of 
power to make a change regarding the issue. The final unit that developed the lexciogrammar concept in SFL instructed students to select an issue that affected the United States and inform an audience of the causes and effects of the issue.

Before students turned in each final assignment, they were assigned a 250-word project proposal that explained the issue, the mode, the audience, and why the selected mode is the best way to reach the audience. This project proposal provided the opportunity to make sure students were on the right path before turning in the final assignment. With each formal assignment, students had the opportunity to gain insight into the foundational SFL concepts of culture and situation in text through selecting their own issue and audience.

The formal writing assignments students developed within each unit consisted of either a traditional, academic 4-page essay with outside sources or a textual representation and 2-page academic essay. The textual representations could be any of the following: autobiography, biography, letter, billboard, campaign speech, comic, character sketches, poetry, song, rap, photojournalism, interview, blog, vlog, website, PowerPoint presentation, letter to the editor, letter to elected official, social media post, short story, pamphlet; play, poster, review, speech, commercial, movie; documentary, policy, law, proposition, contract, white paper. (Hughes, 2009). The textual representations were assigned as a way for students to gain experience with the SFL component of mode within the register level. The mode reflects what form the text will take on based on the register and genre. Students were tasked with selecting the best mode for the genre and the audience. The writing produced had the potential to be authentic in nature as students selected what audience to direct the writing toward and what mode and language choices met the needs of that particular audience. This has the potential to provide students with practical experience developing texts for outside of the composition classroom. 
The academic essay that accompanied the textual representations provided students with the opportunity to explain and justify the choices made in selecting and developing the textual representation. Students must address why they selected the particular textual representation and how they developed the textual representation to meet the needs of the audience. Students also had the opportunity to use the SFL concepts in the development of a traditional, academic 4-page MLA-formatted essay. This provided students who felt they needed or wanted more experience developing academic essays with the opportunity. With both options, students were provided with the instruction and applications of developing an academic essay. This is important to prepare students for other classes in college and fulfill the student learning outcome of writing structurally varied and grammatically correct sentences, paragraphs, and essays.

On the day the assignment was due, students were encouraged to share their textual representations with the class. This provided an additional chance for students to see the concepts of SFL in action and get ideas from their classmates.

\section{Conclusion}

The purpose of this study was to understand the affordances and limitations of using a SFL approach to teaching college composition at a community college. A different approach to teaching composition was researched as a result of the recent laws passed in California pertaining to the community college system. These new laws-AB 19, AB 504, and AB 705have the potential to increase enrollment in the freshman composition class. In addition to increasing enrollment, community colleges need to find opportunities to provide greater instructional support for students who do not enter college with college-level writing skills as a result of these new laws. This research project sought to understand if SFL as the framework for composition class can meet the diverse learning needs of the community college population. 


\section{CHAPTER 2: A REVIEW OF THE LITERATURE}

Halliday's Introduction to Functional Grammar was first published in 1985 and detailed the sociocultural approach to language he referred to as systemic functional linguistics (SFL; Matthiessen, 2014). That text is now in its fourth edition and continues to inform pedagogy around the world at all levels and in many different languages. According to Halliday and Webster's (2009) Bloomsbury Companion to Systemic Functional Linguistics, SFL is a "system of meaning which is distinguished from other semiotic systems by the fact it is founded on grammar" (p. 5). SFL as a semantic system is composed of three main components: ideational, interpersonal, and textual. The three levels build upon each other and in combination comprise a linguistic system. Halliday created a practice through SFL that accounts for meaning being constructed through experience and social relationships (Halliday \& Webster, 2009). SFL analyzes how language functions in society; therefore, the moves made in developing writing have a purpose.

The majority of SFL research is being conducted in Australia. Halliday's position as a linguistics professor at University of Sydney has influenced and supported the popularity of SFL research in Australia. Although SFL is not systemically incorporated into curriculum throughout the United States at this time, SFL research is currently being conducted at UC Davis with Dr. Colombo, University of Michigan with Dr. Schleppegrell, and University of Massachusetts, Amherst with Dr. Gebhard. International peer-reviewed journals, conferences, and online discussion groups have emerged to share SFL research and pedagogy (Moncada \& Linares, 2020). This research has provided insight into how SFL can be used to support learning outcomes in reading and writing at all levels. 
The recent passage of assembly bills in California designed to improve equity and access to higher education through the community college system has created the opportunity to research how to meet the learning needs of the diverse community college student body. AB 705 changes how students are placed into developmental or transfer-level English and math classes (CCCCO, 2017). Instead of taking a placement test, students can now use high school transcripts to determine class placement. AB 19 was passed to make community college more affordable to students to increase access to higher education (CCCCO, 2017). The purpose of AB 504 is to expand the student equity plan for each community college to include information regarding underrepresented students' ability to complete ESL and basic skills courses, achieve degree and certificate completion, and transfer to a university (CCCCO, 2017). Collectively, the bills are designed to improve access to higher education by easing financial barriers, decreasing the number of developmental classes a student may need to take, and by providing support to help students achieve their educational goals.

Already the community college student body is diverse as the system is considered to be an open-access institution (California Community Colleges, 2021). The community college attracts students of all ages, ethnicities, economic brackets, and abilities. Students enrolled in a community college composition class also have varying degrees of exposure to language instruction from K-12 education, which can complicate teaching students to write for an academic audience (Schleppeggrel, 2004). The inherent diversity in the community college composition class, coupled with the recently passed laws to improve equity and access to higher education for students, has the potential to make teaching college-level reading and writing skills even more challenging. The sociocultural approach to language of SFL has the potential to 
provide a useful framework for teaching reading and writing skills to the diverse student body of the community college classroom.

This chapter seeks to understand how instructors have taken up SFL in their teaching practice and to gain insight into the affordances, limitations, and outcomes of SFL in practice.

\section{Literature Review}

A review of literature was completed to inform my approach to incorporating an SFL framework into the curriculum of a community college composition class. The ERIC database was used for research through the Leatherby Library at Chapman University. Table 1 is an outline of the articles selected for review. Articles were limited to those that specifically researched the influence of SFL in the teaching and development of writing and reading within academic contexts. Articles were further limited by academic level with articles addressing secondary and postsecondary education selected; however, a few articles at the middle school level were included as the skills the articles researched directly relate to skills needed in postsecondary education.

Presentation of the Literature

A thorough review of SFL texts, along with research articles that employ SFL, were analyzed to develop a description of SFL and how it is used in writing and reading instruction. An analysis of the literature revealed the affordances of SFL in multiple academic areas that affect writing instruction. The limitations of using SFL in instructions was also researched to learn from the experiences of other instructors and researchers. 


\section{Table 1}

\section{Articles Included in Review of Literature}

\begin{tabular}{|c|c|c|c|c|}
\hline Article & $\begin{array}{l}\text { Academic } \\
\text { subject }\end{array}$ & $\begin{array}{l}\text { Academic } \\
\text { level }\end{array}$ & SFL used in study & $\begin{array}{l}\text { Component of academic literacy and } \\
\text { curriculum }\end{array}$ \\
\hline $\begin{array}{l}\text { Achugar \& } \\
\text { Carpenter (2014) }\end{array}$ & History & High school & $\begin{array}{l}\text { Lexico-grammatical; discourse- } \\
\text { semantic }\end{array}$ & Academic language development \\
\hline $\begin{array}{l}\text { Aguirre-Munoz et } \\
\text { al. (2007) }\end{array}$ & $\begin{array}{l}\text { Teacher } \\
\text { education }\end{array}$ & $\begin{array}{l}\text { Professional } \\
\text { development }\end{array}$ & $\begin{array}{l}\text { Genre based pedagogy: field, mode, } \\
\text { tenor }\end{array}$ & $\begin{array}{l}\text { Writing instruction; academic; response } \\
\text { to student writing }\end{array}$ \\
\hline $\begin{array}{l}\text { Carpenter et al. } \\
(2015)\end{array}$ & $\begin{array}{l}\text { History; } \\
\text { teacher } \\
\text { education }\end{array}$ & $\begin{array}{l}\text { High school; } \\
\text { professional } \\
\text { development }\end{array}$ & Stance & Disciplinary literacy \\
\hline Colombi (2015) & Spanish & University & Dialect, register, and genre theory & Biliteracy; critical language awareness \\
\hline Donohue (2012) & Film studies & University & $\begin{array}{l}\text { Ideational metafunction: field, tenor, } \\
\text { mode }\end{array}$ & Taxonomic film analysis \\
\hline $\begin{array}{l}\text { Fang \& } \\
\text { Schleppegrell } \\
(2010)\end{array}$ & $\begin{array}{l}\text { All content } \\
\text { areas }\end{array}$ & High school & $\begin{array}{l}\text { Metalanguage; nominalizations; } \\
\text { multimodality; theme/rheme }\end{array}$ & Cross-disciplinary literacy \\
\hline $\begin{array}{l}\text { Gebhard et al. } \\
(2014)\end{array}$ & $\begin{array}{l}\text { Science; } \\
\text { history; ESL }\end{array}$ & Elementary & Nominalization & $\begin{array}{l}\text { Writing development; reading } \\
\text { comprehension; standardized testing }\end{array}$ \\
\hline Lancaster (2011) & Economics & University & Interpersonal stance & Argumentative writing \\
\hline Lancaster (2014) & Economics & University & Stance & Critical reasoning \\
\hline Lee (2012) & English & University & Mood; modality & Expository essays \\
\hline Liardet (2016) & English & University & Grammatical metaphor & Argument writing \\
\hline $\begin{array}{l}\text { Macken et al. } \\
(2010)\end{array}$ & English & High school & Projection; stance; nominalization & Literary analysis \\
\hline Neal (2015) & Reading & University & $\begin{array}{l}\text { Metalanguage field, tenor, mode; } \\
\text { lexicogrammar; progressive } \\
\text { reconstruction; nominalization }\end{array}$ & Academic language proficiency \\
\hline $\begin{array}{l}\text { Pessoa et al. } \\
(2017)\end{array}$ & $\begin{array}{l}\text { Global } \\
\text { histories }\end{array}$ & University & $\begin{array}{l}\text { Genre; metafunctions: ideational, } \\
\text { interpersonal, textual }\end{array}$ & Argument writing \\
\hline Ryan (2011) & English & University & & Reflective writing \\
\hline Schulze (2011) & ESL & $\begin{array}{l}\text { Middle } \\
\text { school }\end{array}$ & Register & Genre-based writing \\
\hline Schulze (2015) & ESL & $\begin{array}{l}\text { Middle } \\
\text { school }\end{array}$ & $\begin{array}{l}\text { Metalanguage: processes, } \\
\text { participants, circumstances }\end{array}$ & Close reading; persuasive writing \\
\hline Slater et al. (2010) & Science; ESL & High school & Register analysis & Content-area literacy \\
\hline $\begin{array}{l}\text { Stuart-Smith } \\
\text { (2003) }\end{array}$ & Social science & University & $\begin{array}{l}\text { Metafunctions: ideational, } \\
\text { interpersonal, textual; clause; clause } \\
\text { combining; theme and cohesion. }\end{array}$ & Writing; Critical reading \\
\hline Zhang (2017) & ESL & University & $\begin{array}{l}\text { Metafunctions: ideational, } \\
\text { interpersonal, textual. }\end{array}$ & Teacher education; content literacy \\
\hline
\end{tabular}




\section{Affordances of SFL in Instruction}

The review of literature revealed four themes that show the affordances of incorporating SFL in instruction. The first theme is SFL as a framework for writing instruction. The second theme uses SFL as an instructional tool for teaching critical reading skills. SFL as a means to provide instructional support to students from marginalized communities is the third theme. The final theme is SFL as an assessment tool that provides instructors with a structured language to provide students with valuable feedback on writing assignments.

\section{Theme 1}

Traditionally, composition classes at all levels teach writing skills through the development of genre-specific writing prompts — argument, personal narrative, rhetorical analysis, etc. In addition, teachers assign both nonfiction and fiction works for students to read and analyze. Instead of writing and reading assignments being limited to the development of a specific writing assignment for the composition class, SFL studies how language is a reflection of social contexts motivated by a social purpose (Eggins, 2004). The language of SFL can provide insight into how language events are created through the interaction of purpose and social context (Halliday \& Matthiessen, 2004). An SFL approach to writing instruction can provide access to the language of composition for students (Schleppegrell, 2004). The language of SFL can provide students with the tools to understand the system that language is created within and how their choices as a writer are a part of this system (Martin, 2016). SFL as a framework for teaching writing in higher education can provide a shared a language to explicitly teach writing skills (Schleppegrell, 2004). 


\section{Shared Language for Writing Instruction}

Writing in academia needs to articulate purposeful and critical attainment of knowledge to show transformative learning has occurred (Lancaster, 2011; Macken-Hoarrik \& Morgan, 2010; Ryan, 2011). Ryan (2011) researched how SFL instruction over the course of a semester can improve the reflective writing of students in higher education. According to Ryan, reflective writing in academia needs to articulate purposeful and critical attainment of knowledge to show transformative learning has occurred. As academic reflection is complex because it involves showing specific knowledge acquisition, Ryan found the shared language of SFL guides students in applying contextual requirements to writing and also helped students choose expressive resources. Students learned how to make appropriate contextual choices in writing through answering probing questions of exemplar texts, as this is the foundation of a social semiotic approach. The questions were based on the principle of SFL that all language in a text achieves a specific purpose. The ability to recognize language features were applied to analyzing the writing of classmates and then students were able to assess their own reflective writing for appropriate structure and language features. Students were constantly directed to refer to the purpose, subject matter, and audience of the reflection. Ryan found SFL provided the scaffolding to guide students in showing discourse competence through reflective writing.

SFL can provide teachers with the language to give students insight into the system that language is created within, which will help students learn how to incorporate their voice into the system (Schleppegrell, 2004). Macken-Hoarrik and Morgan (2010) studied how the metalanguage of SFL can help students develop their voice in writing through literary analysis in a high school English class. Voicing is an important concept in writing as it is used to produce “dialogue between characters, cite an author's views or debate the merits of different theoretical 
positions" (Macken-Hoarrik \& Morgan, 2010, p. 134). Students need to develop their own voice to articulate their personal response to literature while also relating the literature to theoretical discourses. In SFL, voicing is referred to as projection, which "makes visible the potential of this resource not just incorporating the words of another into one's discourse but for projecting experience through the words and thoughts of a conscious subject" (Macken-Hoarrik \& Morgan, 2010, p. 137). The SFL concept of projection enables students to articulate their perspective and the perspective of outsiders into their writing. Students use their own voice in writing, known as averral, by using "I" statements. Conversely, students can incorporate the views of others in writing through attribution, as in "Experts state" or "She argues." Explicit instruction into the types of projection used in voicing expands a student's ability to incorporate their views with the views of experts. The development of this metalanguage provides students with a resource to integrate multiple voices, including their own, into writing and insight into how their voice can interact with the voices of experts.

An SFL analysis of student writing can provide insight into how students interact with the language of the discipline and this information can be used to inform class instruction (Schleppegrell, 2004). Lancaster (2011) used an SFL approach to analyze four argumentative research papers of upper-division economics students to understand how the stance taking patterns present in student writing reflect the professor's learning goals. Stance taking in SFL refers to the moves a student makes when making assertions in writing. Lancaster (2011) found "conscious awareness of the ways valued interpersonal meanings are built up in student coursework genres can help instructors attend to specific discursive goals that pose challenges for their students" (p. 2). Once the stance-taking patterns are realized, teachers can provide instruction into the linguistic choices students can make to position themselves within the 
discourse community. In addition to benefitting L1 writers, Lancaster found the metalanguage of SFL can also be used as a shared language between instructors across disciplines to support the language needs of $\mathrm{L} 2$ writers.

\section{Writing Across Curriculum}

Describing the linguistic system of an entire culture would be a time consuming task, but describing the linguistic feature of discourse communities is manageable and useful to understand what the community values in language (Halliday \& Mathiessen, 2014). An SFL approach to writing can provide insight into the choices that matter at each level of language in a discourse community (Eggins, 2004). Although higher education has its own discourse, each individual discipline within higher education also maintains a separate discourse (Schleppegrell, 2004). Each discipline has its own discourse community with its own set of linguistic choices and expectations. Halliday and Matthiessen (2014) provided an example to illustrate the different discourse communities within higher education:

Explanations in school science and in school history are similar in various ways, but they are also different in certain respects. For example, the repertoire of explanations deployed in school history appears to be narrower; and they differ lexicogrammatically: scientific terms are construed and used very frequently in school science but hardly at all in school history. (p. 37)

The language differences between disciplines is a result of differences in epistemology, methodology, and pedagogy (Schleppegrell, 2004). For example, science values "theorizing experience" while history values "interpreting experience" (Schleppegrell, 2004). Students are expected to intuitively know which grammatical resources to use for each discipline. Schleppegrell (2004) asserted an SFL approach to writing in higher education can enable 
students to develop an awareness of the different genres that construct meaning within disciplines. The SFL framework provides students with "new lexical and grammatical strategies to fit new texts and contexts" (Schleppegrell, 2004, p. 114). Schleppegrell argued students need to be explicitly taught the register of academia because school-based tasks often cannot be constructed using students' natural language resources. Research has been conducted into the benefits of introducing students to the SFL framework as a way to prepare students for the demands of writing in different disciplines.

SFL has been used to benefit instruction in a specific discipline. For example, the emphasis on language in SFL compliments the disciplinary expectations of school history genres. Pessoa et al. (2018) researched an SFL-based collaboration between faculty in English and a history professor to scaffold the writing of the argument genre in a university global histories course and then examine the differences in developmental trajectories after the instruction. Over the course of a semester, the researchers studied how the writing of nine students improved after attending three SFL-based workshops that taught how to write historical arguments. The SFL-based $3 \times 3$ toolkit provided the foundation for the instruction and analysis of student writing. The $3 \times 3$ toolkit is used to deconstruct linguistic features in academic genres: "The $3 \times 3$ allows for an understanding of a text by considering how meanings of SFL's three metafunctions of language (ideational, interpersonal, and textual) are realized through linguistic resources at the levels of the whole text, paragraph, and sentence/clause" (Pessoa et al., 2018, p. 83). This toolkit was used to explicitly teach students the expectations of the genre of argument in the discipline of history. A quantitative analysis of the writing of the nine focal students found the SFL-based workshops that employed the $3 \times 3$ toolkit enabled students to incorporate linguistic resources into their writing to meet genre expectations. Most importantly, the analysis 
of findings showed that students who initially scored lower on a baseline test made gains in writing that placed them on a level similar to students who scored higher on the baseline test.

Another discipline that specific application of SFL in curriculum can benefit is foreign language instruction. Students may choose to take a Spanish class for career purposes, but other students may take the class to connect or reconnect with their cultural roots and identity (Colombi, 2015). Colombi (2015) studied how SFL can encourage students' cultural awareness and academic literacy. Heritage language learners often use Spanish in familiar, informal settings, so adapting language to formal academic or professional settings can be a challenge. The study focused on heritage language learners of Spanish who are taking a college-level Spanish class at a university in California. Specifically, the study describes the pedagogical practices using the SFL concepts of dialect, genre and register theory to show the connection between social and situational contexts. This approach can aid in the development of advanced literacy for heritage Spanish language users by highlighting the relationship between language and power in social practices. SFL as a pedagogical practice in language instruction exposes the norms of the language and allows students to objectively analyze the language from the perspective of an outsider. Through readings and reflective activities, Colombi illustrated dialectal variety, which is language use according to the user, and register, which is language variety according to use. SFL enables instructors to move away from the prescriptive pedagogy of formal language instruction to a descriptive and functional approach that views all languages as a meaning-making resource. In addition, this approach to language instruction was found to apprentice students into the academic community by developing a critical consciousness of language and the social role that language plays in society. 
SFL, as a language based theory of learning, can provide the opportunity to show students how to listen, speak, read, and write within the discipline of films studies. Donohue (2012) researched how SFL could benefit the academic writing produced in a university film studies course. This action research project was conducted through the collaboration of a film studies lecturer and writing development lecturer over the course of a year and involved the analysis of 30 essays. The lecturers used the SFL concept of genre to teach taxonomic film analysis. An intervention was developed by the lecturers to address repeated comments on the first-year film students' academic writing from external writing examiners. The SFL concept of genre focused on the thematic formations within the conceptual framework of film studies. The concept of genre was supported by explicit instruction in field, tenor, and mode. These concepts were used to teach students how to build sentences to address the genre of taxonomic film analysis. Donohue believes the findings show the linguistic resources students learned through writing the taxonomic film analysis can be applied to other academic contexts that require thematic formation. The collaboration in this study between the lecturers of different disciplines demonstrate the shared language of SFL can be used across disciplines.

\section{Theme 2}

While SFL is useful in developing writing by making visible the linguistic choices available to construct meaning, SFL is also useful in developing students' reading aptitude through deconstructing text using the SFL framework (Eggins, 2004; Halliday \& Matthiessen, 2014; Schleppegrell, 2004). According to Halliday and Matthiessen (2014), the SFL framework can be applied to reading by analyzing the levels of meaning in a single text. Through the analysis of the single text, patterns of language resources are identified and then sought out in 
different texts. This analysis leads to an ability to recognize types of texts. These texts types adhere to a particular set of systemic probabilities and are referred to as the register in SFL.

\section{Tool to Develop Critical Reading Skills}

School-based text can be particularly tricky for students to decipher because each discipline uses language differently, so students are expected to intuitively know how to navigate each discourse (Schleppegrell, 2004). The discourse used in textbooks is also markedly differently from the discourse used in everyday contexts as textbooks are authoritative in tone and informationally dense. How information is presented in textbooks can be foreign to students, so they feel they cannot interact with or challenge the text. SFL as an approach to analyzing texts focuses on the different contexts of texts by making visible the linguistic choices the writer makes to produce a text for a particular discipline (Eggins, 2004; Halliday \& Matthiessen, 2014) Advanced literacy practices emerge from specific instruction in "unpacking the meanings and recognizing the positioning and ideologies" (Schleppegrell, 2004, p. 44) of the writer. SFL moves reading instruction beyond the "whole language" or "phonics" debate by teaching students how to recognize the linguistic choices that create different meanings in texts.

SFL can provide students with the ability to recognize and analyze language patterns in different disciplines, which enables students to engage in the more complex texts of school. Fang and Schleppegrell (2010) developed the functional language analysis approach to teaching content area reading skills to students in secondary school. This approach to reading instruction is based on the SFL framework to offer students a way to actively engage in finding meaning in content area texts by providing a metalanguage to talk about the linguistic choices the author made in constructing the text. The authors asserted the reading skills taught in elementary school—predicting, inferring, thinking aloud, fluency, phonics, and phonological awareness - do 
not prepare students for the reading demands of secondary school. Fang and Schleppegrell supported the reading skills needed for secondary school by teaching students how to identify the SFL concepts of experiential meaning (field), interpersonal meaning (tenor), and textual meaning (mode) in content area texts. This approach to reading instruction enables teachers and students to engage in a discussion about how meaning is made through the language choices of the author to reach the intended audience.

The metalanguage of SFL can also be used to illustrate how academic language functions within disciplinary texts (Schleppegrell, 2004). Through an SFL analysis of text, the function of language in the various disciplines is revealed to the student (Matthiessen \& Halliday, 2014). For example, Neal (2015) used SFL as a tool to teach academic language in a postsecondary developmental reading class. Neal (2015) asserted SFL can be "used to support developmental reading students by exposing language challenges posed by disciplinary reading tasks and by engaging students in close readings of disciplinary texts so students can better understand and critique them" (p. 13). Students' reading skills are supported by specific instruction into the SFL concept of taxonomies, which divides content into hierarchies. Students are instructed to break down subject matter into taxonomies in academic and social contexts. The SFL approach to reading instruction also teaches students how to deconstruct nominalization and grammatical metaphors in texts by separating action from agent to find meaning. According to Neal, the SFL approach to reading instruction makes explicit disciplinary language patterns, which will help support students reading comprehension academically and professionally.

History requires a close reading of the texts to reveal the biases, representations, orientations, and accounts. These aspects of text are valued within the discipline of history. Carpenter et al. (2015) researched how teaching history teachers the SFL framework would 
provide teachers with the metalanguage to show students how to engage in text analysis strategies to understand the meanings of history texts. This study was conducted over the course of a semester in a multilingual history class at a high school in Texas. Through case study, disciplinary literacy in history was taught through sociocultural activities. These activities were developed between the researchers and the teacher to move beyond decoding texts to understanding the historical implications and significance of texts. Students were instructed during whole group reading how to identify the SFL concepts of genre, transitivity, appraisal, theme and reference. This metalanguage learned through reading instructions use the events and social actors of the historical text to teach how agency was constructed. Through using this metalanguage when analyzing historical texts, students can learn to develop critical historical arguments that provide an understanding from multiple perspectives. Carpenter et al. found SFL provides teachers with the language to make these expected discipline specific linguistic choices explicit through teaching reading strategies that use sociocultural knowledge.

\section{Theme 3}

One factor that affects the inequalities that exist in education is that students who come from marginalized communities, such as "nonnative English speakers, speakers of nonstandard dialects, and other students with little exposure to academic contexts" (Schleppegrell, 2004, p. ix) —are not versed in the "language of schooling" (p. ix) often necessary to be successful in school. Schleppegrell (2004) asserted students who come from privileged social class backgrounds have greater exposure to the conventional linguistic features of school, while students from marginalized communities are penalized in assessment and achievement for not having the same exposure to language resources. Unfortunately, students who come to school without the expected and conventional language of schooling are tracked into remedial classes 
that do little to develop the language skills necessary to close the gap with students from privileged communities.

\section{Instructional Support to Students From Marginalized Communities}

Students who do not use the language expected in school contexts and instead use a natural language from their home environment may be viewed as disorganized. Schleppegrell (2004) has found

students' difficulties in "reasoning," for example, may be due to their lack of familiarity with the linguistic properties of the language through which the reasoning is expected to be presented, rather than to the inherent difficulty of the cognitive processes involved. ( $\mathrm{p}$. 2)

These students may be judged to have learning difficulties and pulled out from mainstream language instruction and placed in a resource or remedial class, which increases the language divide. Schleppegrell (2004) found "teachers use different interactions strategies with different groups of children, based on assessment of their "abilities"' (p. 39). The effects of language discrepancies between privileged and marginalized communities illustrate the need to make explicit the language of schooling.

An SFL approach to language instruction can help students and teachers understand the difficulties students face when talking and writing in school contexts. SFL as a functional approach to language analysis and development, asks "how do people use language" and "how is language structured for use?” (Eggins, 2004, p. 3). These two questions when applied to the language of schooling enable students to see the differences between the structure of their natural language and the structure of language expected in school. SFL provides an opportunity "to value the language children bring to school from their homes and communities at the same time 
they are provided with an understanding of how new ways of using language will help them accomplish new kinds of tasks" (Schleppegrell, 2004, p. 17). SFL as a framework for language analysis and instruction respects the language students use outside of school as valuable because language is a semiotic system that construes meaning within social contexts and one context is not privileged over another because they all achieve a purpose. Schleppegrell (2004) argued:

Socializing all students to middle-class interactional patterns is not an appropriate goal for schooling. In a multicultural society, it is important to value different ways of making meaning and appreciate the different ways of using language that students bring with them to school. (p. 40)

SFL explains how language is structured in different discourse communities. This functional approach to language instruction provides a bridge for students to move between discourse communities while developing new ways of thinking as a result of increasing exposure to linguistic resources (Halliday \& Matthiessen, 2014).

\section{Students With Disabilities}

SFL can be used to teach writing skills to adults with language-related learning difficulties. Stuart-Smith (2003) conducted a case study by following the writing development of one adult reentry student with language-based learning difficulties enrolled in a university social studies class. The author tutored the student using the fundamental semantic and grammatical strategies of SFL to show how these skills will support a student writing essays for a universitylevel class. The student in this case study experienced difficulty taking the high-level abstract concepts of a university social science course and developing the ideas into writing. The student's writing was supported through explicit instruction in the lexicogrammar level of SFL. Students learned the constituents of the clause, clause combining, theme, and cohesion. Through 
learning these lexicogrammar concepts of SFL over the course of a year, the student passed the social studies and showed improvement in both reading and writing skills. The researcher attributes this improvement to SFL's focus on how meaning is made through language choices rather than tutoring on specific grammar rules. Accordingly, abstract notions of grammar are more relatable with this functional approach to making meaning through language choices at the clause level for students with language-related learning difficulties.

\section{English Language Learners}

Students' language experiences are shaped by their cultural practices; however, students at school are confronted with a different set of cultural practices and literacy experiences that create a secondary socialization process (Achugar \& Carpenter, 2014). The secondary socialization process for ELLs can be supported by using language as a method for learning (Slater \& Mohan, 2010). SFL can accomplish this by providing the analytical tools to analyze how the structure and features of academic language create meaning. Traditionally, how language differs in social contexts versus academic contexts is often not discussed in education (Schleppegrell, 2004).

How SFL can benefit the writing and reading instruction within the discipline of history was researched by Achugar and Carpenter (2014) through a longitudinal study over 7 months in a multilingual high school history class taught by the same teacher. The authors asserted cultural knowledge of language and references support an ELL's knowledge acquisition in history class. Accordingly, students from multilingual backgrounds may not have access to this cultural knowledge, which will inhibit their ability to learn discipline-specific knowledge. The authors found the language used in every day contexts is not sufficient to develop the higher levels of literacy necessary in constructing discipline-specific writing. Achugar and Carpenter used an 
SFL framework that focused on language as a sociocultural process through which students construct meaning. The study researched a literacy intervention that focused on the language used in history to study the effects of language on student learning and the teacher's perception of advanced literacy within the discipline. Specifically, students were given an assessment developed with the SFL features of genre, audience, representation (such as verb, participant choices) and interpersonal positioning. The clause combining choices made at the lexicogrammar level enabled students to construct texts that connected and expanded upon ideas. All groups studied showed increases in the number of words produced, lexical density, and grammatical intricacy. Students also demonstrated an increase in use of clauses and system expansion. The authors conclude all students can benefit from explicit work on language and content in discipline specific classrooms, instead of developing disciplinary literacy interventions for language minority students.

A significant issue in education is content-area teachers do not teach interactively with the ESL teachers to support the needs of struggling ELLs (Lee, 2010; Schulze, 2011; Slater \& Mohan, 2010). In response to this issue, Slater and Mohan (2010) studied how a partnership between an ESL instructor and science instructor in secondary education could support ELLs. Both instructors used the SFL concepts of genre and register to develop content literacy in science. The genre of lab report was taught and reinforced in both classes, along with explicit instruction in developing the register of science through assigning specific science tasks. SFL provided the framework in both classes to illustrate the connection between language and learning. The theory and tools of SFL enabled teachers from different disciplines to work in collaboration to prepare ELLs for mainstream science class. The authors of the study found 
collaboration between ESL teachers and content area teachers through using the SFL framework of register is an effective way to show students how to apply theory to practice.

In addition to the concept of register in SFL, ELLs can also benefit from learning the SFL concepts of mood and modality (Lee, 2010). Learning how to use mood and modality as resources in writing can help second language writers develop stance and identity in expository essays at the undergraduate level. Specifically teaching students how to use common strategies associated with mood and modality "can help enact interaction with an audience, and this is particularly true when essay questions require the writer to make suggestions or recommendations about the problem raised" (Lee, 2010, p. 61). Most importantly, mood resources work to create "a critical voice in a formal tone" (Lee, 2010, p. 75). It is helpful to teach students the relationship between the "social interactive and pragmatic nature of an argument" (Lee, 2010, p. 75) by using mood and modality as successful writers were found to be able to command interactional resources and exhibit audience awareness.

An issue for ELLs is negotiating the difference between social and academic language (Schulze, 2011). To counter this issue, Schulze (2011) taught writing using the SFL framework of genre and lexicogrammar to support ELLs in learning how to navigate the academic language required for persuasive writing. As the teacher-researcher, Schulze analyzed the genre approach to writing instruction of SFL through a qualitative study that analyzed three instantiations of texts the middle school students produced and the surrounding context of composition. The SFL approach supported students by illustrating the field, tenor, and mode of model texts. These concepts were then developed in students' writing. This cycle of studying model texts using the SFL concepts and then applying skills to students' own writing provided students with the 
opportunity to learn how their new language functions, which helped students to develop writing that was aligned with register of the persuasive writing.

In training teachers for the ELL classroom, SFL text analysis has the potential to enable prospective and new TESOL teachers to develop teaching strategies that will fulfill the Common Core State Standards that require students to read and understand complex content texts (Zhang, 2017). This strategy will enable prospective teachers "to conduct a comparative qualitative analysis of two quantitatively comparable content texts to enhance their own understanding of text complexity in order to design effective teaching strategies to support content literacy development of English language learners" (Zhang, 2017, p. 166). The use of SFL to analyze texts will enable new teachers to understand the complexity of texts in content areas, which will provide insight into appropriate curriculum design necessary for effective literacy instruction for ELLs in the classroom.

\section{Theme 4}

Often, students in writing classes receive feedback and a grade on their final draft (Schulze, 2015). The feedback sometimes is only error correction, which may not help students develop linguistic knowledge about what academic register and genre they should be writing within (Schleppegrell, 2004). Teachers may not be able to provide the feedback necessary to develop a student's linguist knowledge in a specific discipline because teachers are often experts in the field who have internalized the linguistic features of their discipline (Schulze, 2015). SFL can provide teachers with the metalanguage and tools to make explicit how language is used in their discipline (Halliday \& Matthiessen, 2014; Schleppegrell, 2004). 


\section{Shared Language for Instructional Discussions}

The SFL framework can be used to enable teachers to make the content-specific linguistic choices explicit to students and provided a shared language to provide meaningful feedback on students' papers (Lancaster, 2014). Students that exhibited command of the SFL concept of stance received higher marks on papers written to fulfill the writing requirement of an upper-division economics class, according to a study by Lancaster (2014). However, the instructor interviews that were conducted during the research revealed instructors were not communicating to students how to achieve an academic stance in writing. An SFL framework provides a metalanguage for instructors to not only teach writing, but also to make explicit responses to student writing when providing feedback. The metalanguage of SFL can provide instructors with a way "to both monitor their evaluative responses more deliberately and discuss their writing expectations with students more explicitly and precisely" (Lancaster, 2014, p. 51).

As students advance through higher education, they are expected to select appropriate linguistic resources for different discourse communities. Grammatical metaphor represents language choices moving from concrete to abstract as discipline-specific knowledge increases. Grammatical metaphor refers to "situations where meanings typically (congruently) realized by one type of language pattern get realized by other less typical (incongruent) linguistic choices" (Eggins, 2004, p. 99). Liardet (2016) researched grammatical metaphor as a feature of advanced academic writing and found "high scoring texts deploy experiential GMs more frequently, with slightly greater variation and with more significant textual impact than the low scoring texts" (p. 116). The research suggests specific instruction in grammatical metaphor is beneficial for students to learn how to develop lexically dense nominal groups. In addition to specific instruction in creating lexical density, students should also be explicitly instructed in the 
deconstruction of the grammatical metaphor to guarantee clarity in the language choices. Instruction in both creating and deconstructing grammatical metaphors will provide students with the opportunity to practice developing and revising this linguistic tool.

SFL training can prepare teachers to recognize and respond to genre-specific issues in student writing (Aguirre-Munox et al., 2009). Using an SFL approach for a weeklong ELL middle school teacher training program, Aguirre-Munoz et al. (2009) developed a mixedmethods study that sought to increase teachers' understanding of the features of academic language. The researchers developed the teacher training to show how the SFL concepts of field, tenor, and mode can be used to teach students to identify the protagonists/antagonists and events in stories. This inspired teachers to develop lesson plans that improved clarity in their students' writing by increasing students' knowledge of linguistic resources. The research team then observed teachers at 2-3 months after the training to gain insight into how often teachers were teaching with the SFL framework. The results revealed teachers who used the SFL framework for instruction were able to provide specific language-driven feedback to students on functional grammar and planning feedback, instead of vague comments about cohesion or grammar rules. The researchers found using the language of SFL to teach ELLs how to write expository texts and then using the language SFL to follow-up through commenting on student writing supports students' understanding of how key linguistic elements are part of school-based genres.

\section{Outcomes of SFL in Writing Instruction}

Incorporating an SFL framework into writing instruction can provide an opportunity for students to think about how they interact with language and use language as a meaning-making resource to achieve a purpose (Eggins, 2004; Halliday \& Matthiessen, 2014; Schleppegrell, 
2004). An SFL approach to writing instruction is also beneficial to teachers by making implicit knowledge that has been internalized explicit to students (Schleppegrell, 2004; Schulze, 2011).

\section{Outcomes for Students}

This focus on language and content has the potential to enable students to gain deeper insight into the issues discussed in class and in the assigned readings by breaking concepts down into the register, lexicogrammar, and mode categories of SFL (Schulze, 2011). The focus on language and content is especially useful for ELLs who struggle with understanding the differences between social and academic language (Lee, 2010; Schulze, 2011; Slater \& Mohan, 2010; Zhang, 2017). SFL as a genre approach to reading and writing instruction can support students by showing them how to identify what content is expected for academic discourse by analyzing model texts and then students can incorporate those expectations into developing the register of the target genre (Neal, 2015; Schulze, 2011). Research has also shown upper-division college students can benefit from a focus on the language content of academia in the various disciplines, so that students can recognize author stance in the text (Lancaster, 2011). This explicit instruction into identifying author stance can enable students to understand what each discipline values (Carpenter et al., 2015). Notably, within school contexts writer's gain an awareness of the discursive moves that are valued and expected in different disciplinary contexts, which provides the student with knowledge in how to effectively interact and construct text for a specific context (Schleppegrell, 2004). This finding is important as it shows SFL pedagogy has the potential to foster improvement in literacy skills for all students through using the metalanguage of SFL to teach both reading and writing skills (Eggins, 2004; Halliday \& Matthiessen, 2014; Schleppegrell, 2004). 


\section{Outcomes for Teachers}

SFL provides teachers with a metalanguage to discuss what language means and what it does in different texts (Eggins, 2004; Halliday \& Matthiessen, 2014; Schleppegrell, 2004). The explicit awareness of how language functions to create meaning is beneficial for teachers in designing accessible lessons that expand students linguistic knowledge (Aguirre-Munoz et al., 2007; Fang \& Schleppegrell, 2010; Neal, 2015). Teachers who apply a genre-based SFL approach to writing instruction tend to develop curriculum that moves away from traditional grammar lessons and instead develops tools that help students construct and clarify meaning in their writing (Aguirre-Munoz, 2009). Using the metalanguage of SFL in class curriculum can enable teachers to connect language to semiosis (Carpenter et al., 2015; Eggins, 2004). When the teacher makes this connection explicit to students, students are able to construct meaning in disciplinary specific ways. This outcome is a result of students' ability to discern patterns of meaning in different disciplinary texts, which enables students to gain insight into what knowledge each disciplinary community values (Fang \& Schleppegrell, 2010). The explicit focus on language with an SFL approach to instruction enables teachers to provide instructional support to both ELLs and native speakers by increasing disciplinary literacy through developing language awareness and content knowledge simultaneously (Achugar \& Carpenter, 2014). The metalanguage of SFL can also provide additional support by providing a structured language for assessment of student writing, which can reinforce how the skills being taught to improve reading and writing are applied to the development of the student's writing (Aguirre-Munoz et al., 2007; Lancaster 2014). The metalanguage of SFL can benefit students from diverse backgrounds and abilities by providing insight into the language of schooling, which is applicable in all disciplines (Schleppegrell, 2004). 


\section{Limitations of SFL in Writing Instruction}

Although there are many positive outcomes when using an SFL framework to teach writing, an SFL approach to writing does have limitations. SFL is used in elementary through college classrooms; however, instruction in SFL is not offered at many universities in the United States. Teachers and researchers interested in learning about and applying SFL need to teach themselves through research, conferences, and networking with other SFL practitioners. This can be an issue because application of SFL in the classroom can vary in practice without formal instruction in the theory. In addition, SFL can be viewed as complex by teachers. The main text, Halliday's (2014) Introduction to Functional Grammar, breaks the theory into 10 chapters over 731 pages. The complex system may be a problem for students as well. SFL is not systemically incorporated into curriculum, so students may be introduced to SFL concepts in a class and achieve successful outcomes. However, if those skills are not reinforced and further developed in future classes, students may lose the ability to apply SFL concepts to writing and reading (Ryan, 2011). For SFL to become accessible and useful to teachers and students, explicit instruction and research into the application of SFL concepts should be conducted (Carpenter et al., 2015).

\section{Discussion}

SFL places focus on literacy as a practice that is developed to analyze how texts and culture interact (Eggins, 2004). A text is a product of culture; therefore, SFL is defined as "authentic products of social interaction, considered in relation to the cultural and social context in which they are negotiated" (Eggins, 2004, p. 2). Language is viewed as a meaning-making resource by studying how people use language to interact with each other in society. This sociosemantic approach to language is interested in understanding why a text means what it does and why it is valued in society. To understand how people use language to make meaning, 
language use must be viewed as functional, semantic, contextual and semiotic. The priority in SFL is to understand the system that language is created within and then interpret how the structure emerges from systemic choices (Martin, 2016).

An SFL approach to teaching writing in college can be beneficial for both the student and teacher. For the student, SFL develops critical reading skills, develops language awareness for students from marginalized communities, and can be applied to disciplines outside of composition. SFL provides teachers with a language to talk about writing, while also providing a framework for assessment of student work. An SFL approach to writing instruction can provide access to the language of composition for students. The language of SFL can provide students with the tools to understand the system that language is created within and how their choices as a writer are a part of this system. An SFL framework for writing instruction provides teachers with a shared language to make explicit the purpose of language and how language functions in academia and society for students. This approach to writing instruction can help teachers illustrate the choices that matter for different discourse communities. SFL can benefit the assessment of student writing by showing students how the concepts of SFL used to deconstruct the writing of others can also be applied to their own writing.

The metalanguage of SFL may improve equity and access to higher education for students at the community college by providing insight into the language of schooling, which is helpful in achieving successful outcomes in all disciplines (Schleppegrell, 2004). As the requirements for class placement are changing as a result of $\mathrm{AB} 705$, the concepts of SFL may provide the framework for teachers to meet the diverse ability levels in the community college composition class. SFL can provide teachers with the language to explicitly show students how to use linguistic resources to meet disciplinary writing demands, which research has shown can 
close the achievement gap between experienced and novice writers (Pessoa et al., 2017). In addition to closing achievement gaps, an SFL approach to writing instruction has shown promise through research to benefit native speakers of English, English language learners, and students with language based disabilities (Slater \& Mohan, 2010; Stuart-Smith, 2003). The ability for SFL to support the learning needs of students from a wide variety of backgrounds and abilities may prove to be a good fit for the open-access community college system.

To understand the lasting effects of SFL in writing instruction, however, more research should be conducted into the application of SFL in higher education. For example, research into how SFL can support students with disabilities in higher education who missed out on language instruction due to segregated special education classrooms would be helpful. Also, research is needed to understand how SFL can support the diverse learning needs of the community college student in classes outside of English that require writing. More research could be conducted into how an SFL approach to writing instruction affects the writing outcomes and student perceptions of writing. This research can provide insight into how the specialized culture and language of post-secondary education is made apparent to students through SFL. This insight can provide valuable information into how educators can enable students to navigate between the familiar everyday language and the unknown, disciplinary-specific language of academia.

\section{Locating My Research as an SFL Instructor}

While there is literature available for how SFL is used at the university level, there is not any research available for how SFL is taken up at the community college level. Community college provides a pivotal access point for students to access higher education. This study into the affordances and limitations of teaching college writing with an SFL framework can provide 
insight into how students' literacy development can be supported during the important transition stage in a student's life.

The data developed during this research study can also provide information into how SFL can prepare students for writing demands outside of the university setting. Most SFL research at the university level addresses skills for academic environments. As community colleges prepare students for technical careers that do not require a university degree, this study can fill the gap into how SFL can prepare students for a wider variety of writing situations.

The multimodal assignments students completed for this research study can provide the insight into how SFL can be applied to different genres and audiences, in addition to conventional academic writing applications. Much of the research into the applications of SFL addresses one level of SFL or one assignment. The research for this dissertation provides data into how SFL can build literacy skills over the course of a semester.

Finally, this research study can grow the body of SFL research conducted in the United States. For SFL to be incorporated into curriculum at all levels of education in the United States, more research is needed to build upon the benefits of using SFL as a framework for an entire semester. This research study can also provide insight into the limitations of the SFL in writing instruction, so that strategies and solutions can be developed through future research. Until more research is done in U.S. contexts, SFL will not grow as a discipline that is offered as a course in higher education in multiple institutions. 


\section{CHAPTER 3: METHODOLOGY}

The purpose of this research study was to gain insight into the affordances and limitations of a systemic functional linguistics (SFL) approach to teaching composition in a community college classroom. This study applied qualitative methodology to gain insight into participants' experiences while collecting rich, descriptive data with examples (Leavy, 2017). In addition, this qualitative research study incorporated field research, interviews, and document analysis to provide insight into the affordances and limitations a student experiences learning writing skills with an SFL framework in a community college composition class.

\section{Qualitative Research}

Qualitative research draws from the disciplines of anthropology, sociology, and clinical psychology (Merriam, 2002). This type of research has gained popularity in the fields of "social sciences and helping professions" (Merriam, 2002, p. 3). In qualitative research, meaning is socially constructed as a result of how individuals interact with the world. As Merriam (2002) asserted, "The world, or reality, is not the fixed, single, agreed upon, or measurable phenomenon that it is assumed to be in positivist, qualitative research. Instead constructions and interpretations of reality that are in flux and that change over time" (p. 3).

Qualitative research was needed in my study because I was interested in researching how students experienced an SFL framework in a community college composition class. In studying an SFL framework for writing instruction, the outcome could change from semester to semester based on students in the class. Qualitative research provides insight into how this group of students perceive the SFL approach at the time the study was conducted. This approach to teaching college composition has been under-researched, so qualitative research was needed to gather data to build a hypothesis as there are not existing numbers or values that can be 
quantified through a quantitative study. The qualitative approach enabled me to expand my understanding through "data collection, process information (data) immediately, clarify and summarize material, check with respondents for accuracy of interpretation, and explore unusual or unanticipated responses" (Merrian, 2002, p. 5). Qualitative research provided the space for a descriptive picture to emerge of how students responded to an SFL approach to writing curriculum.

The qualitative research study took place during two college composition classes at a community college. The lesson plans and assignments were all developed using SFL concepts. Data were collected over the course of a semester and then analyzed after the grades were submitted. The context, participants, and data analysis were fully developed by using the individual interviews, participants' research projects, and responses to an end-of-semester questionnaire to convey the research results.

\section{Research Study}

The qualitative research took place in one of the 116 California community colleges with the researcher also acting as teacher. The research study was conducted in two composition classrooms to support relevant data collection due to the diversity present in a community college.

\section{Purpose of Study}

The purpose of the study was to research a new approach to teaching college composition to address the changes in developmental composition class offerings and the move to selfplacement in transfer-level composition classes in higher education. As a result of recent legislation, the diversity in readiness for transfer-level composition may continue to increase at community colleges. AB 19 was passed to make college more accessible to students in 
California by waiving tuition or providing other services that will improve access to community college (California Legislative Information, 2021). AB 504 requires community colleges to develop a student equity plan that uses funding to improve retention, degree and certificate completion, and transfer rates to a university. Finally, AB 705 changes how students are placed into freshman composition by using a student's high school transcripts instead of using a placement test. The goal of these three assembly bills was to make community college more accessible to students by removing the barriers of cost and developmental classes that prevent students from taking transfer-level classes. As a result, there is a potential for greater diversity in writing abilities among students to emerge in the composition class.

The recent passage of these bills in California reflect the current national trend for policy in higher education to focus on accountability and efficiency (Community College Research Center, 2019). As a result, improving retention in introductory community college classes is necessary as the highest rate of dropout occurs after the first term, and most students who drop out after the first term never return to college. A study analyzing early community college dropouts conducted by the Community College Research Center at Columbia University found the failure/withdrawal/incomplete rates to be at $58 \%$ for the developmental composition strategies class and $65 \%$ for the developmental writing foundations class, while the transfer-level expository writing class had a failure/withdrawal/incomplete rate of $46 \%$. The high dropout rate for these first semester courses shows students are not having a positive first-term experience in higher education. The study by the Community College Research Center (2013) concludes by asserting the high dropout rate of first-term community college students "suggests an academic support deficiency and perhaps also problems in the domain of teaching and learning" (Crosta, 2013, p. 3). The purpose of this study was to research the affordances and limitations of an SFL 
approach to teaching composition in response to the growing diversity in the community college composition classroom.

\section{Study Location}

The research took place at Coastal California Community College (pseudonym) in California. Coastal California Community College (CCCC) is a community college located in an upper middle class community in Orange County, California. For the 2018-2019 school year, CCCC had one of the largest student bodies in the state with between 15,000 and 25,000 students enrolled, and $30 \%-40 \%$ of those students were attending classes full-time (ranges are given to protect privacy of students who participated in the study). Although the campus is in an upper middle class community, $\mathrm{CCCC}$ does pull from surrounding working-class communities. Students also commute to campus up to 2 hours for the specialty workforce certification programs the college offers. CCCC is a top transfer school in the State of California, which draws students throughout southern California. $\mathrm{CCCC}$ has a robust international community as many international students are drawn to the campus due to the location in Orange County and the wide variety of immigrant communities located in nearby communities. CCCC also attracts many adult reentry students who are interested in pursuing a career technical certificate, an associate degree to compliment an existing career, or are interested in completing general education requirements to transfer to a university. $\mathrm{CCCC}$ is an ethnically diverse campus as well with $20-25 \%$ identifying as Asian, $25-30 \%$ identifying as Hispanic, 1-5\% Black, 35-40\% White, and 3\% identifying as two or more races.

\section{Study Participants}

Participants were enrolled in a developmental composition class that is one level below transfer-level, freshman composition. Students enrolled in the class were self-placed to develop 
college writing skills or were placed in English 099 through placement testing or for earning less than a $\mathrm{C}$ in high school English. Traditionally, adult reentry students enroll in the class to brush up on writing skills due to taking a significant break after high school. English language learners often enroll in the class as a bridge between ESL classes and transfer-level freshman composition. Students with disabilities who have struggled with writing enroll in 099 to further develop writing skills. Outside of class, students enrolled in community college classes can struggle with food insecurity, housing insecurity, childcare conflicts, job conflicts, lack of transportation, and family conflicts. These struggles can make completing assignments and coming to class difficult.

The study took place in two classes to gather more data. The class dynamic can be different from class to class, so studying both classes provided a broader perspective of how students experienced an SFL approach to writing instruction. As the researcher and instructor, it has been my experience from teaching these classes for 8 years prior to the study that students who enroll in the Monday and Wednesday class are first-year students who are enrolling in community college out of high school. Although students who enroll in the Friday class are often adult reentry students who are fitting the class in with other work and family commitments. Conducting the study in both classes provided a broader perspective of student experiences. The first class was held on Mondays and Wednesdays from 7:20-9:20 a.m. and the second class was held on Fridays from 9:35 a.m.-1:50 p.m. The class met for the duration of the 16-week spring semester.

\section{Researcher Positionality}

As the researcher and instructor, it was important to identify and monitor subjectivities because "the human instrument has shortcomings and biases that might have an impact on the 
study" (Merriam, 2002, p. 5). As I fulfilled a dual role as researcher and teacher, it was vital that I acknowledged any subjectivities that may taint the perception of the research. I had been teaching composition at CCCC since the fall of 2010. Although I had taught all levels of composition at CCC, I primarily taught developmental composition classes. Prior to teaching college composition, I received an MA in English with an emphasis in composition and rhetoric in the spring of 2009. For my final MA project, I focused my research on addressing the writing needs of students with learning and developmental disabilities. In the fall of 2016, I entered into the $\mathrm{PhD}$ program in education with an emphasis in disability studies to continue the research that I started with my MA in English project. Before I started the PhD program, I was teaching five composition classes per semester as an adjunct instructor at three local community colleges, including CCCC. In addition to my professional background, I understood and related to many of the same struggles of the community college students because during my doctoral studies I was a single mom juggling the responsibilities of raising three teenagers with going to school and working full time.

\section{Research Design}

The research study employed qualitative research methodology for data collection and data analysis to answer the research questions.

\section{Research Strategy}

A base writing sample was collected the first week of the semester. The first writing assignment was assigned on the first day of class without any instruction and then collected on the second day of class. This intent of the initial writing assignment was to provide students with insight into their writing skills and comfort with writing for an academic audience. The initial 
writing assignment was used as a baseline during interviews and the end-of-semester questionnaire as a way for students to gauge growth in writing using the SFL framework.

After the initial writing assignment, the remainder of the semester was divided into three units, with a level of SFL introduced in each unit and instruction of each unit lasted 1 month. The first unit introduced students to the SFL concepts of genre, register, and the subconcepts - field, tenor, and mode. The second unit introduced students to the SFL concept of semantics and the subconcepts of ideational metafunction, interpersonal metafunction, and textual metafunction. Students were taught the SFL concept of lexicogrammar, along with the subconcepts of transitivity, mood, and theme.

The SFL concepts were illustrated in class and through homework through the reading of and reflective writing about primary texts from significant historical and current issues in the United States. For the first unit, students learned about the Greensboro Lunch Counter Sit-In and the Flint, Michigan water crisis. The second unit introduced the class to the UFW Grape Boycott and current immigration legislation. The final unit addressed the war on drugs during the 1980s and the opioid epidemic. The historical issue was contrasted with the current issue for students to infer the SFL components through the reading. Original articles from newspapers and magazines, academic journal articles, political cartoons, editorials, and letters to the editor were assigned to students to read about each issue to gain insight into the facts, context, and societal attitudes surrounding each issue. The variety of reading assignments, including visual rhetoric, illustrated how the SFL concepts of context and culture affected the choices writers made and how those choices affected audiences' perception of the issue. All of the issues students learned about addressed civil rights with writing as an instrumental component in initiating or creating change in society. 
Students were assigned a formal writing assignment at the start of each unit that was due at the end of the unit. The first formal writing assignment for the register level of SFL was to identify an issue that affects a community to which the student belongs. The genre for the assignment was informative, so students had to inform either the audience the issue affects or an audience outside of the community the issue affects about the issue. In the second unit, students had to select an issue that affects the State of California and argue for one side of the issue to a specific audience that has the power to enact change regarding the issue. For the final unit, students were tasked with identifying an issue that affects the country and then developing the causes and the effects of the issue in the country.

Students had the choice to either write a traditional 4-page research essay or create a textual representation of the issue and write a 2-page reflective essay detailing the choices the student made in creating the textual representation to meet the needs of the audience in conjunction with the context of the situation and the culture within which the issue was happening. Students had the opportunity to choose from a variety of multimodal forms for their textual representation: autobiography; biography; letter; billboard; collage; campaign speech; comic; character sketches; poetry, song, photojournalism; interview; laboratory notes; blog; vlog; website; letter to the editor; novella; pamphlet; play; poster; review; speech; commercial, movie; documentary; policy; law; proposition; contract; etc. (Hughes, 2009). The purpose of the textual representation was to function as the vehicle to teach the metalanguage of SFL. Before students turned in the final assignment for each unit, they had to write a 250 -word project proposal that detailed the issue, the audience, the textual representation, and why the textual representation was the best choice for the audience, context and culture of the situation. 
The homework and in-class activities students were assigned helped to illustrate the concepts of SFL. In each unit, students were assigned to conduct primary research—observation, interview, and/or survey — to gain insight into the attitudes and beliefs of the potential audience for each issue. Choices made at each level of SFL are reflective of the audience, so it was important for students to gain firsthand insight into what the audience knows about the issue, what they believe to be true about the issue, and how their beliefs are reflective of their values. Students were also assigned worksheets that provided definitions of each SFL concept introduced during the unit, along with previous SFL concepts. Students used the worksheet to apply the SFL concepts directly to the formal writing assignment they were in the process of developing. SFL concepts were also reinforced during peer review as students used their classmates' work to identify the SFL concepts and respond to the effectiveness of the choices made by the student writer based on SFL.

After students submitted their final assignment of the semester, an end-of-semester questionnaire with open-ended questions was given to students. The questions solicited students to reflect upon their experiences learning the SFL concepts and applying the concepts to their writing. The questionnaire also sought feedback on what students felt could be improved in the curriculum. The final questions asked students if they believed the SFL concepts prepared them for writing in other college classes and in situations outside of college. Questionnaires were turned in anonymously to protect students' privacy and to prevent students from feeling pressured to provide positive responses.

The field research took place over the entirety of the semester. Students were informed on the first day of class that I was working on completing a doctoral degree in education and the SFL curriculum used throughout the semester was the framework of the research study for the 
dissertation. Students were also made aware the data collection and analysis would not take place until after the semester was over and their grades were submitted. Throughout the semester, the priority was to teach the students, so data collection and analysis did not take place until the role of teacher was completed. On the last day of class in both classes, I read the approved IRB to the students. Then I asked for a student to volunteer to distribute and collect the consent forms. The consent form asked students if they consented to having the work they produced throughout the semester used as data for the research study. They were informed pseudonyms would be used and the work would be saved in a cloud server to protect their identity. Also, they were told I would not know who agreed to have their work used as data until after final grades were submitted. In addition, students were asked on the consent form if they were interested in participating in an informal interview to discuss their experiences with SFL. As I was fulfilling both the role of teacher and researcher, I was not in the room when the consent forms were distributed or collected to prevent students from feeling pressure to participate.

\section{Data Collection}

After the final grades were submitted, I gathered the work produced by students who consented to have their work collected. I also arranged interviews with students who expressed interest in participating in a one-on-one interview on the consent form. Triangulation of data during the collection phase was sought to guarantee quality in the research. Triangulation involves "using multiple methods for data collection" and drawing "data from multiple sources" (Bailey, 2007, p. 77)

\section{Student Work}

Multiple sources of data were gathered as 48 students from both classes agreed to have their work collected for the study. The diversity that makes up a community college classroom 
was reflected in the data gathered as a result of collecting student work from two classes. The formal writing assignments, textual representations, project proposals, and questionnaires were gathered as data to be analyzed for the research study. The benefit to collecting students' work was the materials were not dependent upon participant interviews and observations; therefore, greater insight into how students use the metalanguage of SFL could be ascertained (Merriam, 2002). Students' work was saved in a cloud server and students' names were removed from the work to protect privacy.

\section{Interviews}

Six former students met with me for one-on-one informal, semistructured interviews. According to Merriam (2002), in semistructured interviews, "The largest part of the interview is guided by a list of questions or issues to be explored and neither the exact wording nor the order of the questions is determined ahead of time" (p. 13). The informal interviews were structured as conversations with the goal to "seek a position that is unknowing rather than expert, a position that is responsive to cultural differences, rather than one that marginalizes these differences, and a position that involves more listening than talking" (Glynn, 2013, p. 38). As the researcher, I intended for the conversations to make students feel part of the research process, instead feeling like they were being subjected to the research. Semistructured interviews were conducted like "a comfortable conversation to enable nondirective and informal chat and conversations to flow, at a pace determined by the research participants" (Macfarlane, 2013, p. 143).

Interviews took place at neutral locations on campus and off-campus in coffee shops. The researcher met with each participant one time and each interview lasted approximately 1 hour. Interviews were loosely structured around each of the three main components of SFL: register, semantic, and lexicogrammar. Participants provided background information about themselves 
and their previous experiences with writing instruction. Participants were asked to reflect upon how they experienced each level of SFL and how it influenced their writing. Through conversation and fulfilling the role of researcher, I engaged students in a discussion about their understanding of the SFL concepts, how each concept helped them develop their writing, and what issues they experienced with learning and applying the SFL concepts to their writing. I also asked students if they felt the SFL concepts will help them develop their writing in other college classes and for writing situations outside of college. Interviews were recorded and transcribed using a transcription service. Interviews and transcripts were saved in a cloud server for analysis. Participants' names were replaced with pseudonyms to protect participants' privacy.

\section{Research Journal}

A research journal was used throughout the semester and was saved as a data source after the semester. The research journal is "hybrid literary form in which researcher uses one's own personal experience as the basis of analysis" (Angrosino, 2007, p. 80). The research journal is similar to an authoethnography as it reflects the researcher's "inner thoughts, descriptions, paraphrased quotations, self-reflections, and profound thoughts" (Bailey, 2007, p. 113). SooHoo (2013) described the research journal as "a tool for self-conscious criticism" (p. 201) by providing a place to record personal reflections "through an interfacing of philosophy and field word" (p. 201). The research journal functioned as a memo to continuously reflect on my positionality as teacher and researcher.

\section{Field Notes}

Finally, field notes were kept throughout the semester to jot down thoughts, experiences, student comments, observations, and interactions (Bailey, 2007). These notes were valuable in recording reactions as they happened, instead of writing about them with hindsight. The field 
notes represented observational data, which records firsthand encounters (Merriam, 2002). As the teacher acting as researcher, I was an active participant observer, which means the researcher was "a member of the group organization who is thus participating while observing" (p. 13). The personal experience that was recorded through the field notes was useful as data because the SFL curriculum was refined and concepts reinforced in response to students' questions about the curriculum during class. The field notes provided a place to record student responses and reactions to continue developing material for the class that was being taught and for future classes. In addition to field notes, I took pictures of the white board as a record of the class discussions, activities, and answers to student questions. The field notes were recorded from the position of teacher to hone curriculum throughout the semester.

The variety of data — interviews, questionnaires, and student work—allowed for triangulation among researcher, data, and participants (Merriam, 2002). Although the data were not collected until after the final grades were submitted, the data gathered reflected a "long-term process built upon established relationships and increased trustworthiness and responsibility rather than discrete time segments of contact hours" (Berryman et al., 2013, p. 18).

\section{Coding of Data}

Students' writing, textual representation, end-of-semester questionnaire, and interviews were coded using the Cycles of Dialogue (Pinnegar \& Hamilton, 2009, p. 91). An idea is expressed and then knowledge emerges from inquiry, reflection, critique, evidence, or response. In the cycles of dialogue, meaning is forged through the tensions created by the elements of dialogue. The cycle of dialogue was used to code the data for "expressions of commonality among competing ideas; expression of difference among similar ideas; mediation process where individual terms are explored; presentation of research that supports or conflicts ideas" (Pinnegar 
\& Hamilton, 2009, p. 91). The themes that emerged from the cycle of dialogue were coded by hand. Acting as the researcher and not teacher, I read through the interview transcripts and the final student questionnaires multiple times and coded the themes that emerged using different colored highlighters to differentiate between themes.

\section{Student Work}

The formal writing assignments and textual representations that were collected were coded for the values of each SFL metafunction. For the first writing assignment, the researcher coded for language in the writing and examples in the textual representations that showed evidence of students making choices based on the genre and SFL concept of register and the components of register: field, tenor, and mode. For the second writing assignments, the researcher coded for genre, register, and for the ideational, interpersonal, and textual aspects of the semantic level of SFL. The final assignment was coded for the lexicogrammar aspects of transitivity, mood, and theme. The project proposals and reflective essays that were submitted along with the textual representation were coded for students' use of the SFL metalanguage in their writing.

All textual representations, project proposals, and reflective essays from students who agreed to be in the study were coded. If there was evidence of an SFL metafiction in the student's textual representation or academic essay, I would cross reference with the project proposal and reflective essay to verify the metafiction used was purposeful by the student. The project proposal provided students with the opportunity to use the language of SFL to describe their textual representation and how the textual representation fit the context of the situation and the culture of the audience. The reflective essay instructed students to write about choices they made as a creator developing the textual representation. The exploratory and explanatory nature 
of both assignments provided a way for me to confirm that evidence of SFL application in the textual representation was intentional by the student.

\section{Interviews}

In addition to the project proposals and reflective essays, I read through participant interviews multiple times to code for affordances and limitations students expressed regarding their experience learning SFL and applying SFL to their writing over the course of the semester. Specifically, I looked at each level of SFL to ascertain how participants experienced each level of SFL. In addition to each level of SFL, I coded for overall how students expressed the affordances and limitations of SFL in their development of writing skills and their ability to apply the skills learned through SFL to situations outside of college.

\section{Questionnaire}

The end-of-semester questionnaire was coded with a similar approach as the student interviews. The questionnaire was coded to see how students expressed affordances and limitations of SFL at each level. In addition, the researcher coded the questionnaires for expressions of how the SFL concepts developed their writing during the semester and how the SFL concepts will continue to use beyond the semester.

\section{Research Journal and Field Notes}

Although the research journal and field notes were used throughout the semester, neither was included in the coding process. The research journal was mainly used as way to record my thoughts and experiences while teaching SFL. This enabled me to record my thoughts and concerns about teaching using the SFL framework, which kept me focused on my role and teacher and not researcher. The field notes recorded the questions, comments, and concerns students had about SFL. These notes enabled me to further develop the curriculum as I was 
teaching. Both the research journal and field notes functioned as reflective tools to help with curriculum development for future classes and did not provide insight into the affordances and limitations of the SFL framework in writing instruction.

\section{Data Analysis}

As a qualitative study, the data was collected over an extended period of time, specifically the 16-week semester (Merriam, 2002). During the semester of the research study, I highlighted "key events, divergent findings, daily routines, and important processes" (Bailey, 2007, p. 6) of the course curriculum and classroom interactions in the research journal. The ability to analyze the classroom and curriculum data as they are being collected enabled me to make adjustments and respond to the needs of the class (Merriam, 2002). The analysis of work participating students produced and the questionnaires were not analyzed until after the final grades were input to guarantee that grading of the final assignments was not affected by a student's decision about participating in the study.

\section{Data Analysis of Interviews and Questionnaire}

Both interviews and the end-of-semester questionnaire were analyzed for how students reported their experience learning SFL and using SFL to develop their assignments. How students reported the affordances and limitations of SFL at each level and overall were analyzed.

\section{SFL Applied to Data Analysis of Student Work}

This level of analysis provided insight into how students used the three concepts of SFL to develop their assignments. This analysis involved looking for how students applied the concepts of SFL to the creation of textual representations and academic essays. The work students submitted for the first unit were analyzed for how well students incorporated the concepts of register into their work. The work students turned in for the second unit were 
analyzed for the concepts of register and semantics. The final unit was analyzed for all three SFL levels - register, semantics, and lexicogrammar. The textual representations, reflective essays, and academic essays were analyzed to ascertain how students applied the metalanguage of SFL to their work and how SFL either benefited or hindered their ability to create effective texts.

\section{Trustworthiness}

Trustworthiness in research refers to "the ways we work to meet the criteria of validity, credibility, and believability of our research—as assessed by the academy, our communities, and our participants" (Harrison et al., 2001, p. 324). The trustworthiness of research is carried out at every stage of the research process (MacGibbon \& Morton, 2001).

\section{Research Design}

Throughout the qualitative research study, I applied Ferguson and Ferguson's (2000) approach to ensuring trustworthiness in the research process. Ferguson and Ferguson (2000) forwarded the perspective that "there are three dimensions of quality in interpretivist research: 'truth'-value and accuracy; context and relations; and utility and relevance" (p. 183). These separate dimensions each employ a specific set of strategies that encourage quality and trustworthiness in the research.

The first quality dimension, "truth" value and accuracy, encourages researchers to use a variety of techniques to ensure themselves and their readers that they have not made mistakes in the research. For this research study, I used a variety of data points—research journal, field notes, document analysis, and interviews with participants - to gather research. The quality dimension of truth value and accuracy also encourages researchers to take a long time in the field to gather more research. This research study took place over the course of a semester and in two separate classes. The purpose of this quality dimension is to illustrate to the audience that the 
researcher did everything possible to gather "the information as accurately as possible, captured the phenomenon, reflected the participants' points of view, and considered as much as possible of the whole topic/setting/phenomenon" (Ferguson \& Ferguson, 2000 p. 183). Triangulation of the data occurred through analyzing the student interviews, students work, and the end-ofsemester questionnaire to encourage quality and trustworthiness.

The second quality dimension is context and relations, which entails "recounting the research context and the relations the researcher had with the people in that context" (Ferguson \& Ferguson, 2000, p. 183). This quality is important in proving trustworthiness of the study because the knowledge and meaning that comes from the research emerges from the interaction between researcher and participants. As the relationships are so important in fostering trustworthiness, studies that present both researchers and participants as coconstructors of the knowledge exhibit greater accuracy and are more trustworthy. Students functioned as coconstructors during the research study as we functioned as a cohesive class as we experimented with SFL together. In addition, feedback from students was solicited through the end-of-semester questionnaire. This positioned students as coconstructors in the research because their input on the affordances and limitations was sought out, as opposed to the researcher collecting and analyzing the student work without taking into consideration students' first-person experiences. As the researcher, I also engaged participants in the interviews as coconstructors through the informal, participant-led conversations. Finally, as I acted as both the researcher and the teacher, the relationship that developed with participants was more interactive than a traditional researcher who observes from an impartial distance.

The third quality dimension is use and relevance. Although research should be relevant and useful, by usefulness in this context Ferguson and Ferguson (2000) mean "something much 
broader than simple instrumental utility or predictive success" (p. 184). Research that is trustworthy enables the reader to place themselves within the research to gain insight into the relevance of the research. The use and relevance of the research is measured by four different aspects of utility: instrumental, enlightenment, symbolic, and emancipatory. For this qualitative study, I framed the individual and group conversations around these four areas to ascertain how participants experienced the utility of SFL and to see if they felt SFL will be useful in the future. All three of these quality dimensions together contributed to the trustworthiness of my research.

\section{Research Dissemination}

Trustworthiness moves beyond research design, collection, and analysis to include the dissemination of the knowledge gained through the research. Moss (2004) asserted trustworthiness must "include the situating of the resultant knowledge or voices of critique in the academy for a participator democracy to become more intersubjective between researcher, researched, and literature" (p. 370). As I transitioned from teacher to researcher at the end of the semester, I added to the integrity of the research by contextualizing and disclosing the research procedures to students. I shared with students the conferences and publications I planned to use as platforms to share the knowledge gained from the class. I was not able to share with students the initial findings because I did not analyze any of the data until after the semester ended.

Now that the dissertation is completed, I will seek to develop the research study into journal articles. The purpose developing the research study into journal articles is to disseminate the findings to a wider audience. SFL is an under-researched area in the United States, so the publication of the findings will add to the body of SFL research in higher education settings. My goal is to publish journal articles in both publications that regularly publish articles related to SFL, such as English for Academic Purposes, and also to journals that have not published SFL 
research. The researcher hopes publishing data in journals outside of the SFL will increase awareness of SFL and encourage educators to seek out additional information about SFL.

In addition to publishing, I plan to pursue sharing the research at national conferences to gain feedback from colleagues to continue developing the curriculum. The National Conference of Teachers of English (NCTE) is a highly regarded conference that brings together elementary through post-secondary English teachers. This practitioners conference will provide useful feedback regarding the viability of incorporating SFL in other literacy classrooms. The English Council of Two Year Colleges (ECTYC) is an off-shoot of NCTE and offers a conference each year. This conference will provide valuable insight into how well SFL addresses the changing placement requirements in composition classes. The International Systemic Functional Linguistics conference is another conference that can provide important feedback into how I used SFL in the curriculum. I plan on submitting proposals for each of these conferences to continue to develop the curriculum through feedback from colleagues and mentors. The conferences will also provide an opportunity to introduce educators to SFL to encourage incorporation and development of SFL into curriculum at other institutions of higher education.

As a researcher, I will continue to strive to guarantee trustworthiness when disseminating the findings when publishing or presenting findings by including the perspectives of multiple students, protecting students' privacy by using pseudonyms, being transparent in sharing, and describing all aspects of the research design, collection, and analysis.

\section{Conclusion}

This study was conducted in an effort to understand how SFL can be applied in the community college classroom. Qualitative methodology was used for the research study to enable the diversity of the community college classroom to come through the research. The study 
gathered data from the 16-week semester to provide the depth necessary to ascertain the affordances and limitations of an SFL framework for instruction. The analysis of the interviews with students, the questionnaires, and the student work provided a holistic perspective into how SFL curriculum functions in the college composition classroom. With the changes to how students are placed in transfer-level freshman composition as a result of AB705, a new approach to teaching composition may benefit the increased diversity in writing skills that will continue to occur in the community college classroom. 


\section{CHAPTER 4: RESULTS}

This chapter contains the results of the qualitative study conducted to answer the research question: What are the affordances and limitations of using a systemic functional linguistics (SFL) framework to teach composition in the community college?

To answer this question, six students were interviewed to gain first-person perspective into the affordances and limitations of learning college composition with the SFL framework. In addition to the student interviews, the academic essays and textual representations students in both classes submitted were used to ascertain the affordances and limitations of SFL in the composition classroom in the development and completion of the assignments. Finally, an endof-semester SFL questionnaire students completed supported triangulation of the data analysis of the student interviews and collected work.

\section{Students Interviewed}

Students who agreed to participate in interviews were as diverse as a typical community college classroom. Interviewees represented international students, adult reentry students, firstsemester freshmen, nonnative English speakers, and veterans. Students were in the Monday/Wednesday 8:00-10:00 a.m. class and the Friday 9:30 a.m.-1:50 p.m. class. Students' participation in interviews was voluntary. Interviews were conducted one on one after the semester was over and final grades had been submitted. After interacting with these students during class and through writing assignments, a comfortable rapport between interviewer and interviewee developed. Questions were designed to gain insight into how each student experienced the three levels of SFL: register, semantic, and lexicogrammar. The questions sought to understand the affordances and limitations of SFL in the composition classroom. 


\section{Description of Students Interviewed}

To gain insight into students who shared their experiences learning with the SFL framework, this section provides background information about the six students who agreed to be interviewed.

\section{Hao}

Hao was born in Vietnam and came to the United States when she was 10 years old. When she started the fifth grade in the United States, Vietnamese was her primary language and she reported she only knew the basics of English, like the alphabet. Hao recalled recalled learning how to read and write in English was really difficult, but she learned to adapt over time. However, she recalled negative experiences with writing in school, mostly because she could not recall scoring above a "C" on a paper she wrote. The most challenging aspect of writing in high school was meeting teachers' expectations, as she felt her teachers were harsh graders. When asked about how writing was taught during high school, Hao responded she does not remember being taught how to write. Her memories of English class are of being given a writing prompt and then being expected to write based on the prompt. When asked what happened between the assigning of the writing prompt and turning in the completed essay, Hao replied that her teachers “just explained how the essay should go, but they didn't give examples that can show me or point out what I need to do."

This was Hao's first semester in college and my class was her first college class, as she was in my Monday and Wednesday 8:00 a.m. class. When asked how she felt about going into her first college-level writing class, she reported feeling "kind of nervous because I thought I wouldn't be doing well since my grades were bad in high school." She thought the first essay 
assigned on the first day of class was hard because there were not any examples and "the compare contrast genre has always been a hard genre for me to write."

\section{Michelle}

Michelle is an adult reentry student who enrolled in community college after taking 10 years off from school. She did attend community college right after school and even played volleyball for the college team. After her first year in college, she dropped out and then began the cycle of enrolling and dropping out for the next 2 years. Her career goals also kept changing each time she enrolled. She was interested in becoming a dolphin trainer, animator, and architectural design. She reported, during her 10-year break, she wanted to go back to school but the party phase she was in kept her from pursuing higher education.

After experiencing a personal trauma, Michelle resolved to enroll in college because "if I didn't do something about my life, it was like I experienced that for nothing." The composition class was the first she attended after her break. She enrolled in community college with a renewed focus and interest in pursuing communications because "communications is something I've always struggled with, so just sharpening that skill." Her long-term goal is to work with sports organizations as she still enjoy being part of the volleyball community. The break from school has given her the perspective that "the main thing of all the paths that I've gone down, is design, it is the creating."

\section{Carrie}

After a 10-year break since graduating from high school, Carrie felt really excited to take a writing class because she has always loved English: "I just never knew what to do with it for a job, but I always enjoyed it." This was her first semester in college and she enrolled in the

optional Confidence in College Writing class at the suggestion of her counselor. She was willing 
to take the class because she knew she liked English and she felt she could handle the class.

Carrie did not have any idea what a college class would be like, so, even though she did not have to take the class, she felt it was an opportunity to ease into college. She believed she was up for the challenge of taking a college-level writing class because of her experience enjoying writing in high school. Her purpose in returning to school was for career advancement. She was working in dental office full time, but she hoped the college degree would give her the opportunity to move up at work. Carrie was enrolled in the Friday class because her boss was willing to give her Fridays off to attend school.

\section{Jessica}

This was Jessica's second semester in college, but her first writing class since high school she graduated high school over 20 years ago. Jessica was nervous to take a writing class because it has been so long since she has been in school and she does no[t have fond memories of writing when she was in high school. She felt her writing was not very good and she was overwhelmed after the first day of class: "At first I felt a little overwhelmed, like how am I going to do this?" In addition to being a student, Jessica was also a stay-at-home mom to five children — one was away at college and the other three were at home. Her husband was very supportive of her returning to school and helped her register for classes. She was not sure yet if her long-term goal was to obtain her associate degree or to transfer to a university. The plan at the moment was to take school on a semester-by-semester basis. Jessica was enrolled in the Friday 9:30 a.m.-1:50 p.m. class because this class allowed her to drop her kids off at school and then pick them up in the afternoon. 


\section{Zaire}

Zaire was born to an American father and a Jordanian mother, which enabled him to spend his childhood in both Jordan and the United States. He considers Arabic to be his native language, as Arabic was spoken in his home growing up; however, he does consider himself to be bilingual in Arabic and English. Zaire graduated from an American high school in Jordan and then he decided to take a gap year before enrolling in college. That gap year turned into 5 years and he was now back in school with the goal to become a surgeon. The Monday and Wednesday 8:00 a.m. composition class was his first college class since graduating from high school.

Although Zaire stated the reason he took the composition class was because he thought it was a mandatory prerequisite for his major, he was excited to "learn how to write properly." The ability to write well was important to him because he felt writing well is a reflection of being educated: "I mean, if you can't write, how can you be called educated?" Zaire felt confused about writing when he entered the class. He reported he was not familiar with how to write an essay. He vaguely understood he needed to write an introduction, body paragraphs, and a conclusion, but he was not sure how to go about writing the elements of an essay. He was not sure if he was taught how to write an essay in seventh or 10th grade, but he did not remember getting much practice writing essays throughout high school.

\section{Niguel}

Niguel graduated from high school 5 years earlier, and he has spent the last 4 years as a Marine serving overseas. After taking such a long break, Niguel felt scared to come back to college because he did not know what to expect. He was especially afraid to take a writing class as his first college class because he thought he was going to fail. When asked why he thought he would fail, he replied he “didn't really practice or do any type of English material or any formal 
education while in the Marine Corps." He was concerned with the "grammar, essays, basically anything that involved writing. The whole thing, everything." Mostly this fear came from remembering he did not do well on essays back in high school and writing was not a focus in his classes. He learned how to get away with doing the bare minimum in each class. In the Marine Corps, Niguel reported he did not write a single essay or even a paragraph while enlisted because writing was not the focus.

The student interviews provided a first-person perspective of the affordances and limitations of an SFL framework to composition instruction. The interviews allowed me to clarify answers to questions and seek additional information to questions. The analysis of student work and end-of-semester questionnaire would not have provided the personal insight the interviews provided. Interviews were conducted after the semester was over, so member checking was not possible as students went back to their busy lives: two students left the country for the summer, one became pregnant, one moved away, and another took multiple summer school classes. The student work and end-of-semester questionnaire, along with the interviews, provided different perspectives into the affordances and limitations of the SFL framework in writing instruction.

\section{Discussion}

The following section will discuss the affordances and limitations of using the SFL framework in the community college composition classroom based on the six student interviews, students' work, and the end-of-semester questionnaire. The findings are divided into register, semantics, and lexicogrammar subsections. The organization of the findings reflects the design of the course over the semester. The semester was divided into three units with each unit teaching a level of SFL. As the teacher and the researcher, I also structured the student interview 
questions and end-of-semester questionnaire to seek feedback on the separate levels of SFL because this followed the structure of the semester. Students were taught each level of SFL as a unit, so the same organization was followed in the questioning. Each level of SFL was analyzed separately for affordances and limitations to understand how students experienced each level. The stratification of SFL enables any level to be taught independently; therefore, I sought to gain insight into each level. In addition, I sought to understand how students' writing continued to develop with each level. The section concludes with the overall affordances and limitations of SFL in its entirety as it was taught during the semester.

\section{SFL in the Composition Classroom}

The first writing assignment of the semester was assigned on the first day with minimal instruction as to how to develop the essay. The prompt was to write a compare and contrast essay about how two different sources for news covered the same current event. The essay was due at the beginning of the next class. This essay was designed for students to act a base for students to reflect upon how they experienced learning SFL throughout the semester. A level of SFL was taught with the remaining three formal writing and multimodal assignments. Each level was taught in order — register, semantic, and lexicogrammar — and each level was taught over a 4week period. During the end-of-semester interviews, students shared their experiences applying the three levels of SFL to their writing and multimodal projects.

\section{Register Level of SFL}

The SFL level of register was taught for the second composition assignment of the semester. The register level addresses the context of the situation in a text. This level is composed of three areas: field, tenor, and mode. The field is the specific topic of the text. The area of tenor deals with who the text is being pitched to and what is the relationship between the 
creator and the audience. Finally, the mode is the form of the text. Students were instructed to select an issue that affects a community they are a part of and inform an audience about the community issue. Students could choose to inform the audience about the issue through a multimodal project and academic essay or a through a longer traditional academic essay.

\section{Affordances of the Register Level of SFL in the Composition Classroom}

Through the interviews, analyzing the textual representations, and academic essays students submitted, benefits of the first level of SFL emerged. The interviews revealed SFL afforded students help with organizing the text, guidance in developing the text, and presented a challenge compared to previous writing experiences. The work students developed reflected these affordances as well, which is revealed in their academic essays and textual representations.

\section{Organization}

Students often struggle with organizing material from idea gathering stage to drafting stage. The uncertainty of how multiple pages of text will be generated from just an idea or free write can overwhelm students in the early stages of the writing process. This can create writer's block and can lead students to change topics entirely or broaden the topic to something so vast the topic cannot be adequately addressed with any depth in an essay. In my experience teaching, students will often lament, "I know what I want to say, I just don’t know how.” For many students, moving from idea gathering to drafting is the hardest part of the process. At this point, students may fall back on the idea that they are not a good writer because they have ideas but cannot move the ideas into an organized text.

An affordance of the register level of SFL is that the concepts of field, tenor, and mode provide direction in how to move ideas into an organized text. Field in the register level of SFL challenges students to narrow the broad idea into a specific topic. Often, the more specific the 
topic the easier it is to organize because there is not as much information to manage and form into a text. The concept of tenor, which reflects the power structure between creator of the text and the audience, can enable students to organize their ideas to fit the expectations and needs of the intended audience. The mode provides insight into how a text should be organized and structured based on the social context the mode is being produced within. By developing the field, tenor, and mode for a topic, a student takes the ideas and begins organizing the ideas into text.

The students interviewed reported the concepts of the register level did help them organize their ideas. Hao reported learning about the register and the three facets of registerfield, tenor, and mode — was interesting because they were new concepts that enabled her to organize her writing by using the concepts to order her ideas. She created a pamphlet for the assignment and applying the concepts of field, tenor, and mode helped her to "think about the layout and what I should put in each column and organize it." Michelle also believed the new SFL concepts within register made her writing more structured, focused, and organized. Reflecting upon field, tenor, and mode she stated "you have to be specific in what you're talking about. You need to know what you're talking about, and when you know who you're talking about ... you know what words to use." Overall, she reported, "The main thing I can say about it is it's structured, so you're not all over the place." Together she felt the introduction of these concepts made the second essay of the semester easier than the first one that was assigned. Without the concepts of field, tenor, and mode. Niguel stated he would "have been more lost than I was already." The SFL concepts gave him the tools to organize the large issue of ocean pollution into a manageable project with a specific focus. He chose plastic pollution as the field, which he felt the audience he was addressing had more control over. He used the concept of field 
to go from a large topic, ocean pollution, to a manageable topic, plastic pollution in the ocean, through working with the concept of field. The interplay between tenor and mode can help students organize their writing by thinking about what the best mode is to communicate the field and what expectations the audience will have for both the field and mode. With this information, the writer can select what information the audience needs to know and how to arrange the information.

The benefits of the register level helping students organize their text is also evident in the student projects that were submitted. One first-year freshman developed an infographic about the dangers of the e-cigarettes, or JUULs. The student combined hand-drawn pictures and facts about Juuling as the mode and the tenor is parents of teenagers. The drawings move in logical order that is easy for the audience to follow and grasp the information. Out of all the information available about Juuling, the student can narrow the field down to the specific information parents need to know and from there decide what order the information should be organized in for parents. After informing the audience about the issue, the student provides solutions for parents to keep teenagers away from e-cigarettes. Another student is a recent immigrant from Syria. He developed a PowerPoint presentation for other recent immigrants about the importance of a credit score in the United States. The mode of the PowerPoint enabled him to move the slides around to find the best organizational pattern for the specific tenor of other immigrants. A further example of the organizational benefits of SFL is evident in a student's infographic depicting where a server's tips go at the end of the shift. This student was a server at a popular family restaurant. She shared frustration at how people do not understand how tipping functions in the service industry. She had an emotional investment in this issue because she had just experienced a large party only tipping her $\$ 10$ and thanking her for her service. She stated in class, "A thank 
you doesn't pay the bills." The concept of tenor and mode enabled her to take an issue she felt strongly about and channel that into an organized infographic that communicates with an audience of diners how tips are distributed. The infographic shows a typical receipt with all the food, drinks, and tax listed and then the tip portion of the receipt shows what percentage of the tip goes to the person bussing the tables, another portion goes to the bartender, and another portion goes to the employee prepping the food for delivery to the table. The infographic communicates a wealth of information because of the organization of the content. The concepts of field, tenor, and mode of the register level of SFL provided students with direction to move from broad concepts and ideas for the assignment to issues that were personal and important to them, which created more depth in development.

\section{Guidance in Developing the Text}

For many students, the college composition class is taken the first semester of college. First-semester freshmen can feel intimidated by writing for a college class. Adult reentry students have not been in college for a while and do not remember what they learned about writing in high school. How to take the idea from concept to developed draft can be challenging for students. What to include in a text and why can leave students feeling overwhelmed and faced with writer's block. An underdeveloped essay that lacks focus is often the result of the student's uncertainty in developing the text during the drafting stage. The concepts of field, tenor, and mode can afford students with the guidance to develop their writing during the drafting stage of the writing process.

The students interviewed, who have not been in school for a while and felt intimidated by the process of going from idea to complete product, reported the SFL concepts of field, tenor, and mode helped guide them throughout the writing process. Jessica found the audience 
awareness piece from the SFL concepts of tenor and mode to be helpful in developing a pamphlet for other parents who are navigating the boundary issues inherent with adult children living at home: "What audience you were going to cater to, or write to. I think that helped me a lot because if it was a certain audience, I would be able to guide myself. How am I going to put it out?" Through asking questions specifically about the audience that will consume the composition, Jessica expressed she enjoyed researching and writing about an issue she was personally dealing with. Zaire also found the composition assignment easier to write than the first essay as a result of the SFL concept of register. Upon reflecting about field, tenor, and mode, Zaire reported:

When you know the aspects of what you need to write, it's going to make it easier for you rather than just writing down whatever. The more you know what you need to write about, who is the audience, all that stuff, it makes it kind of easier because there are some things that hint you to do or to write what you want to write.

Zaire felt lost writing the first essay assignment; however, the introduction of the SFL level of register provided hints he viewed as "directions" to what he wanted to write about and what the body paragraphs were going to be about. The SFL concept of tenor provided Niguel with a "baseline of who is being addressed" and from knowing that information, he worked out the rest of the development for his composition. Niguel felt addressing a larger, specific audience than just the teacher made this assignment easier to develop than the first essay that was assigned. Throughout developing his assignment, he reported "thinking about other people like me and how they are affected. And how it affected them and why it affected them. And I brought it back to myself and I thought the same way about myself. And I was like okay, that helped out." The audience awareness that comes from tenor made the writing easier for Niguel because when he is 
writing for a teacher he reported feeling pressure from the teacher's high expectations. The SFL concepts field, tenor, and mode removed this pressure and guided him through the writing stages.

The guidance through the writing stages afforded by the register level of SFL was also apparent in the other adult reentry students' work. One adult reentry student, who was a mother of school-age children, reflected in her academic essay that the infographic she created was intended to visually inform other parents about the effects of sleep deprivation in children. The concept of field kept the text focused, the tenor enabled her to limit the information presented to specifically what parents of school-age children need to know, and the mode enabled her to creatively put together bright graphics and visuals to communicate the necessary information. Another adult reentry student really wanted to develop her assignment about the benefits of growing your own food. This was too large of a topic to be addressed in one assignment, so the register level concepts helped her narrow down the issue to a manageable topic within gardening and guided her development throughout the writing process. The student created a fictitious organization, "Lunch From Our Garden," and created a brochure that informed parents in Orange County about the benefits of having a vegetable garden. The student reflected in her academic essay:

To ensure the information will go out to the correct targeted audience, the brochures will be distributed at the pediatrician's office, planned parenthood, churches, PTA meetings, elementary schools, after school programs, and other environments where parents and parents-to-be are most likely to be present.

The register level of SFL enabled her to hone her ideas and create a specific text from her original desire to write about the general topic of gardening. The structure provided by field, 
tenor, and mode of the register level of SFL supported students in creating text that was focused and well developed with insight from personal experiences.

\section{Challenge}

For students who are comfortable with writing, college composition can be boring as they feel they have already learned how to write. Many students have been conditioned to write a standard academic essay and feel comfortable with the formulaic style of academic essays. These students often checkout in class and move through the motions of class by completing assignments. This set view of writing may limit the student's potential to write for a variety of situations in different disciplines and work environments. Students are not challenged to look at composing in different ways outside of conventional writing for an academic audience. The introduction to SFL through the register level can expand a proficient student writer's skill set by challenging them to expand their composing process beyond academic writing.

Students reported throughout the interviews that learning SFL was a challenge to create and compose in a different way. This enabled them to stretch beyond usual writing strategies by developing a mode to move a specific audience. Michelle reflected she enjoyed the challenge of designing and of creating. She reported in the past she "never really took notes, I only took notes if I had to." Now that she is back in college, she wants to actually learn the material and SFL provided something new and different she has never experienced before. She took the concepts of field, tenor, and mode to design a poster that informed Orange County residents about the need for more homeless shelters. Carrie also reported she enjoyed writing when she was in school and felt she was a good writer. She enjoyed how the register level encouraged her to experiment with her writing: "I pushed myself, yeah . . . I was comfortable in writing . . but once you gave that opportunity to expand and add onto your project with the visionary, like 
videos, it was kind of freeing." She used this opportunity to learn how to create a video for her textual representation, which is something she had never tried before but she was challenged by the concept of mode in meeting the needs of the audience. For students who feel confident in their writing skills, learning the concepts of SFL can challenge them to look at writing in terms of designing text beyond a standard academic essay.

There were also students who completed projects that rose to the challenge of creating something unique with the register concepts of SFL. One first-year student wrote and spoke in class quite passionately about the gentrification happening in his community. He stated in class he no longer sees familiar faces in his community and the family run businesses have been replaced by mainstream chains. Instead of writing an academic informative essay explaining gentrification, he created a rich and deep poem that conveyed the loss he felt seeing the changes take place all around him:

I was born in this country.

Brief.

The fit' and the scape'

The wash and the whirl, corruption in sight, ain't no one insight.

The student explained in his academic essay that "the moving tone of the poem is very emotional but concentrated on concrete facts, which is appropriate in tone for a community, more specifically the Latino community." The emotion he felt about seeing his community change was communicated effectively through his poem. That same emotion may not have come through in an academic essay. The concepts of field enabled him to home in on the specific issue happening is his community that was creating the change in the demographic. The concept of tone enabled 
him to address his poem to people in his community to inform them of the corrupt motives behind the changes. The mode enabled him to make an emotional appeal to the audience; as he stated in his academic essay:

the poetic form of my project is made to appeal to the senses of each individual of this community, so that they too may see the truth. Only then will we be able to address this issue, not by force but by letting our voices be heard.

Another student took the concepts of SFL and created a moving text about the city where he grew up: Ho Chi Minh City. The field for the assignment was the pollution in the city, the tenor was the people living in the city, and the mode was an anecdotal autobiography. The anecdotal autobiography, titled, "Smog-Stained Memories: Autobiography," developed a collection of memories about growing up in Vietnam while surrounded by pollution. He wrote about the acid rain and littering he experienced as a child:

The rain is what I remember the most. It tasted sour, acidic, lingered on my tongue with a bitter after taste. The air was stale, humid and full of gasoline smell. I, 12 years old and comparable in size to a guinea pig, sat in the back of a motorcycle my mother was driving, holding on for dear life while she weaves through the traffic to get me to the next tutor spot. I asked my father why the rain tasted sour, and the answer he gave stuck with me. He told me it was tears from the Heavens, as humans do not know how to take care of their environment, and whoever is the Higher Power is crying for our foolishness.

In his academic essay, he explained:

The problem comes from the public's general willful ignorance on the effects of pollution and undermining their part in such matter; that is, no one is willing to help prevent pollution, because they think everyone else but them is enough to prevent pollution. 
For him, the concept of tenor enabled him to identify the people in power that can create change, which are the people in the city who are not aware of the effects of pollution. The concepts worked together to inform his audience about the issue in a personal manner: "To reduce and prevent pollution, awareness is of utmost importance, as informed individuals tend to make individual decisions that benefit the community." The register level concepts provided the student with the opportunity to elevate his writing.

Student interviews and the work submitted for the assignment showed addressing the aspects of field, tenor, and mode in the register level of SFL enabled students to move from general idea for the assignment to a focused and organized final product. By answering the questions of field, tenor, and mode the developed texts exhibited depth in development based on personal experiences and audience awareness. The register level supported students who were unsure and hesitant about writing for a college class by providing guidance and structure through the development of the text. At the same time, the register level provided a new way of looking at composing text from a sociocultural perspective that challenged students to look at the power structure the text is being produced within. For both the unsure and confident student writer, the register level of SFL encouraged students to create texts beyond the formulaic academic essay.

\section{Limitations of the Register Level of SFL in the Composition Classroom}

The limitations of SFL revealed in the interviews and students' work include the challenge of learning new vocabulary and overestimating the time needed to complete projects.

\section{Vocabulary}

Students did communicate in the interviews that the vocabulary of SFL in the beginning was confusing, as all of the concepts were new to them. Learning how to apply the concepts took time and practice. For example, Carrie felt she grasped the SFL concepts within the register, but 
she did not fully develop the concepts of field, tenor, and mode in order. She recalled speeding through the ideas and research she found without any organization. Once receiving feedback through peer review, she went back and used the concepts as a guide. Although she understood the concepts, the new ideas were challenging to apply so she rushed through them and relied on her previous writing experience. Jessica also found the new SFL terms to be challenging to remember and apply to her assignment. At first, she reported feeling overwhelmed with the terminology. She used the handouts from class and Googled the terms to become comfortable with the definitions. Once the terms became more familiar, she was able to apply the concepts to her assignments.

\section{Time Constraints}

Another limitation was the time involved to develop the concepts of field, tenor, and mode into a textual representation and academic essay. Students had grand visions for their projects, but underestimated the time needed to produce what they had envisioned. It is easier for students to rely on previous writing experience and stay in the comfort zone of writing a traditional essay. One student identified as a gamer, who particularly enjoyed gory video games, and she intended to design a video game case for a gory video game to inform an audience of gamers of the benefits of gory games. Instead, due to computer issues and work conflicts, what was turned in was a poster that listed why the student liked gory games with a few images from games pasted on the poster board. Another student planned on developing an infographic on the dangers of drowsy driving, but what was turned in was a short, traditional essay about drowsy

driving. The student reverted back to the comfortable mode of essay writing when the pressure of the deadline loomed. A further example is an international student from China who wanted to create a protest poster against the Lychee and Dog Meat Festival. The ideas for the poster 
discussed in class were interesting and insightful; however, due to time and hesitation in developing the mode, what was turned in was an informative poster encouraging the audience to adopt homeless dogs from shelters. The poster featured hand-drawn pictures of dogs with the benefits of adopting a homeless dog written next to the picture. It can be daunting for students to embrace new ideas and concepts that are different from what they have been taught in their previous schooling.

\section{Semantic Level of SFL}

The semantic level of SFL reflects the text as a unit of meaning within a culture. There are three areas that make up the semantic level: ideational, interpersonal, and textual. The ideational area is what the text is specifically about. The interpersonal area takes into account the attitude and values of both the creator and the audience in creation and consumption of the text. The final area, textual, addresses how the text is structured to send the intended message to the audience. For this composition assignment, students were instructed to select an issue that affects the state of California and develop either a multimodal project and essay or a traditional academic essay to argue one side of the issue to a specific audience.

\section{Affordances of the Semantic Level in the Composition Classroom}

Students became more comfortable with the terminology of SFL as the concepts of register were reinforced and the concepts of the semantic level were added during the development of the California issue assignment. Students' work for this assignment and the interviews revealed the semantic level helped students with the research process, developed the emotional appeal of the argument, and supported the construction of the argument. 


\section{Guidance Gathering Research During Early Stage of Text Development}

The research stage of the writing process for students often involves a simple Google search using the topic of the essay and then reading the first few resources that come up in the search. Students also tend to wait to search for articles until they are in the drafting stage, so research is not a part of the development of the text. Research then becomes a way to support a topic sentence of a paragraph. Research often appears to be dropped into the middle of the paragraph — mostly because it is a requirement of the writing prompt to incorporate outside sources.

Several students during the interview described how this second level of SFL provided guidance during the research stage of the writing process. The textual representations and academic essays submitted for the argument assignment displayed a deeper development of the issue. The ideational and interpersonal aspects of the semantic level particularly supported students through the early stages of the research process. Instead of researching the issue in general, the ideational component requires students to use research to gain understanding of all facets of the issue to select what the text will specifically address. The ideational aspect works in conjunction with the interpersonal component as researching all sides of the issue reveals the values of each side. An effective argument is based on how well the ideational intersects the interpersonal. The uncovering of the ideational and interpersonal during the early stages of the research process provides direction for students who have not been taught or do not remember how to conduct research to form an effective argument.

Students in a community college classroom are often adult reentry or international students, so research strategies may have changed or be different from when the student was in high school. Zaire described how he did not remember being taught how to do research in 
school. He stated back home "they don't care about copying and pasting stuff so that's what I was doing at the beginning." The semantic level of SFL taught him what he should look for while researching a topic by encouraging students to understand all sides of the issue, so the ideational level is developed based on the interpersonal level. Therefore, an issue is selected through researching what the audience knows about the issue and what they believe to be true about the issue. For Zaire, he stated once he understood all aspects of the topic "it kind of becomes more clear to you of how to write it down and stuff." The concepts of ideational and interpersonal taught Zaire how to do focused research to gain understanding of an issue, instead of regurgitating what someone else wrote.

Another adult reentry student, who had not been in school for two decades, expressed interest in arguing an environmental issue in California. There are many issues specific to California, so finding a specific issue to argue was difficult for the student. The student thought about selecting a topic about ocean pollution or plastic waste. However, through researching what California residents against environmental regulations believe, the student decided the best route was to argue for California residents in the market for a new car to buy an energy efficient, green vehicle. Air quality will be greatly improved if more California residents drive energyefficient vehicles. Through using the levels of SFL to guide the research process, the student narrowed down environmental issues to the SFL field of air quality to the ideational level of arguing California residents should purchase a green vehicle. This is a specific argument that can be further developed through the interpersonal level by discovering opponents of environmental issues desire incentives to motivate behavior; therefore, the emphasis in the argument was on the monetary savings at the gas pump and the ability to drive in the carpool lane. Further, the information gained through researching by using the SFL levels enabled the student to select an 
infographic for the textual level to highlight the benefits of the purchase through images and brief text. The student explained in the thesis statement for the academic essay that "the proposal is to influence [the audience] to buy an electrical car using an informative infographic with relevant data to impact this audience." By researching through the levels of SFL, the student moved from a desire to select an environmental issue to a very specific final product designed to move a target audience.

In addition to helping students learn how to work through the research process, students also reported the semantic level of SFL focused the research process by narrowing down research terms to specific concepts, instead of researching the general issue. Students will often use Google to research by typing in the general topic and then only look at the first five Google hits. An example of how the semantic level of SFL focuses the research and saves time is seen in Michelle's argument research. Michelle decided to argue against the death penalty in California, which is a huge issue to take on. However, she described how the semantic level of SFL enabled her to focus her research early on, which saved her time. By thinking about her audience, people in Orange County who support the death penalty, she used deathpenalty.org to find a case that was closest to Orange County as she felt it would be more compelling for her audience to learn about a case close to home. While discussing her intention to find a compelling case close to Orange County, she stated, “Because if I did, I don't know, a random city in Nor Cal that people never heard of, I don't think it would've hit them as much.” The interpersonal aspect of SFL showed Michelle she needed to focus the large issue of death penalty on something the audience can relate to. The need to limit the issue and what to limit the issue to focus on is addressed through ideational and interpersonal components of SFL. Michelle moved away from conducting a simple Google search and instead sought out different sources that would provide the 
information she needed to develop an argument for a specific audience, which led to the development of a compelling argument against the death penalty.

Niguel also selected the death penalty in California as his issue for the second assignment. He became overwhelmed with the enormity of the issue early on. He asserted thinking about the values of his audience, those in California who support the death penalty, enabled him to narrow down his argument to the fiscal implications of the death penalty. This helped focus his research, and he filtered out information that did not support his specific focus. He included statistics about how expensive it is for the state to house an inmate on death row compared to the regular prison population and how most prisoners on death row die from natural causes. The ideational aspect of the semantic level gave him guidance he needed to limit his issue to something specific and the interpersonal aspect provided insight into how to select a focus. As evidenced in Niguel's argument, the ideational aspect based on the interpersonal creates an argument with deeper insight than a student trying to develop multiple superficial reasons to support a position.

\section{Audience Awareness in Building an Argument}

It is tempting for students to select a really broad topic for a writing prompt out of fear of being able to meet the minimum page requirement. This fear can lead to writer's block, so, to avoid staring at a blank computer monitor, students select a broad topic with which they are comfortable. The text the student produces ends up being too broad and does not provide insight into the topic for the audience. The broad topic the student selects is usually one that has been widely debated already, so the student produces a text that recites the general talking points about the issue. The audience is already familiar with common talking points in support of the argument, so moving the audience to the student's side of issue or creating an engaging topic so 
the audience wants to read the text does not happen. The crafting of the text to meet the needs and expectations of the audience, while considering what the audience already knows about the topic, is usually not taken into consideration.

The semantic level of SFL addresses this issue in writing because the text as part of the culture is taken into consideration. How the culture feels about the topic and what the culture knows about the issue is taken into account through the ideational aspect of the semantic level of SFL. In terms of argument, this level requires the student to understand what the commonly held pros and cons of an argument are. Through the semantic level, the student answers what the argument is about within the culture. Once the student is aware of what is already known about the issue, the student can select a specific field that will provide new information, reasons, and/or insight into the issue for the audience, through the interpersonal component of the semantic level. The student can then develop an argument that takes the audience's values and their own values into account when constructing the text. The textual aspect of the semantic level challenges the student to select and craft the mode to meet the values of the audience. The textual aspect invites students to consider how the text should be ordered and constructed to be familiar to the audience, while challenging the audience's beliefs. The writer also gains insight into their own beliefs, which enables the writer the find the common ground within the argument.

For many students I interviewed, the semantic level built upon the register level and helped them effectively structure their argument. Hao developed an academic argument essay for the second assignment. She described how the concept of field from the register level focused her argument. Then the narrow focus from the field and the emphasis on the values of the audience in the semantic level enabled her to develop and structure her argument "to argue what I believe in." For Carrie, who described understanding the concept of register but not initially 
applying to her writing in last assignment, the interaction of the semantic level helped her put the pieces together and gain understanding into the application of SFL to her writing. She explained her experience with the semantic level as making the development of her argument easy:

Once you understand like what the community values, then you can see if you agree or disagree and then you find your common points. And once I was able to find those common points, it was easy to get that audience interested and develop that theory or that idea to present to them.

As Carrie saw the concepts build and work together, she found value in them as they simplified the actual composing process. The semantic level of SFL helped students develop a structured argument by providing the opportunity for the student to understand their values and how their values intersect and interact with the intended audience.

The importance of a writer knowing where they stand on an issue to construct an effective argument is evident in one student's selection of the controversial issue of animal testing for the assignment. The student was against animal testing and she knew persuading those in favor of animal testing to reject animal testing would be difficult. The student discovered during the research process that a law banning animal testing in California did not go far enough to protect animals. Instead of trying to argue against animal testing to a likely disaffected audience that supports animal testing, she selected the governor as her audience by writing a letter. The semantic level of SFL helped her to build a specific argument that honored her values. The ideational aspect was the specific law banning animal testing in California. The interpersonal component was the governor, as he is in a position of power to change the law. The textual feature of the semantic level is the letter because this is the best way to reach the governor. The student explained her choices in developing her textual representation: 
Who has the most power to make changes to a Senate Bill in California as of April 2019? Our current Governor Gavin Newsom does. Because he has the authority to alter and or sign the Senate Bills, I've chosen to write a letter to him regarding Senate Bill No. 1249: Animal Testing Cosmetics. Many may believe that this bill stops animal testing for cosmetics from reading the title of the bill. Therefore, most of Californians and their values were thrilled when this bill was signed off by Jerry Brown when he was still in office as of September 2018. However, according to my research, this bill is flawed. There are mainly two loopholes within this bill that does not stop corporations to utilize and fund animal testing for cosmetics completely. Foreign regulations and the U.S. Food and Drug administration regulations are what allows corporations to continue resorting to animal testing for cosmetics. This is why I decided the best course of action was to write a letter addressed to a person of power, Governor Gavin Newsom, informing him on the issues and requesting for changes of the bill and or rebuking the bill.

The student built the argument on two specific loopholes, which is more effective than trying to argue against animal testing in general. The student also explained how she purposely stated the foreign regulations before the FDA regulations because "California is a part of the United States. Therefore, it seems like a possible and less further of a reach to fix the issue." This shows she made a conscious decision in structuring her argument to meet the audience. The levels of SFL enable to the student to construct a tangible, thoughtful argument that appeals to a specific audience, while honoring her values and what she believes in. The student did not write an essay from the first sentence to the last; instead, she demonstrated thoughtful planning in developing the argument. 
Another benefit of benefit of SFL in building an argument is seen through thoughtfully developed paragraphs. Niguel explained the semantic level of SFL helped him develop his body paragraphs, instead of just free writing and trying to find body paragraphs within a free write. Niguel used the focus of how expensive the death penalty is for California taxpayers to structure his argument. Each body paragraph was based upon an economic fact related to the death penalty in California specifically. Niguel described he put more thought into which economic facts he would develop, as compared to how he recalled writing before which was to start writing from the first sentence of the essay to the last as a free write. Before he started composing his text the economic, he knew facts that would ground his paragraphs and then he organized those body paragraphs based on what he felt would most shock the audience. For example, he developed how expensive housing a death row inmate is in the beginning of his composition and then he built up to the economic reality that most death row inmates die of natural causes. He hoped the audience would be moved through knowing taxes are used to maintain an inmate on death row for decades. He expressed he "100\%" believes taking into consideration the values and attitudes of his audience helped him develop his writing because he thought about his values and perspectives toward the death penalty and then that helped him think about his audience's perspectives and values, which aided him in structuring his argument: "I thought to myself, okay, this is my opinion. And then I thought of another side, what's their opinion. So, I was able to do that to structure or create my essay and poster." Niguel felt he was more thoughtful in developing his composition as a result of the register and semantic levels of SFL.

\section{Development of Emotional Appeal in Argument}

Another ramification that occurs when students select a broad topic is the development of the text is also broad and does not provide the necessary emotional appeal to move the audience 
to side with the student. The examples and evidence selected to support the topic are too vague to be convincing because the topic is too big. The examples often do not show the audience the scope of the issue and the evidence often does not prove the significance of the issue because the examples and evidence do not take the values of the audience into account, so the audience does not have an emotional connection to the text.

The lack of convincing and moving support in the development of a text is remedied by the interpersonal aspect of the semantic level of SFL. The interpersonal aspect examines the values of the audience and how to appeal to those values through text. The concept of persuading an audience through emotional appeal is built into the semantic level through pointedly addressing what the audience holds dear. The interpersonal component of the semantic level also enables the student to take into account their own values and beliefs in the development of the text, which provides for common ground to be established. The interpersonal component of the semantics level provides the writer with an explicit opportunity to contemplate how an argument can be tailored to garner emotional appeal based on the values of the audience and the writer's values. This is an important step in developing an argument so valuable time and text space is not taken up by reasoning that will not appeal to the intended audience.

Part of developing an argument that appeals to the values of the intended audience is being purposeful in selecting supporting evidence that will move the audience by making them feel part of the issue. The semantic level of SFL accomplishes this by creating a step that invites the writer to develop an argument angle and arrange the argument to appeal to the values of the audience. For example, Michelle cited the textual concept of the semantic level as influencing her decision to choose a social media post for her mode. She developed a social media post through Instagram stories that involved a series of questions developed as polls pertaining to the 
death penalty case she researched. She described she selected this textual representation because she wanted "to make them feel something," and she received immediate feedback regarding how the audience felt based on how the audience answered her poll questions. She described her intention in creating the polls was to make her audience feel part of the case, to situate themselves within the actual case to become aware of the complexities of the death penalty. In developing the poll, Michelle stated "it was like I was a part of the audience too, so it made it a little easier because I can relate." The semantic level enabled her to narrow the focus of her argument and develop the textual component of the composition based on not only the values of the audience, but her values too.

Michelle further described taking a lot of time ordering her Instagram poll to address the semantic level of SFL. She described developing the progression of the slides based on a buildup of the emotion of the death penalty case she chose to highlight was difficult and time consuming. Her followers were interacting with the polls as she posted them on her Instagram story, so she would adjust the polls or add to the development of a slide if the audience did not vote on a poll. She was able to gain immediate feedback as to how the audience was responding to her argument based on how they voted in the polls. She took this information and continued to develop and restructure her argument based on the audience response. Once she felt there was similar engagement in all of the polls she posted, she felt she had accomplished an effective argument. The concepts of SFL built upon each other to strengthen and deepen the argument by focusing the issue to be reflective of the intended audience.

Zaire also expressed in his interview that the semantic level helped him tailor his writing to address the values of his audience: 
So, I believe it helps in a way that, when you know what the people you are going to show them what you have written, when you know what they think about, what their attitudes are about, it kind of makes it more clear for you to write something down because you have to do a little bit of research about them and then write according to what they believe.

Zaire went on to describe at first he did not "know about when you write something down you have to know about the interpersonal level, like the attitudes of the people and all that stuff, and knowing that, I mean it would be easier for you to develop something to write about."

Niguel used the semantic level to persuade the audience through emotional appeal by choosing to emphasize the financial constraints of the death penalty. The statistics and examples he used to develop his argument all related to how costly the death penalty is to taxpayers. He chose this focus because he thought it was what "the audience wanted to see, actually how it personally affects them in some sort of way, even if they don't notice it." He went on to explain, "it affects me because it comes out of my taxes, and it affects you because it comes out of your taxes." Niguel understood he could more effectively persuade his audience by appealing to what they value - money and taxes. A deeper argument that addresses the values the audience holds dear emerges when writers incorporate the semantic level into their writing. This has the potential to create an argument the audience may care and be willing to engage in the argument.

The textual aspect of the semantic level of SFL enabled students to choose how the text would convey emotion to move the intended audience. A traditional, academic essay does not always allow for emotion to come through the text. There are limits as to how much emotion examples and evidence can convey within the confines of a paragraph. The textual aspect provides the student with the opportunity to move beyond the paragraph to produce an argument 
through the text that will appeal to the audience. An example of the potential the textual aspect has to persuade an audience through the mode is demonstrated in a student's decision to develop a poem to move his audience to support the legalization of medicinal mushrooms to treat depression, anxiety, and posttraumatic stress disorder: "The many psyclobin producing mushrooms populate the state we live within and they inhabit our parks and our backyards. Mushrooms aren't a threat to our values, yet why are they so deserving to be classified with drugs that are far more dangerous and addictive when they cause so little harm to those who enjoy them." The student believed younger voters in California he was targeting for his argument would be moved by a poem over an academic essay. The rhythm of the poem has the potential to stay with the audience after the poem has been read:

Many Addictive.

One Explorative.

Are they truly identical.

Yet its truly practical.

If these mushrooms are seen so often.

Then what do they have in common

A law from decades past

Marijuana was first and won't be the last.

The proposition not cast.

This won't be the last.

The student chose to have the audience receive the argument through a poem, which can be viewed as a more intimate and personal way to make an argument for an emotional issue, such as mental health.

Another student chose to make his argument through writing a rap song after being moved by the murder of Los Angeles community activist and rapper Nipsey Hussle. The intended audience was the youth of Los Angeles, so a traditional essay would not work to move the audience to take up Hussle's call for peace: 
We suffered a tremendous loss last month, former rapper Nipsey Hussle was gunned down in front of his store on March 31st, 2019. This situation has spread fresh soil to allow for peace amongst rival gangs throughout California. However, before the death of Mr. Hussle, there have been continuous violent gang crimes being committed throughout California. Things can't remain positive if we don't continue to water the soil that Nipsey Hussle's death created in California. With that, I chose to write a HipHop song targeted at the youth; real change has to be with our children because they are the future.

To move the intended audience, the student created a rap with an upbeat tempo to make the audience want to not only listen, but listen repetitively. The student also chose to purposely repeat lyrics in the rap to make a lasting impact on the audience. For example, the rap repeats, "The marathon continues since 1992 / We need to make change / we need to stop the violence with gangs," which includes a direct reference to The Marathon Clothing ore Hussle owned in Los Angeles. The reference to the clothing store gives credibility to the student writer as being knowledgeable about Hussle beyond his music career. The student chose to develop his argument in the form of a rap because he remembered the primary reason he did not join a gang was the considerable influence hip-hop had in his life, especially artists like "Nipsey and Dom Kennedy who talked about the negatives of gangs and promoting positivity." The student was able to develop a text that incorporated the values of the audience by taking into account his values at the audience's age, which created an effective argument that moves beyond the structure of a traditional academic essay.

Once the text is constructed based on the values of the audience, the text can be further developed with examples and evidence that incorporate audience awareness; the semantic level 
of SFL makes this process explicit through the development of the ideational, interpersonal, and textual components. The semantic level affords students with the opportunity to select examples for emotional appeal that match the values of the audience. The three components of the semantic level illustrate how a convincing argument is built through appealing to the values of the audience. From the research to the design stage of the writing process, the semantic level directs students to understand the intended audience so an appropriate field, tenor, and mode is selected and developed. This supports students in learning how to build a convincing argument with audience awareness.

In addition to audience awareness, the semantic level of SFL provides students with the opportunity to understand where they stand on an issue based on their values. The research stage of the writing process becomes purposeful in gaining insight into how the student's values support the stance on the selected issue. The semantic level provides an awareness of the common ground between writer and audience, which can be used in the development stage of the writing process as the argument can be built from a shared starting point. This affords students the space to develop writing based on their ideals and values, as opposed to reciting the broad arguments recited in society. Students can move beyond developing an argument based upon the general pros and cons of the issue to one that demonstrates a deeper understanding of the nuances of the argument based on the culture the issue is located within and the value system of both the audience and writer

\section{Limitations of the Semantic Level in the Composition Classroom}

There were not any demonstrated limitations that emerged in the development of students' assignments. Students who were interviewed also did not reveal any limitations to the use of the SFL during the creation of the assignment. The students interviewed expressed 
increased comfort using the terms of SFL. Although SFL helped with developing, structuring, and supporting the argument, when reviewing the final assignments submitted for a grade, the incorporation of outside sources into the textual representation was tricky for students. Students had difficulty finding ways to incorporate quotes and evidence from outside sources into shorter modes, like poetry and letters, and visual rhetoric. Students demonstrated difficulty in finding creative ways to build credibility in their argument through citing outside sources. The ability to cite outside sources in a rap, poem, political cartoon, or infographic can be more challenging than the linear, formulaic approach to incorporating outside sources into an academic paragraph. However, the ability to incorporate outside sources into a variety of texts will benefit students in other areas of study and in life outside of academia. As a teacher, I need to show more examples of outside sources being incorporated into a variety of modes and provide opportunities for students to experiment with incorporating sources into different modes.

\section{Lexicogrammar Level of SFL}

The lexicogrammar level was the final level taught to students. This level turns the meaning of a text into a working text through the areas of transitivity, mood, and theme. The area of transitivity addresses the process type and participant roles. The area of mood considers the interpersonal relationships between the interactants. Finally, the theme is the continuity of the clause. For this final composition assignment, students were instructed to select an issue that affects the United States and develop a multimodal project and essay or a traditional academic essay that informs the audience about the causes and effects of the issue.

\section{Affordances of the Lexicogrammar Level in the Composition Classroom}

The lexicogrammar level of SFL further builds upon the previous levels of SFL by addressing the finer details of writing students often overlook or do not take the time to develop. 
Students' final assignments and interviews showed the lexicogrammar level helped students incorporate appropriate word choices based on audience awareness and develop cohesion in their text. Together the three components of the lexicogrammar level provided students with a framework for revising their writing.

\section{Word Choice}

Once a student has drafted the text, the revision stage often involves a quick glance through the document to check for any misspelled words the word processing program catches. Students who read their writing through more closely will try to elevate their writing by using the thesaurus to find words that sound more academic; however, these elevated words may not be the correct word for the context. The lexicogrammar level provides students with a framework to help students understand what words to change and why. The aspect of transitivity instructs students to select words that reflect and support the genre, field, and mode of the text. The aspect of mood in the lexicogrammar level provides students with guidance to incorporate appropriate words for the tenor of text.

\section{Transitivity}

The transitivity component is reflective of the genre of the text and helps convey the purpose of the text to the audience. The genre should be clear to the audience based on the word choices incorporated into the text. For example, if the genre of a text is argumentative and the purpose of a text is to persuade an audience, then the words should reflect there are two sides to the issues through using words like proponent and opponent. For this assignment, the genre is cause and effect, so transitivity provides the opportunity for students to incorporate words reflective of cause and effect into the text. The word choices should also reflect the writer's neutrality on the issue as the purpose of the cause and effect genre is to analyze the issue and not 
persuade the audience. The transitivity component provides guidance in the revision phase of the writing process by making explicit how abstract meaning becomes tangible to the audience through word choices.

Students who were interviewed expressed the transitivity component helped them make word choices that reflected a neutral stance on the issue. For example, Niguel selected the issue of childhood obesity for his issue affecting the United States. He chose to develop a speech as his mode and he even made arrangements to present his speech to a parent group at his local elementary school. This was a tricky issue to develop because he was aware his audience parents of children - could easily become offended or defensive about the issue. He expressed he wanted to be "direct, but not too direct" and "sensitive, but not too sensitive." He was very concerned about the feelings of this audience and did not want to offend anyone: "First of all, I didn't want to offend the audience. And I didn't want to offend, or disrespect, their children." Therefore, maintaining a neutral stance on the issue focused on the causes driving obesity in America and the effects of childhood obesity helped Niguel connect with the audience, instead of alienating the audience.

Carrie expressed during the interview that the lexicogrammar level of SFL enabled her to see the value in keeping her word choices neutral. Carrie expressed, for her final issue, she had a strong opinion about the issue, but she did not want her opinion to influence her audience. She expressed she "was making sure not to put my specific opinions in the middle, so I had to make sure I was adapting to ... my audience. Carrie expressed an awareness that her word choices could reveal her opinion, which could in turn alienate her audience and affect how her audience views her writing. 


\section{Mood}

The mood component of the lexicogrammar level refers to the power dynamic between the writer and the audience. This aspect enables students to make appropriate word choices based on the relationship between the writer and audience. The mood makes explicit the need to consider the relationship the writer has with the audience, so an appropriate tone is developed through word choices. The importance of appealing to the power dynamic in choosing appropriate words the audience will recognize and connect with will build the writer's credibility. The mood also helps students visualize when choosing words and phrases they can be in the power position if they are experts in the subject, which is different than always appealing to the teacher. The student learns how to build credibility in their text by honoring the relationship with the audience by accounting for the mood in the text when revising.

Hao explained during the interview how the concept of mood influenced her writing. She developed a pamphlet about the antivaccination movement in the United States for her final mode. The mood component enabled her to consciously choose her words during the revision process to convey the importance of the issue to the audience:

For my U.S. issue, I used the word "outbreak" in my project and I thought it would help to inform people that the measles epidemic is actually really spreading fast and is really dangerous. I thought that was very ... it did help me develop a more effective project. Hao considered what word choice would illustrate the urgency of the situation to her audience, so they would care about the issue and want to read her pamphlet. In this situation, Hao was the expert, the person in a position of power, because she had the knowledge from her research process and she was sharing her knowledge with the audience through the pamphlet. 
During the interview, Niguel expressed he did not have children, so he was also aware the audience may not trust him because he is not a parent and that was "the last thing I wanted to do." When asked how he managed to accomplish not offending or alienating his audience, he explained:

I was actually ... so even though I am not a parent, I understand that, I was able to relate to them because ... I used to be overweight when I was a child. And I explained to them my situation, how it was So I was able to relate or connect my past experiences with them.

Niguel was aware his word choices were important and had to be selected carefully to keep the audience engaged and not offend anyone. The lexciogrammar level of SFL made Niguel aware of the importance of word choice in developing his speech and through his word choices he could connect with the audience.

The mood aspect of lexicogrammar made Jessica aware of repetition in her word choices. She expressed that this level helped her to think about the words she was choosing throughout her composition:

Actually, that really helped me a lot too because I felt like sometimes I was being repetitive in some of the stuff I would say. So, by understanding the lexical grammar made me look for other words that are meant almost the same, but changing, so it doesn't seem too repetitive.

The mood concept of SFL taught her to be more thoughtful about word choices to add variety to her writing. Jessica was aware the varying word choice would keep her audience engaged in the text and build her credibility as a writer. 


\section{Cohesion}

Composition is often viewed by students as a linear progression from introduction to the conclusion or from the first sentence to the last sentence of an essay. Once the minimum page requirement is met and the conclusion written, many students feel they are done with the assignment and turn it in for a grade. Even when students take the time to read through the text in an act of revision, building connections between ideas through the development of clauses and the repetition of words or images is often not taken into account. The ability to develop to cohesion in a text is often viewed as an advanced writing skill.

\section{Theme}

The theme component of the lexicogrammar level reflects cohesion in a text. This is what makes the individual parts of the composition work together as a whole. Specifically, the theme refers to the continuity of the clause. In SFL, text is the building of clauses into a composition. The theme is how the clauses are connected and relate to one another. Thoughtfully constructed theme in a text will carry the audience through the text from clauses to clause. The theme makes explicit that text is constructed through building of clauses and the theme is the material in the text that binds the clauses into one whole unit of meaning. Theme is an important concept for composing visual rhetoric, poetry, and music. In these types of shorter text, space is limited so words and concepts must have impact and be connected together to convey the intended purpose. In longer works, such as reports and academic essays, the theme is important in maintaining focus and guiding the audience through the text. The theme component of the lexicogrammar level of SFL teaches students to connect clauses to form a picture that reflects the purpose of the text. The theme specifically gets students to pay attention to developing the connections between the clauses. 
An example of student using the concept of theme to create a unified text is a woman who developed a song to analyze the causes and effects of untested rape kits. The student dedicated the song, "Collecting Dust," to sexual assault victims who never received justice as a result of untested rape kits sitting on a shelf collecting dust. The student repeated the "here i am / here I am / I said here I am / I am collecting dust," and she explained in her academic essay that "the chorus is referring to me, as a sexual assault victim, yelling for help, attention and justice. Even though 'here I am' is sung three times, I still haven't received the attention I needed. Therefore, I, the victim, the rape kit box, 'am collecting dust.'” The chorus is repeated throughout the song, showing she continues to wait for justice. Repetition is used again at the end of the song when she repeats, “They say that I'll be ok but my scars won't just fade." This is repeated three times showing the effects of untested rape kits on the victim last a lifetime. The repetition of the words and phrases in the song demonstrates the continuity of the clause in lexicogrammar. Another example of the continuity of lexicogrammar level creating cohesion in the song is evident in the student's tempo choice throughout the song:

'Collecting Dust' was set at a tempo of 63 beats per minute . . . a song set at a temple close to the human's average resting heart rate makes the audience more attentive to the song and makes them feel calmer.

This tempo throughout the song ties the lyrics together to form a cohesive whole.

Another student used the concept of theme to create cohesion in visual rhetoric to create a cartoon that illustrated the causes and effects of online tracking. The student explained in her academic essay she drew a cartoon of "a home environment with data tracking surrounding every inch of the home, from Alexa to a smart refrigerator and smart tv, all of these appliances ... have been monitoring and profiting from the unaware consumer." To illustrate the online 
tracking, she created a cartoon depicting a female sitting in front of a computer entering her online grocery order with the refrigerator in the background with a grocery shopping list. The though bubble above the female reads, "How do they know? it's like they are alive aware lol!" Then she says, "Shouldn't be anything to worry about, it's so helpful. What's the harm?" The male sitting close to the female says, "What a coincidence we just ran out of these exact foods lol!" There are drawings of other parts of the home as well. Throughout the home the Amazon Alexa speakers are prominent. At the top of the drawing in bit letters reads, "Do you know where your online data goes?" The Alexa speakers prominently drawn in each room depicted in the cartoon illustrates the theme because the repetition provides continuity between the images. The combined effect of the Alexa speakers drawn throughout the cartoon enables the audience to take in the overall cartoon as one complete text. According to the student, "The cartoon ... shows a home environment with data tracking surrounding every inch of the home, from Alexa to a smart home refrigerator and a smart tv, all these appliances ... have been monitoring and profiting from the unaware consumer." Without the Alexa speakers drawn in each room depiction, the singular message would not be communicated. The Alexa speakers contribute to the clause continuity between images and provide a whole message.

The lexicogrammar level of SFL is significant because it provides the student with purpose during the revision stage. Instead of reading the text over for misspelled or incorrect words, the student is specifically developing and including words that reveal the genre. This subtle detail provides valuable information to the audience. Beyond the thesis statement, signs of the genre are infused throughout the text, which helps the student stay focused on developing the assignment and fulfilling the purpose of the text by revising for transitivity in the text. The mood will help the student revise for word choices that reflect both appropriate tone, context, genre, 
and mode based on the relationship between the writer and audience. The mood achieves this by specifically asking students to consider the power dynamic shared with the audience. The theme aspect portrays individual elements of text as a clause. The idea that clauses can be built and combined is reflected in the theme through the concept of continuing the clause. This allows the abstract concept of cohesion to become concrete and visual. The student interviews and assignments illustrated the benefits of the lexicogrammar level of SFL in developing the finer details of word choice and cohesion in students' assignments.

\section{Limitations of the Lexicogrammar Level in the Composition Classroom}

Although students demonstrated increased comfort with the vocabulary of SFL, the finer details of composing the lexciogrammar level addresses is as challenging for students to incorporate into their writing as it was when I was teaching traditional college composition. The lexicogrammar level should account for grammar in composition, especially the theme aspect in which students can build clauses to form sentences and then paragraphs. However, the benefits to sentence construction were not notably improved in students' work and increased fluency in grammar was not mentioned in students' interviews. The lexicogrammar level was introduced to the class toward the end of the semester. Often at this point, students are overwhelmed with school and burnout has set in. This can make teaching detail-oriented grammar a challenge. More research is needed to understand if the lexicogrammar can benefit students' grammar acquisition.

\section{End-of-Semester Reflection on SFL}

On the last day of class, students filled out a questionnaire that asked 10 questions about their overall impressions of learning SFL during their college composition course. The questions ranged from "How did you feel using the SFL framework in this composition class" to "What 
can be done to improve instruction of SFL concepts?” The responses to the questions were compiled and sorted into the affordances and limitations of SFL.

\section{Overall Affordances of SFL in the College Composition Classroom}

The themes that emerged from the analysis of the responses reflected that SFL afforded students with tangible writing skills and increased confidence in writing within and outside of the college classroom.

\section{Development of New Writing Skills}

Students reported SFL afford new writing skills that were more tangible than writing skills taught in previous classes. The development of new writing skills increased students' confidence in writing. This theme in students' SFL end-of-semester reflection is notable because many students had not been in writing class for a long time. Many students reported insecurity in their writing and hesitancy in taking a college writing class. Skills gained through the SFL framework provided students with confidence in their ability to complete writing tasks. The skills students reported SFL afforded them include the ability to focus the writing, structure and organize writing, and developing writing to fit a specific audience.

\section{Focus Writing on Subject}

Students reported the SFL framework taught them how to narrow down and develop a specific writing subject. One student reported, "It narrowed down what subjects I had to focus on and understand what to write about." An adult reentry student expressed that the SFL framework helped her adjust to academic writing:

This was the first time I've ever used this type of framework and I really like it. I need structure, especially as a returning student after 10 years. It helped me have something 
like an outline to follow that I can remember for the future. In the past, my essays were a little scattered, so this helped narrow to specifics.

Another student reported the SFL framework has made them feel more prepared for English 100 because they now understand how to move from the broad topic to the specific details. The ability to focus writing will help students avoid developing a broad topic out of fear of meeting the writing requirement. The skill of developing focused writing will also help students write clearly and concisely, which helps communicate the purpose of the writing to the audience.

\section{Organize and Structure Ideas}

A common theme that emerged in students' final assessment of SFL was SFL helped them organize and structure their ideas into text. The structure of SFL supported students in organizing and structuring their ideas. At first, students reported SFL seemed complicated, but after becoming familiar with the levels of SFL, writing became easier: "At first it seems a little complex, but when you start doing it more you can see how it organizes your essays." Another student reported, "It's a better way to help me write about anything because it is organized, like step-by-by. I felt this way is easier to write an essay." A student also reported the structure of SFL helped organize their writing: "I like the structure. Essays can always go in so many directions and when that happens, the essay can be unorganized and hard to follow." One student succinctly expressed what they liked about learning using the SFL framework is "it helped me become an organized writer.” The structured SFL framework enables students to visualize how to structure their own writing into an organized composition.

\section{Audience Awareness}

Another tangible writing skill students reported learning from the SFL framework is how to write for a specific audience. SFL emphasizes audience awareness at each of the three levels. 
SFL specifically addresses how to write with respect to the relationship between the writer and audience. The audience awareness component was a theme repeated often in students' writing about SFL. One student reported the SFL framework provided "great guidance to writing, especially writer's block. I also like the emphasis on catering your writing to the audience. This makes it very applicable to all sorts of writing." Another student was repeating the English 99 class and expressed that the previous professor "had us do a lot more reading and response exercises rather than explaining to us how to target audiences." Beyond writing for an academic audience, the audience awareness component of SFL provided students with the skills to write for a variety of audiences as well. One adult reentry student stated they liked learning SFL because "it gave me the availability to write in different types of contexts and to different audiences." Another student echoed that sentiment by stating, "SFL prepares me to write outside of English courses because it reminds me to whom I'm writing and therefore having to tailor what to say and how to say things to my audience." One student lamented they were "never taught to write to my audience or register or even tenor! Having this knowledge has definitely made writing essays super easy now (even though I still don't like it)." The development of audience awareness in writing is a skill that will prepare students for a variety of writing situations inside and outside of the college composition classroom.

\section{A Different Approach to Writing Instruction}

Students reported in their assessment of SFL that they appreciated being taught a new way to develop texts. Although students who had been out of school for a while appreciated the structured approach of SFL instruction, students who were still familiar with how writing was taught in high school appreciated learning a new approach to developing texts. Students stated learning a new way to approach writing provided more options in constructing texts. One student 
reflected that in other writing classes the "guidelines were just MLA format and usually based on a book or movie." Another student reflected "the other classes were so cookie cut. I think because this was a new style of learning, I saw improvement in my essays very quickly." The SFL approach for a student was "different from other writing classes because it helps by getting your thoughts, topic, organizational and structural for your writing." Another student reflected "other classes just gave me a writing prompt then told me to run with it. With this class, I have to take the prompt and do specific steps to get it done.” To further that sentiment, a student asserted, "Other classes I felt were confusing. Overall, I just had a hard time understanding. SFL made it easier with the way it was broken down. Then going into the categories deeper." A student echoed this sentiment in their comment: "It was the layout that helped a lot. When asking other teachers of help with writing, they'd either give me the ideas/answers up front or be extremely vague with no help. The SFL layout is set up where students know the structure while having to fill out the creative spaces." Finally, the SFL approach differed from previous classes because the student "learned how to write essays without being nervous to think what to write." For this student, SFL provided guidance in choosing the idea they want to write about, choosing who to write to, and why they are writing about it. The SFL framework enabled students to find ways to break out of the 5-paragraph model often taught in high school, which will prepare students to write in a variety of situations.

\section{Writing Across Curriculum}

An overarching theme students expressed in their end-of-semester SFL reflection writing is that the SFL framework can be used for writing assignments in other college classes. Students saw the value in learning how to write to help fulfill writing assignments throughout college. For example, one adult reentry student stated she liked SFL because it will help her as she moves 
toward her goal of graduating college. Another student believed SFL taught them "how to do research about a certain topic and breaks it down," which is helpful in most college classes. A student expressed SFL provided preparation "to be a more constructive writer and also as a reader. With the SFL concepts, I can break down the hard texts and understand the writing better." Although a student reported they were not sure about their major yet, the SFL framework had already helped them successfully complete an essay for music appreciation class. The writing skills students learned through the SFL framework will support students with writing tasks throughout college. With emphasis on the values of the audience in each level of SFL, the structure of SFL can be applied to the writing conventions of any field of study.

\section{Writing Outside of Academia}

Each level of the SFL framework develops the text in regard to the values of the audience and the power dynamic between the audience and writer. This emphasis on the tenor and mode enables the concepts of SFL to be applied to writing situations outside of the college classroom. One student stated they liked learning SFL because "I can use this for everything because it is a more organized way of writing." Another student explained how she has already used the SFL framework in her work at a dental office to write her biography for her work's website, write letters to insurance companies, and develop informational handouts for families. Another student expressed the concepts of SFL helped her to understand the importance of word choice in developing her writing, which will help her in both written and oral communication: "It is important to know your audience and who you are speaking to. This just doesn't use help with writing, but in everyday communication. Word choice is key!" Further, a student wrote the structure of the SFL framework was helpful because "when using the SFL framework you can change the properties to fit your genre of writing." A film major reported SFL has prepared her 
for writing outside of the English because she has been able to apply the concept to writing scripts and reports for her work. The three levels of the SFL framework are adaptable to suite written, oral, and visual communication conventions in work and personal situations.

\section{Overall Limitations of SFL in the College Composition Classroom}

Students reported the limitations of the SFL framework include the consuming nature of learning a new writing framework and the disappointment that other teachers do not use SFL in instruction.

\section{Time Consuming}

Students cited learning a new approach to writing as a benefit; however, students also asserted learning a new method of writing was also time consuming. Students who considered themselves to be proficient or comfortable with writing viewed learning and applying the SFL framework as time consuming. One student reflected, "With the SFL framework my work can be more organized, but at the same time, I had to do more work to organize the genre, register, field, tenor, and mode." Another student felt the development of the SFL concepts was time consuming because "it needed a lot of research." One student also felt using the SFL framework involved extra steps:

It takes more time to find and organize things into each category. For example, usually when I do an essay, I only have to make research and then put all of the info from the research into the essay. But, with the semantic framework, I have to do one extra step to organize my essay in genre, register, field, tenor, and mode.

For students who have adapted to a more traditional process pedagogy approach to writing, the SFL approach to writing can seem more cumbersome with the additional steps. 


\section{Semester Limitation}

The SFL framework is new to students, so learning and applying the concepts of SFL takes time. Unfortunately, the semester is limited to 16 weeks, so teaching the concepts of SFL must be compressed into a limited timeframe. One student expressed how his perception of SFL changed over the course of the semester: "At first I disliked SFL due to it being new and complicated. As time went on I started to enjoy this format, since it made it easier for me to write." Another student echoed initially being unsure of SFL: "I was a little hesitant at first, but with more clarification as to why this class is being taught this way, I have more appreciation for it." A student acknowledged she would not say she disliked it "but it takes time to learn and adjust to new concepts." Another student expressed frustration with learning to correctly apply the SFL concepts to writing:

One thing I disliked about learning using SFL framework would be that it kinda took me awhile to understand how to format it. For example, I would put the genre is ... the register is .... and so on. I soon learned that I wasn't supposed to do that.

SFL has many new terms for students, so learning the new terms and getting time to practice applying the new concepts to a variety of writing situations is difficult within one semester. It is difficult to introduce, practice, and reinforce the SFL framework within one semester.

\section{Other Teachers Not Familiar With SFL}

A limitation of using the SFL framework to teach college composition is other teachers and tutors within the department are not familiar with SFL. Students need to learn how to apply the concepts of SFL to their compositions within the semester as faculty in future classes will not reinforce SFL. From experience, students are aware each instructor has their own way of teaching and their own requirements for assignments. One student expressed feeling prepared for 
the next class: "But each professor has their own method of teaching and all you have to do is learn from each one." Another student reflected they felt prepared for English 100 after seeing how their writing has changed over the course of the semester; however, the student stated, "The only thing I am concerned about is how differently other teachers will structure their course.” Specifically, a student shared in their end-of-semester SFL assessment that their business law professor did not want students writing according to MLA conventions and "he wanted me to adapt to his format." This reality can temper a student's enthusiasm for learning a new method for writing because they may need to adapt their writing to the next instructor's teaching method.

\section{Future Considerations}

The final question students were asked to answer on the end-of-semester reflection asked students to reflect upon what can be done to improve the instruction of SFL concepts in future classes. Some students reported an in-depth list of terms and definitions would help students grasp the concepts and provide future guidance in applying SFL to other writing situations: "I think having a list categorized and defined of each term would be helpful." Other students reported a detailed list of genres and the different characteristics of each genre would be helpful. I also introduced one SFL level at a time and some students felt it would have been beneficial to learn all the SFL levels in the beginning of the semester. For example, one student reflected it would have been helpful to gaining understanding of the concept at first because "if you are not used to it then you can get lost in the direction to write." Another student echoed a similar sentiment when they stated it would be helpful "to go over it more in the beginning." Finally, students reported in their writing that more examples showing how SFL is applied to different modes would be helpful to visualize the concepts of SFL. The addition of examples from student 
work and in-depth handouts of the SFL terms will be collected and created as the SFL curriculum is developed.

\section{Conclusion}

Overall, the analysis of students' work, students' interviews, and students' end-ofsemester SFL reflection writing revealed overlapping affordances and limitations of teaching college composition with an SFL framework. Students appreciated the structure the SFL framework provided in both the development and drafting stages of the writing process. During the development stage, addressing the each component of the three levels of SFL enabled students to narrow down their focus to a specific topic and this provided students with direction while researching the topic. Students were able to focus their research to a specific topic and gather research that would provide insight into the values of the audience. During the drafting stage, the components of the three levels of SFL provided support in organizing the information into a structured text that reflected audience awareness. SFL also supported students in selecting word choices that were reflective of the power dynamic between the audience and writer.

Students reported learning the SFL framework increased their confidence and the principles of SFL were applicable for writing situations in college, work, and personal life. Students did report a limitation of the SFL framework was the terminology because it was complicated at first and took time to learn to apply the terms to writing. Another limitation was the limited timeframe to practice using the SFL framework. Students were also aware future instructors would not provide opportunities to continue developing the SFL framework as each instructor employs their own teaching methodology, and SFL is not commonly used in composition courses. Affordances of the SFL framework for teaching college composition support continued research and development into best practices for incorporating SFL into composition curriculum. 


\section{CHAPTER 5: DISCUSSION}

Community college provides open-access to higher education to anyone over the age of

16. The open-door policy of community college that fosters accessibility to higher education also leads to classrooms full of students with a range of college readiness skills, especially writing skills. The diversity in writing skills often poses a challenge for college composition instructors. In addition to diversity in writing skills, there is diversity in students' purpose for attending community college. Some students are focused on transferring to a 4-year university while other students are pursuing a career-technical certificate. It is also not uncommon for students to enroll in community college without a clear purpose. The diversity in skills and purpose can pose a challenge for instructors who strive to challenge competent writers to further skills and at the same time teach new skills to struggling writers.

The challenge for composition instructors to meet the various writing needs of students has increased as a result of recent legislation in the state of California that moves from placement testing to self-placement in transfer-level composition classes. This has also resulted in the reduction of developmental composition class offerings as more students are enrolling in transfer-level composition. Students enrolling in transfer-level composition class can feel unprepared and uncertain as they may have taken a break after high school or they may have had a negative experience with writing in their K-12 education. Students may also be reluctant to take the transfer-level writing class as they feel they already know how to write well after high school or they do not see how writing will apply to their chosen career path. The change in the structure and placement in composition courses can pose as a challenge for both instructors and students. 
As a result of the changes in the structure of the community college composition class offerings, I researched different approaches to teaching college composition. Systemic functional linguistics (SFL) was found as an approach to teaching writing in other countries. SFL provides a sociocultural approach to writing instruction by viewing all language as functioning within a system with language purposely functioning according to the system. SFL consists of three main components - register, semantics, and lexicogrammar - that function together to create the language system. Within each main component exists three smaller components that develops the subject, audience, and text. Specifically, SFL examines the context of the situation, the context of the culture, and the relationship between the audience and creator that the text is created within. The type of text is chosen and developed based on the situation, the culture, and the power dynamic between the audience and creator. With this framework, this dissertation sought to answer the following question: What are the affordances and limitations of using a systemic functional linguistics framework to teach composition in the community college?

To answer the question, I used the SFL framework to teach two sections of a developmental composition class for one, 16-week semester at a community college. The first essay was assigned as a compare and contrast essay without any writing instruction. For the next three essays, a new level of SFL was introduced to students and used for the development of the assignment. Students had the choice of developing a traditional academic essay or a textual representation and a shorter academic essay. Students had the opportunity to select an essay or textual representation so they could select an appropriate mode for the context of the writing situation, which is reflective of the sociocultural framework of SFL. On the last day of class, students filled out a questionnaire that asked reflective questions about their experience learning SFL. Six students also agreed to individual interviews to discuss how they experienced SFL in 
the composition class. Finally, the class assignments, both the essays and textual representations, were analyzed to gain insight into how students composed with the SFL framework.

\section{Discussion of Findings}

The findings of the qualitative study to understand the affordances and limitations of SFL instruction in a community college classroom support that SFL has the potential to empower students while also providing tangible instructional benefits for teachers. The sociocultural focus of SFL supports equality in curriculum, allows for authentic student voice to emerge, shows the connection between text and social justice, and prepares students for future writing demands. SFL also supports instruction by affording struggling writers with structured writing support, challenging competent writers to expand writing skills, and preparing students to write for different disciplines in higher education. The limitation of SFL instruction in community college is other teachers are not using SFL in curriculum, so students are not able to build upon SFL writing skills. The discussion of findings is based upon my experience teaching community college composition for 9 years before conducting the research study. As a result of this experience, I compared and contrasted experiences teaching composition with the SFL framework and without.

\section{SFL Framework Empowering for Students}

New legislation in California was passed to reduce barriers and increase access to higher education for students from marginalized communities; however, there is potential for the restructuring of developmental class offerings and the move to self-placement in transfer-level composition to send the message to students that they do not belong in higher education. Writing is a foundational skill for college and students are aware of the importance of writing in college. If a student enters the transfer-level composition class unprepared, they may feel they are not 
college material. Often I have found this negative messaging students internalize comes from feeling they are not good at writing, regardless of their ability. The internalized idea that people are either good or bad writers may affect how a student perceives their ability to be successful in transfer-level composition. This negative mindset may be a result of having limited exposure to or forgotten the language of schooling (Schleppegrell, 2004). SFL can empower students by showing how the language of schooling is another social construct that can be learned and honed through practice. Allows students to learn and experiment with language, context and culture of familiarity and then transfer skills to academic contexts.

\section{Equality in Language, Experiences, and Contexts}

The sociocultural foundation of SFL empowers students by valuing their language, experiences, and contexts as equal to academia. In SFL all languages and experiences are equal because value is placed in the audience's reaction within the context of the situation and culture the text is created within. Writing in higher education is limited to the conventions and culture of academia, which is often privileged and unfamiliar to students from marginalized communities who have not had equitable exposure to the language of schooling.

SFL acknowledges people live within multiple contexts and teaches students how to maneuver between them. This empowers students by placing value in all aspects of their lives through creating the space and opportunity to bring their multiple contexts into the college classroom. All languages - including slang and dialects—are also equal to the formal, prescriptive English of academia. This empowers students by challenging the negative narrative about being a bad writer by showing how they are successfully communicating all the time using different languages based on context and culture. The SFL framework treats all types of text as equal as well; therefore, Mark Twain is as valuable in society as Kendrick Lamar. Many students 
are not able to connect to the White male, Euro-centered canonical works of English literature that is revered in the discipline. This does not mean canonical works should not be incorporated in the SFL structured classroom; instead, the SFL framework allows both canonical and contemporary works to be read and appreciated equally. This empowers students by enabling them to see themselves reflected back in the texts that are studied and used as models for the development of their own texts.

The equality in languages, experiences, and contexts SFL supports is significant to students because they can learn within the multiple contexts of their lives, in languages that are natural to them, and through a variety of experiences. The academic language, context, and experience of higher education adds to students' lives without erasing any aspect of their culture or experience. Through an SFL framework, the context and culture of academia can empower students by providing space for the language of schooling to develop along with the language of home. Most importantly, the message is sent to students that they belong in the college classroom because their lived experience is valued and respected. The SFL framework disrupts the power structure of academia that often leaves marginalized voices out by selecting texts and authority figures that do not reflect the diversity of the classroom. With SFL, a student's voice matters and is integral to the curriculum, which can empower the student to feel seen in the college classroom.

\section{Development of Authentic Writing}

An SFL framework can also empower students by allowing for authentic voice to be used in assignments. The writing produced in a college composition class is often artificial because it is written in a traditional essay format and submitted for a grade to a teacher. Often students want to receive a positive grade on an assignment, so the writing is geared to meet the expectations of 
the teacher. The SFL framework encourages students to understand their values when developing writing.

Students are supported in gaining insight into their values and beliefs while developing writing that accounts for the values and beliefs of the audience. Monbec (2020) asserted the interpersonal metafiction of SFL, "which is concerned with feelings attitudes, and judgments" (p.3), prepares students to use language to construct text "related to social relations between interactants" (p. 3). SFL show students that developing text for an audience is not one-sided; instead, the development of the text is reflective of the relationship between the creator and the audience. Students must account for their values, in addition to the audience's, when developing any type of text. As compared to traditional essay writing, the component of mode provides for creativity to meet the values of the audience. The SFL framework provides structure for composing in a variety of modes based on what is most appropriate for the genre and audience. With the SFL framework, the teacher assigning the grade does not center the development of the writing. As Purser (2020) argued, SFL curriculum a teacher discusses "how and why students might use the information to talk or write in a particular way and further their own interests" (p. 3). SFL places students at the center of instruction by directing students to assess their values when developing writing and showing how language can be personally used as a resource. Most important, students are focused on developing the writing for an audience beyond the teacher, which has the potential to create more authentic writing.

\section{SFL and Social Justice}

Text can shape an individual's environment and SFL empowers students by showing how this happens in society. For many educators who have dedicated their careers to studying language and literacy, instilling in students the power of language is often a goal of instruction. 
In addition to learning how to construct a thesis statement and correctly use a semi-colon, educators often strive to show students through curriculum how the ability to wield language can empower an individual throughout life. As a writing teacher, I have experienced students in class being disconnected from the writing instruction as a result of being disaffected after negative experiences with writing in K-12 classrooms or from believing that writing will not be required in the desired career. SFLs emphasis on centering the writer as in control of using language as a resource in life that can be used to create change in one's environment or society.

Halliday developed SFL during the 1960s as a theory for social action (Moncada \& Linares, 2020). As Monbec (2020) argued, "SFL theory is consistent with its purpose to be appliable, dedicated to solving problems and empowering its users" (p. 11). The structure of SFL illustrates how language is affected by the values and beliefs of the culture the text is created within. Language is part of culture and reflective of society and the components of SFL demonstrate how the choices made in developing text are contingent upon the situation the culture surrounding the text. More specifically, SFL levels address the power dynamic between the creator of the text and the audience. The tenor, interpersonal, and mood aspects of SFL prompt students to examine and reflect upon who specifically the text is being created for and how the choices in developing the text should be reflective of the power structure. Therefore, language is not passive in, so SFL can show students how to use the components of SFL as a tool to understand and help take control over their environments.

Just as students are learning how to make language and text choices based on power, students can also apply the components of SFL to texts they encounter to understand how texts are also designed based on a power structure they live within. What messages are these texts sending to the student? Why were the choices made at each level of SFL? How did the creator of 
the text want the student to react? The power structures that exist in society are often hard for students to see; however, the components of SFL enable students to see how power structures affect them through texts. An SFL curriculum provides the framework to deconstruct texts to examine how the power structure is functioning within the text.

\section{Students Develop Skills for Writing Situations Outside of College}

An SFL framework has the ability to empower students by showing the value of text in a multitude of personal and professional contexts outside of college. Many students who enroll in composition at the community college do not plan to transfer to a university or pursue a degree. There are many certificate programs offered through community colleges; however, the certificate programs still require students to successfully complete Freshman Composition. Even for students who are pursuing a degree, the ability to write for a variety of situations outside of academia is a necessary skill. Students are working while enrolled in school and most jobs require oral and written communication skills. In addition, students are often creating texts for online audiences, such as social media, blogs, and vlogs. Students will need to understand how to adapt writing to the demands of future careers and new technology that has yet to be invented.

Teachers cannot possibly understand the writing situations of all careers or the writing required for current and future technology. However, SFL's ability to analyze the audience, situation, and culture will provide students with the skills to adjust writing to future demands. SFL encourages students to think about the best mode for each writing situation and helps students adapt writing to the situation by taking into account the values of the audience and cultural expectations of the mode. Halliday specifically designed SFL to create texts "in terms of the meanings it makes, not its size or form" (Purser, 2020, p. 2), which positions SFL as a helpful framework to develop writing based on the situation. SFL supports students in learning 
how to write for a variety of situations through presenting language as a resource that "allows people to accomplish different communicative purposes by providing them with a set of available options from which they can construe, express, and negotiate meaning in particular contexts of use" (Moncada \& Linares, 2020, p. 235). Forey (2019) found the linguistic and discursive tools taught through SFL prepared students to write and communicate in a variety of contexts that are valued beyond schooling.

The opportunity to teach students how to adapt writing for a variety of situations outside of the college classroom is important for students who do not see value in taking a college composition course because they do not plan on pursuing a college degree. Students also need to learn how to adapt writing to meet the online demands of 21 st writing. SFL enables students to learn how to adjust writing to suit a variety of modalities and contexts. This can help students see the greater value of writing and prepare students for 21 st century writing demands teachers cannot fathom.

\section{SFL Framework Provides Instructional Support for Instructors}

The SFL framework can help instructors navigate the differences in writing skills and educational goals by supporting students who need more guidance while still challenging students who are comfortable with academic writing conventions. The stratification of SFL provides tangible support for instructors through scaffolding, and instructors can use the familiar process and prescriptive pedagogy within the SFL stratification. The tangible benefits of the structure of SFL extend beyond the composition class to support writing across curriculum. Outside of the classroom, an SFL framework can support instructors and writing center tutors in offering a different approach to teaching writing to students. 


\section{Provides Struggling Writers With Structured Support}

A theme that continued to emerge in students' interviews, students' work, and end-ofsemester questionnaires is that the SFL framework provided structure throughout the writing process. An issue in the community college classroom is diversity in ability. Students enter the community college classroom right out of high school, after taking a break from school, and from other countries. The educational backgrounds of students can be vastly different in a composition class. Many adult reentry students do not remember what they learned in high school about writing. Other students who do remember what they learned may not have had a positive experience in previous writing classes. International students may not have had exposure to composition instruction. Woods et al. (2019) found " $46 \%$ to $48 \%$ of underprepared students chose to enroll in the gateway English class now that they have the option" (p. 20) instead of enrolling in a developmental class. This decision was due to students wanting to save time and money in college.

With students self-placing into English 100 and developmental writing course offerings limited, SFL framework provides students who need more structure and guidance a methodical approach to developing writing. Halliday's intent was developed a system that would enable people to view language as "a resource for making meaning realized through words (i.e., lexicogrammar choices), and grounded in a context situation and context culture to attain the speaker's or writer's communicative purposes and aims” (Moncada \& Linares, 2020, p. 237). Nagano (2020) also found an SFL framework for writing instruction in higher education reduced the gap in writing proficiency among students with varying levels of readiness skills. Through SFL, students can learn to how to use language as resource to make meaning through writing. The choices a student makes at each level regarding the topic, audience, and text will guide a 
student through developing a structured and organized text. The framework of SFL guides students though the levels of language to show "how clear points are linguistically constructed" (Purser, 2020, p. 5). By following each component of SFL, students will have the support to turn a writing prompt into a completed composition.

\section{Competent Student Writers Develop New Skills}

Students in a community college writing class may feel confident in their writing skills. Many students have gone through the $\mathrm{K}-12$ school system in the United States and have learned how to write a traditional, academic essay. The SFL framework provides competent writers with a new way to see writing as a resource to make meaning through the three levels of SFL. The SFL framework enables students to be challenged to expand their writing by developing audience awareness though incorporating the SFL concepts of tenor, interpersonal, and mood. These three components of SFL tailor writing to address the values of the audience and the power structure between audience and writer.

Purser (2020) asserted an SFL framework in instruction supports "learning in formal education is a matter of language development, which can be greatly enhanced and accelerated when subjects are designed around a conscious language development process" (p. 12). Through SFL, writing is not a static skill that is mastered, but part of a larger language system that is constantly changing and evolving due to context and culture. Therefore, students are challenged with understanding the system that writing occurs within and adapting writing to meet the demands of the system. This challenge has the potential to keep students engaged in the curriculum, instead of going into autopilot with what they have already learned through previous writing classes. Teachers can adjust instruction to focus on either the big picture of context or the finer details of lexicogrammar based on students' needs, which will help all students learn new 
skills (Purser, 2020). With the SFL framework, all students are learning something new, which levels the playing field in a classroom with the diversity in writing ability present in most composition classrooms.

\section{Students Develop Skills to Write Across College Curricula}

Currently, college composition is geared for writing in the Humanities, which emphasizes developing and structuring writing according to the conventions of the Modern Language Association. This is helpful in other humanities' courses; however, students will go on to write for a variety of disciplines. On the way to obtaining a college degree, students will have to take classes in disciplines outside of their major to fulfill general education requirements as well. The emphasis on values in SFL provides students with knowledge to adapt writing to different disciplines. Purser (2020) asserted after students have been introduced to the SFL framework students often ask why they have not been taught "how to write as is expected and valued" (p. 6). Each discipline has different values regarding writing and SFL addresses this at each level. Students are taught how to analyze what is expected in writing based on what the discipline values. Forey (2019) found "SFL afforded a shared metalanguage and a shared talk about language and meaning for both the teachers and students in order to identify and discuss the linguistic patterns and appropriate choices within the context a discipline" (p. 15). The SFL framework affords student with the knowledge that writing needs to be geared toward the values of the discipline. This knowledge will prepare students for the demands of college writing from English 100 to degree completion.

\section{SFL Provides Scaffolding for Instruction}

One benefit of SFL that I experienced while teaching the SFL curriculum was that the structure of SFL supports scaffolding of instruction. The stratification of SFL allows for each 
level to be analyzed separately, while still working in harmony together once put back tougher (Purser, 2020). SFL is developed to move from the macro to the micro aspects of a text with each level. The context of the situation and the culture is continually developed deeper through each component of SFL. The register level develops the macro components of what the text is about (field), who is the audience (tenor), and what form the text will be (mode). The next level of SFL, semantic, further develops the register level while developing the who, what, and how of the text deeper through the ideational, interpersonal, and textual components of the semantic level. The semantic level guides the creator of the text to make choices about what the text is about, who is the audience, and what form the text will take on based on the values of the audience and the creator. Each component revisits the previous component and challenges the creator to make more detailed choices about the text. The final lexicogrammar level focuses the creator on making detailed choices at the micro level through the transitivity, mood, and theme based on the interpersonal relationship between creator and audience. The first component of SFL tasks the creator with making a choice about who the text is being created for, in the next component the creator must make textual choices based on the values of the selected audience, and then then the final component has the creators select structural details that will appeal to the values of the selected audience. Through the SFL framework, there is a continuous looping to the previous component as the next component is developed.

The inherent scaffolding in the SFL framework is beneficial in instruction because students have the opportunity to strengthen and develop one concept while learning the next concept. There is the an opportunity throughout the semester for a student to review and continually practice developing a concept, which supports a student's ability to retain the concept for future use. With the SFL framework, a concept is not taught in isolation as all components 
work together. Likewise, a concept is not taught and then not used again during the semester. The entire curriculum based on an SFL framework works together as a cohesive whole, which benefits a student's ability to apply skills outside of the composition classroom.

Further, I found while teaching using the SFL framework that the inherent scaffolding inherent within the structure of SFL also addressed typical issues students experience developing texts throughout the semester. At the beginning of a semester, students often experience writer's block and have trouble coming up with ideas to fulfill the assigned writing prompt. It has been the my experience students either try to develop a topic that is too broad for the prompt out of fear of not being able to fulfill the page requirement or students are unable to come up with a topic for the assignment out of intimidation from staring at the blank computer screen. The first level of SFL, register, that is taught helps students select a topic that is specific for the genre, the context of the situation in the writing prompt, and appropriate for an academic audience thought the field, tenor, and mode aspects of register. The register level helps students get the writing started and moving in the right direction, so they are not staring at a blank computer screen and overwhelmed with a writing prompt. Composition classes and textbooks typically start out with the writing concept of selecting a topic and overcoming writer's block; SFL starts at the same place with the register level.

In a typical semester, composition curriculum builds on selecting a topic to incorporating research to support the topic and develop paragraphs that incorporate outside research. The order of SFL is in alignment with this order, but provides guidance in helping students conduct research by instructing students to develop search terms based on the specific topic chosen through field and based on the values of the audience through the semantic level. The semantic level specifically tasks students with making choices in the development of research and writing 
that meets the values and beliefs of the audience. This helps students make choices about the topics of paragraphs, the evidence and examples that will develop the topics based on what will appeal to the audience. Research and paragraph development is often an area of difficulty for students, which is addressed by developing the ideational, interpersonal, and textual aspects of SFL.

The lexicogrammar level of SFL supports students in making decisions about appropriate word choices based on the audience, the development of sentence structure to meet the expectations of the audience, and the overall cohesion of the essay through transitions. This is often taught toward the end of the semester as well because sentence level development and issues once students have been instructed in essay and paragraph development. The natural order and flow of a composition class is complemented by the scaffolding of SFL. Monbec (2020) explained how SFL "enables a systematic organization of a language curriculum that supports students' literacy development at the sentence level (lexico-grammar) and across paragraphs and whole texts (discourse semantics)” (p. 3). SFL addresses essay level issues to paragraph level issues to sentence level issues, which is helpful for students as their writing skills develop over the course of a semester.

\section{Process and Prescriptive Pedagogy Work Within SFL Framework}

Just as the scaffolding inherent in SFL complements the structure of a typical composition class, SFL supports the process and prescriptive pedagogy that is often used in composition classes. Process pedagogy breaks writing down into steps: prewriting, drafting, revising, and reflection. It has been my experience that some students find these steps too abstract to be helpful. For a student who has difficulty coming up with ideas, the free writing strategies in the prewriting stage can be difficult. The levels of SFL can provide students with 
structure and support during the prewriting stage as students have direction to make specific choices at each level. Halliday designed SFL to simply and visually "explain how any communication is made relevant and coherent in a given context by a principled limiting of possibilities in what might be said or written" (Purser, 2020, p. 3). The concept that writing is a series of choices that limits possibilities provides students with greater direction and framing for prewriting strategies, like freewriting.

Students can find the process of taking the writing developed during the prewriting stage and structuring into an essay daunting. The levels of SFL can act as a bridge between prewriting and drafting as students make choices about the structure of the text based on the context of the situation, culture, and audience at each level of SFL. Making the choices in SFL can guide students in turning prewriting into a structured essay.

The lexicogrammar level of SFL specifically supports students in the revision stage of process pedagogy by guiding students to make sentence level and word level choices based on the audience's expectations. This can provide purpose for students as they are revising with a specific goal in mind: to appeal to the intended audience. With SFL, the choices made in writing are not random or abstract because "each specific social situation limits the range of linguistic choices occurring in communications associated with it, and that the semantic and lexicogrammatic patterns in any text represent choices made to suit and define a specific context” (Purser, 2020, p. 3).

The reflection stage of process pedagogy aligns with the overall purpose of SFL, which is to develop text for a specific context, within a culture, and for an appropriate audience. Instead of loosely writing on how the student experienced writing during each stage of the writing process, SFL can add to the reflection by enabling students to reflect upon how the choices made 
at each stage in the writing process addressed the situation, culture, and audience that the text was created within. Some students can think through the writing process and put their thoughts in words, but students can struggle with the loose, abstract stages of the writing process. SFL provides teachers with an additional framework to structure and support students in making table choices throughout the writing process; in turn, SFL and process pedagogy work well together to help students get more out of each approach to writing instruction.

Prescriptive grammar instruction in composition classes is also supported by an SFL framework. Students need to learn the rules of grammar to develop appropriate writing that conveys the intended meaning to the audience. Students often learn the rules of grammar for a formal audience during the composition class. I have found in previous classes that students view rules of grammar as absolutes that exist without reason. Students sometimes try to memorize grammar rules for later use. Teachers will try to use mnemonic devices or tricks to helps students learn how to apply grammar rules to writing. However, SFL teaches language as part of a system that is mitigated by the culture the language occurs within. Therefore, grammar rules are not abstract rules to be memorized but byproducts of cultural expectations within a society. The foundational concepts of the context of situation and culture in SFL provide students with the "why" behind grammar rules. Zhang (2019) asserted SFL illustrates how sentences are combined coherently through conjunctions, lexical repetition, and thematic progression to make meaning out of words for an audience. The strong emphasis on audience awareness in SFL through the mode, textual, and theme aspects of each level of SFL can teach students that grammar rules are not absolutes, but can differ based on the audience. For example, how commas are used to affect the lexical density and flow of a sentence is based on the intended effect the writer hopes to make on the audience and the expectation the audience has for sentence development. The 
grammar choices and rules are based on the intentions of the creator and the expectation of the audience. This can provide students with guidance on what grammar rules exist, how grammar can be used, and when grammar rules can be broken. As Monbec (2020) asserted SFL "represents a significant shift from a traditional approach to language which tends to prioritize sentence level issues and grammatical accuracy rather than a principled description of the way language is used to make meanings" (p. 3).

Overall, the SFL framework supports existing process pedagogy and prescriptive grammar that is used in composition classes. The existing composition practices and methods of instruction do not need to be thrown out to make room for SFL. What students have learned in previous writing classes can be used within the SFL framework and students may find it helps to use those familiar tools while learning the SFL framework. SFL makes the steps of developing text explicit, which has the potential to benefit students who find process pedagogy too abstract. In addition, the SFL framework can be used in its entirety over the course of a semester, or one concept can be used to support an aspect of instruction. This enables a teacher to decide which elements of SFL will benefit existing curriculum.

\section{SFL Can Be Helpful in Writing Centers}

SFL can complement the instruction taking place in class through the Writing Centers. Community colleges are using writing centers to provide additional support for students who may not have the skills for transfer-level composition, but have enrolled in the class. SFL can be used to support those students by augmenting classroom instruction. Instead of students attending workshop or completing worksheets in the writing center that is being taught in the class, SFL can provide additional writing instruction that complements the classroom instruction. The structure of SFL allows for each level and each smaller components of each level to be 
taught as a separate unit that would further support what students are learning in class. SFL provides a different perspective for students that may interest students because it is different than what they have experienced in the past. Writing centers can develop workshops and worksheets for each level of SFL or the discrete units of SFL to offer additional support and instruction to students outside of class.

\section{Limitations of SFL}

An SFL framework with multimodal assignments can limit the time students spend writing traditional, academic essays. The SFL framework is not widely taught in community college classrooms. The introduction of the SFL framework does take away from teaching composition as it is traditionally taught with an emphasis on process and prescriptive pedagogies. Students will move on to other classes with instructors who have been taught and expect traditional college writing. Students were only in my class for one semester, which is not enough time to thoroughly learn and practice SFL writing techniques. Some students may need more exposure to traditional, academic writing pedagogy to be successful in other classes.

\section{Limitations of Study}

Although time and research were taken into developing the curriculum for the course and methodology for the research study, there were limitations to the study. The most significant limitation for the research study was that I used my students' work and interviews with my students as the data sources. This was a limitation because I was the teacher during the semester, and students may have felt pressure to participate or may not have been comfortable being truthful about their experiences. I accounted for these limitations by not analyzing the data until after the final grades were submitted. I also did not interview students until after grades were submitted and students were done with all of their classes for the semester. The questionnaire 
students completed was also anonymous, so students could feel comfortable sharing their experiences without their name being attached to the questionnaire. This was done to prevent students from feeling their grade was affected by participating or not participating in the interviews.

Another limitation was that the study was conducted in two different classes during the semester. The class dynamic is often different from class to class, so one class may have yielded different results than another class based on how the class interacted and responded to the curriculum throughout the semester. In addition, one class met twice per week and one class met once per week, which can affect how students retain information from week to week. Results were limited to these classes at this time and at this location as well, so further research will need to be conducted to confirm whether the results are the same in future semesters.

The dual roles I served as teacher and researcher is also a limitation of the study. This had the potential to be a limitation as I may have been unintentionally biased while analyzing the data due to my role as teacher. The issue of bias during data analysis was minimized by waiting until after grades were submitted, so I was no longer engaged in a student/teacher relationship with the students. However, I still had to be mindful of the potential for bias and not take negative feedback from students personally while coding and analyzing the data. During coding and analysis, I needed to stay impartial as well and not let my connection to the data as teacher affect my ability to analyze and report the findings. The three separate data sets—-student interviews, student work, and questionnaires - also helped keep my investment as the teacher out of the analysis.

A final limitation was that SFL was not taught in either of my undergraduate or graduate programs, so my SFL knowledge is derived from independent research and attending 
conferences. The study reflects my understanding of SFL as SFL is a multifaceted and complex system. The SFL terms and concepts selected for the research study reflect a practical application for a specific course. The curriculum that was developed for this study will continue to evolve along with my understanding of SFL.

\section{Strengths of Study}

This study does have several strengths that should be considered. A strength of the study is that it occurred over the course of a 16-week semester. The duration of the study enabled students to learn and practice applying the concepts of SFL to their work. The language of SFL was new to all of the students, so time was needed for students to become familiar with the terms in practice before they could provide feedback about their experience. Throughout the semester, students had the ability to apply the concepts of SFL to a variety of genres and modes. Students' responses to the questionnaire reflect time spent learning and applying the SFL framework, while also having previous experience in other writing classes to compare and contrast experiences. The student work that was used as data for this research study also reflect students' ability to apply the concepts of SFL to multiple assignments, instead of one assignment. Interviews with students occurred after the semester ended, so they had time to reflect upon their experience and gain perspective into how SFL affected their ability to acquire writing skills.

One limitation was students may have felt pressure to provide positive feedback or participate in the study to not have their grade affected, but a benefit of acting as both teacher and researcher was students had time to develop a rapport with me. As the semester progressed, students felt more comfortable asking questions about SFL. Another benefit that came from the dual role was students who agreed to be interviewed cared enough about the class to agree to meet with me after the semester was over and grades were submitted. The relationship forged 
over the course of the semester motivated students to come on their own and participate in the interview. In addition, interviews were comfortable and conversational because of the relationship that already existed from the time spent in class together. The relationship that developed between teacher and student benefited the interview between researcher and study participant.

A final strength of the study was my experience as a community college teacher. My classroom experience contributed to my ability to apply the SFL framework to the community college composition class. At the time the study took place, I had taught at three community colleges over 9 years. As an experienced composition teacher, I had the classroom knowledge to plan curriculum, structure class discussions, and provide feedback to students. This knowledge supported the development of the syllabus, class materials, and assignments that used the SFL framework. From years of responding to and grading student writing, I analyzed students' work for the affordances and limitations of the SFL framework in the composition class. My experience interacting with students and reading their writing also provided insight into the challenges students experience with writing. The experience I gained as a community college composition instructor strengthened both the curriculum that was developed and the research study.

\section{Implications for Practice}

SFL as a framework for instructions has several implications for practice in higher education in all disciplines. The implications for composition classes, specifically, in higher education include narrowing the gap in writing skills among students, establishing a shared language to discuss texts, and supporting 21 st century writing demands. 


\section{Bridge the Skills Divide}

This research has implications for practice in higher education by providing a framework for instruction that can help close the gap in college readiness skills while preparing students for a variety of writing situations. As Zhang (2019) argued, teachers and administrations should learn and promote SFL theory because the multiple layers have the potential to "offer students effective knowledge to demystify academic literacy and learn with confidence" (p. 17). Teachers can use the SFL framework as a way to bridge the divide between struggling and competent writers. SFL provides additional scaffolding for struggling students while enabling competent writers to expand their writing to audiences outside of academia. An SFL framework for composition instruction can also provide instructors with a shared language to discuss writing and prepare students for 21 st century writing demands.

\section{Shared Language}

The SFL framework provides a shared language for teachers and students to discuss writing. Forey (2019) found both teachers and students benefited from learning the metalanguage of SFL as it provided a gateway to focus learning on the language. Often students feel writing is subjective and they try to make their essays meet what they think a teacher is looking for. I have found this to be the case with my students. I felt they were not asking questions about the assignment to learn writing skills, but seeking out how to create an essay that would get a passing grade. SFL externalizes the discussions of writing from the class to the context and culture of the writing situation outside of the class. Conversations with students have the potential to move to discussions about genre, audience, and tone with the focus on how to move the target audience. The responding to and grading of student writing is also not as subjective because the teacher is basing the grade and providing commentary based on the expectations of 
the audience, instead of the teacher's expectations. The language of SFL provides the tools to engage in these discussions with students by making audience awareness, context of situation and culture explicit in the development of the writing. This has the potential to shift power dynamic between teacher and student to coconstructers of knowledge.

\section{1st Century Writing Demands}

The shift in focus to context of situation and culture with the SFL framework can also prepare students for 21 st century writing situations. The framework of SFL provides students with tools to adapt text to fit a multitude of genres and situations through developing the levels of SFL. With technology constantly expanding, it is hard for educators to imagine what situations we need to prepare our students to create within. Technology also makes it hard for teachers to envision what the job market will look like once students graduate. SFL enables teachers to empower students to adapt to what the future holds. SFL has the potential to shift the focus of composition class from focusing mainly on the development of academic writing to composing in a variety modes and situations. SFL provides the opportunity for students to become not only writers but composers. This is because within the SFL framework one type of text is not privileged over another type of text. All text is valued equally based on context and culture, so academic writing is not placed in a superior position. This shift has implications to free students to compose different modes and genres, in addition to traditional academic writing.

\section{Future Research}

SFL as a framework for composition classes is currently under researched. Although the body of research for SFL applications in the United States is growing, much more research needs to be done for more instructors to incorporate SFL in curriculum. This research study was an initial investigation into the affordances and limitations of SFL in composition studies. As an 
initial study, the broader implications of the SFL framework were studied. Now that incorporation of SFL has been shown to be have positive implications, while still meeting the student learning outcomes of the composition class, deeper research into SFL curriculum, SFL applications in composition instruction, and the experiences of students learning with an SFL framework needs to be developed.

\section{Develop Curriculum for Diversity in Abilities}

This study took place over the course of one semester, so more research is needed to further develop SFL curriculum to benefit the diverse writing needs of students. More student feedback is needed to further develop the lectures, instructional handouts, and assignments that teach SFL. The collection of the student work that is developed through the use of the SFL framework is also needed to use as examples for teachers and students. Most importantly, the development of SFL curriculum needs to be researched by other composition instructors to add different approaches and teaching styles to the framework. The curriculum that was developed for this study reflected my style of teaching and research interests. The application of SFL into composition classes will grow as more instructors add to the body of SFL curriculum research.

\section{Grammar Instruction}

Within developing SFL curriculum, research into how SFL can help students develop sentences using punctuation and vary their sentence patterns should also be studied. Grammar is often viewed by students as a set of arbitrary rules that need to be committed to memory and used only for formal writing situations. The purpose behind grammar can be lost in instruction. SFL has the potential to help students understand the "why" behind grammar, which may help students develop confidence to develop variety of sentence patterns using punctuation to build clauses. SFL frames sentences as "actor" for nouns and "action" for verbs. This shift in language 
may help students understand how to build sentences. The lexicogrammar level of SFL addresses sentence patterns. Due to the time constraint of the semester, I did not have time during my study to apply the lexicogrammar level of SFL to the development of sentences. In future classes, I would like to study ways to use lexicogrammar to teach sentence development. Students will benefit from other researchers studying this area as well.

\section{Student Experiences}

Beyond the practical research into curriculum development and SFL application, more research should be done into how the student experiences the SFL framework. Often research in education is focused on tangible and measurable outcomes of a product, such as improved grades and test scores. However, SFL is inherently student centered as it places the power in the student as creator developing text according to the context and culture of the situation. As SFL is student centered, research into if an SFL framework shifts a student's perception of their ability to create for a variety of situations. Does the SFL framework increase a student's confidence? For this study, the six student interviews were analyzed for affordances and limitations and were used as one of three data sets. In the future, I plan to conduct a closer analysis into how students experienced SFL and use the student interviews as the only data to focus on students' voices. Future research into SFL that I conduct will place greater emphasis into the experiences of students through interviews during the semester as they are learning SFL and at the end of the semester. I would also like to conduct longer research studies to beyond a semester to understand how students apply SFL concepts after instruction ends. Further research into SFL should place greater emphasis on students experiences versus student outcomes to understand implications of SFL beyond academia. 


\section{Interdisciplinary Research}

Interdisciplinary research into the applications of SFL in higher education settings needs to continue to provide students with multiple opportunities to practice applying the language of SFL to a variety of situations. The language of SFL can be difficult to retain without multiple opportunities to practice using it in different contexts and within the different cultures of academic disciplines. SFL research is especially needed within the discipline of English, so that SFL can be offered as a class at both the undergraduate and graduate levels. Until research into SFL increases, especially in the United States, the full benefit of SFL in the lives of students will not be known.

\section{Conclusion}

This study provided a new approach to teaching community college composition at a time that the diversity in writing abilities was increasing. The SFL framework provided a new structure to teach writing skills to students, while challenging students to learn a new language to create texts within. During the semester teaching with the SFL framework, I was engaged in strengthening my SFL knowledge, developing the curriculum, responding to student questions, and grading their work. After the semester was over, I moved to the researcher role, which required me to be impartial while analyzing the data. Now that I am done with the teaching and researching phase of the dissertation process, I have time to reflect upon what teaching composition with the SFL framework meant to me as a teacher. I found it rewarding to see students make connections between text and audience. The energy and dedication that students put into developing their multimodal projects was exciting to see. In hindsight, what was the most enjoyable aspects of the SFL framework were the discussions that occurred before, during, and after class about the texts that they were developing. I feel using the SFL framework in this 
way shifted the relationship between myself and students to coconstructers of the text, instead of feeling like I am the "sage on the stage" lecturing students. The benefit of the SFL framework for me was the ability to impart skills to students while bonding with them over the development of texts. This was a rewarding experience and I look forward to continuing to learn and teach SFL. 


\section{REFERENCES}

Academic Senate for California Community Colleges, 2017 (11, March 2021). AB 705 (Irwin), as of 05/30/17 Position: Oppose Unless Amended. Academic Senate for California Community Colleges to The Honorable Benjamin Allen, 27 June 2017 [Letter]. https://asccc.org/sites/default/files/AB\%20705\%20\%Letter.pdf

Accurso, K. (2020). Bringing a social semiotic perspective to secondary teacher education in the United States. Journal of English for Academic Purposes, 44, Article 100801. http://doi.org/10.1016/j.jeap.2019.100801

Achugar, M., \& Carpenter, B. D. (2014). Tracking movement toward academic language in multilingual classrooms. Journal of English For Academic Purposes, 14, 60-71. https://doi.org/10.1016/j.jeap.2013.12.002

Aguirre-Muñoz, Z., Park, J., Amabisca, A., \& Boscardin, C. K. (2007). Developing teacher capacity for serving ELLs' writing instructional needs: A case for systemic functional linguistics. Bilingual Research Journal, 31(1/2), 295-322.

https://doi.org/10.1080/15235880802640755

Ayers, D. F. (2005). Neoliberal ideology in community college mission statements: A critical discourse analysis. The Review of Higher Education, 28(4), 527-549. https://doi.org10.1353/rhe.2005.0033

Bailey, C. A. (2007). A guide to qualitative field research (2nd ed.). Pine Forge Press.

Barrett, T. A. (2013). The river is me and I am the river: Principles for the organic Maori researcher. In M. Berryman, S. SooHoo, \& A. Nevin (Eds.), Culturally responsive methodologies (pp. 221-244). Emerald. 
Beach, J. M. (2010). Gateway to opportunity? A history of the community college in the United States. Stylus Publishing.

Berryman, M. (2013). Kaupapa Maori: The research experiences of a Research-Whanau-ofInterest. In M. Berryman, S. SooHoo, \& A. Nevin (Eds.), Culturally responsive methodologies (pp. 263-286). Emerald.

Berryman, M., SooHoo, S., \& Nevin, A. (2013). Culturally responsive methodologies from the margins. In M. Berryman, S. SooHoo, \& A. Nevin (Eds.), Culturally responsive methodologies. Emerald.

California A.B. 19, 2017 (2021, March 11). Ch. 735, sec. 76396, art. 3. California Legislative Information.

California A.B. 504, 2017 (2021, March 11). Ch. 742, sec. 78220 \& 78221. California Legislative Information.

California A.B. 705, 2017 (2021, March 11). Ch. 745, sec. 78213. California Legislative Information.

California Education Code 55002, Title 5

California Community Colleges. (2021, March 11). Admission requirements. https://www.cccapply.org/en/colleges/requirements

California Community Colleges. (2021, March 3). Key facts. https://www.cccco.edu/AboutUs/Key-Facts

Carpenter, B. D., Achugar, M., Walter, D., \& Earhart, M. (2015). Developing teachers' critical language awareness: A case study of guided participation. Linguistics and Education, 32(Part A), 82-97. https://doi.org10.1016/j.linged.2015.03.016 
Colombi, M. C. (2015). Academic and cultural literacy for heritage speakers of Spanish: A case study of Latin@ students in California.Linguistics and Education, 32(Part A), 5-15. https://doi.org/10.1016/j.linged.2015.05.006

Crosta, P. M., \& Columbia University, C. C. R. C. (2013). Characteristics of early community college dropouts [CCRC Analytics]. Community College Research Center, Columbia University.

Donohue, J. P. (2012). Using systemic functional linguistics in academic writing development: An example from film studies. Journal of English for Academic Purposes, 11(1), 4-16. https://doi.org/10.1016/j.jeap.2011.11.003

Eggins, S. (2004). An introduction to systemic functional linguistics. Continuum.

Elbow, P. (1998). Writing without teachers. Oxford University Press.

Fang, Z., \& Schleppegrell, M. J. (2010). Disciplinary literacies across content areas: supporting secondary reading through functional language analysis: by making discipline-specific ways of using language explicit, teachers can help adolescents better engage with school knowledge and more effectively develop disciplinary literacies across academic content areas. Journal of Adolescent \& Adult Literacy, 53(7), 587-597. https://doi.org/10.1598/JAAL.53.7.6

Ferguson, D. L., \& Ferguson, P. M. (2000). Qualitative research in special education: Notes toward an open inquiry instead of a new orthodoxy? Journal for the Association for Persons With Severe Handicaps, 25(3), 180-185. https://doi.org/10.2511/rpsd.25.3.180

Forey, G. (2020). A whole school approach to SFL metalanguage and the explicit teaching of language for curriculum learning. Journal of English for Academic Purposes, 44. https://doi.org/10.1016/j.jeap.2019.100822 
Forey, G., \& Cheung, L. M. E. (2019). The benefits of explicit teaching of language for curriculum learning in the physical education classroom. English for Specific Purposes, 54, 91-109. https://doi.org/10.1016/j.esp.2019.01.001

Foundation for California Community Colleges. (2021, March 11). Facts and figures. https://foundationccc.org/About-Us/About-the-Colleges/Facts-and-Figures

Gebhard, M., Chen, I.-A., \& Britton, L. (2014). "Miss, nominalization is a nominalization": English language learners' use of SFL metalanguage and their literacy practices. Linguistics and Education, 26, 106-125. https://doi.org/10.1016/j.linged.2014.01.003

Glynn, T. (2013). Me Nohotahi, Mahitahi, Haeretahi Tatou: Collaborative partnerships between Indigenous and non-Indigenous researchers (Maori and Pakeha). In M. Berryman, S. SooHoo, \& A. Nevin (Eds.), Culturally responsive methodologies (pp. 35-52). Emerald.

Halliday, M. K. (1961). Categories of the theory of grammar. WORD, 17, 17241-17292.

Halliday, M. K., \& Matthiessen, C. M. (2014). An introduction to functional grammar. Oxford University Press.

Hamilton, M. L., Smith, L., \& Worthington, K. (2008). Fitting the methodology with the research: An exploration of narrative, self-study and auto-ethnography. Studying Teacher Education, 4(1), 17-28. https://doi.org/10.1080/17425960801976321

Harrison, J., MacGibbon, L., \& Morton, M. (2001). Regimes of trustworthiness in qualitative research: The rigors of reciprocity. Qualitative Inquiry, 7(3), 323-345. https://doi.org/10.1177/107780040100700305

Hasan, R. (2004). Analyzing discourse variation. In L. Young \& C. Harrison (Eds.), Systemic functional linguistics and critical discourse analysis: Studies in social change (pp. 1552). Continuum. 
Hughes, J. (2009). New media, new literacies and the adolescent learner. E-Learning and Digital Media, 6(3), 259-271. https://doi.org/10.2304/elea.2009.6.3.259

Jones, D. C. (2002). John Dewey and Peter Elbow: A pragmatist revision of social theory and practice. Rhetoric Review, 21(3), 264-281. https://doi.org/10.1207/S15327981RR2103_4

Kress, G. (2011). Discourse analysis and education: A multimodal social semiotic approach. In R. Rogers (Ed.), An introduction to critical discourse analysis in education. L. Erlbaum Associates.

Lancaster, Z. (2011). Interpersonal stance in L1 and L2 students' argumentative writing in economics: Implications for faculty development in WAC/WID programs. Across the disciplines: Interdisciplinary perspectives on language, learning, and academic writing (Supplement). https://doi.org/10.1111/j.1365-294x.2011.05072.x

Lancaster, Z. (2014). Exploring valued patterns of stance in upper-level student writing in the disciplines. Written Communication, 31(1), 27-57. https://doi.org/10.1177/0741088313515170

Lee, S. H. (2010). Command strategies for balancing respect and authority in undergraduate expository essays. Journal of English for Academic Purposes, 9(1), 61-75. https://doi.org/10.1016/j.jeap.2009.11.001

Liardét, C. L. (2016). Grammatical metaphor: Distinguishing success. Journal of English for Academic Purposes, 22, 109-118. https://doi.org/10.1016/j.jeap.2016.01.009

Loughran, J. (2004). International handbook of self-study of teaching and teacher education practices. Kluwer Academic. 
Macfarlane, S. (2013). To acquiesce and to coalesce: Achieving alignment and unity for Maori through culturally responsive and socially responsible research. In M. Berryman, S. SooHoo, \& A. Nevin (Eds.), Culturally responsive methodologies (pp. 129-148). Emerald.

Macken-Horarik, M., \& Morgan, W. (2011). Towards a metalanguage adequate to linguistic achievement in post-structuralism and English: Reflections on voicing in the writing of secondary students. Linguistics and Education, 22(2), 133-149. https://doi.org/10.1016/j.linged.2010.11.003

Martin, J. R. (2016). Meaning matters: A short history of systemic functional linguistics. WORD, 62(1), 35-58. https://doi.org/10.1080/00437956.2016.1141939

Merriam, S. B. (2002). Qualitative research in practice: Examples for discussion and analysis. Jossey-Bass Publishers.

Nagao, A. (2020). Adopting an SFL approach to teaching L2 writing through the teaching learning cycle. English Language Teaching, 13(6), 144-161. https://doi.org/10.5539/elt.v13n6p144

Neal, H. (2015). Theory to practice: Cultivating academic language proficiency in developmental reading classrooms. Journal of Developmental Education, 39(1), 12-34. https://www.jstor.org/stable/24613997

Nodelman, D. (2013). Culturally responsive methodology within an aesthetic framework. In M. Berryman, S. SooHoo, \& A. Nevin (Eds.), Culturally responsive methodologies (pp. 149174). Emerald. 
O’Hallaron, C. L., Palincsar, A. S., \& Schleppegrell, M. J. (2015). Reading science: Using systemic functional linguistics to support critical language awareness. Linguistics and Education, 32(Part A), 55-67. https://doi.org/10.1016/j.linged.2015.02.002

Pessoa, S., Mitchell, T. D., \& Miller, R. T. (2018). Scaffolding the argument genre in a multilingual university history classroom: Tracking the writing development of novice and experienced writers. English for Specific Purposes, 50, 81-96. https://doi.org/10.1016/j.esp.2017.12.002

Pinnegar, S. E., \& Hamilton, M. L. (2009). Self-study of practice as a genre of qualitative research: Theory, methodology, and practice. Springer.

Public Policy Institute of California. (2018). Majorities put high priority on universal health coverage, free community college. PPIC Statewide Survey: Californians and Their Government. https://www.ppic.org/press-release/majorities-put-high-priority-onuniversal-health-coverage-free-community-college/

Purser, E., Dreyfus, S., \& Jones, P. (2020). Big ideas \& sharp focus: Researching and developing students' academic writing across the disciplines. Journal of English for Academic Purposes, 43, 1-13. https://doi.org/10.1016/j.jeap.2019.100807

Ryan, M. (2011). Improving reflective writing in higher education: A social semiotic perspective. Teaching in Higher Education, 16(1), 99-111. http://doi.org/10.1080/13562517.2010.507311

Savage, N. (2018, June 20). Quick guide: Tuition free college in California. EdSource. https://edsource.org/2018/getting-free-college-tuition-in-california-a-quick-guide/599039 Schleppegrell, M. J. (2004). The language of schooling: A functional linguistics perspective. Erlbaum. 
Schulze, J. (2011). Writing to persuade: A systemic functional view. GIST Education and Learning Research Journal, 5, 127-157.

Schulze, J. (2015). Academic language, English language learners, and systemic functional linguistics: Connecting theory and practice in teacher education. CATESOL Journal, 27(1), 109-130. https:/files.eric.ed.gov/fulltext/EJ1111747.pdf

Shakespeare, T. (2013). The social model of disability. In L. Davis (Ed.), The disability studies reader (pp. 214-221). Routledge.

Smith, L. T. (2012). Decolonizing methodologies: Research and indigenous peoples (2nd ed). St. Martin's Press.

SooHoo, S. (2013). Humility within culturally responsive methodologies. In M. Berryman, S. SooHoo, \& A. Nevin (Eds.), Culturally responsive methodologies (pp. 199-220). Emerald.

Slater, T., \& Mohan, B. (2010). Cooperation between science teachers and ESL teachers: A register perspective. Theory Into Practice, 49(2), 91-98.

https://doi.org/10.1080/00405841003626478

Stuart-Smith, V. (2003). Using functional grammar to teach academic literacy skills to adults with language-related learning difficulties. The Australian Journal of Language and Literacy, 26(2), 69-81.

Strunk, W. (2009). The elements of style. Pearson Longman.

Webster, J., \& Halliday, M. K. (2009). Bloomsbury companion to systemic functional linguistics. Continuum. 
Wilson, A. (2013). Errant wanderings amongst the voices on the margins. In M. Berryman, S. SooHoo, \& A. Nevin (Eds.), Culturally responsive methodologies (pp. 245-262). Emerald.

Woods, C. S., Park, T., Hu, S., \& Jones, T. B. (2019). Reading, writing, and English course pathways when developmental education is optional: Course enrollment and success for underprepared first-time-in-college students. Community College Journal of Research and Practice, 43(1), 5-25. https://doi.org10.1080/10668926.2017.1391144

Xia, R. (2017). Cal State will no longer require placement exams and remedial classes for freshmen. Los Angeles Times. https://www.latimes.com/local/lanow/la-me-cal-stateremedial-requirements-20170803-story.html

Young, L., \& Harrison, C. (2004). Systemic functional linguistics and critical discourse analysis: Studies in social change. Continuum.

Zhang, W. (2017). Quality matters: Content literacy for English language learners. TESOL Journal, 8(1), 166-189. https://doi.org/10.1002/tesj.266

Zhang, X. (2019). Exploring the relationship between college students' writing anxiety and the pedagogical use of online resources. International Journal of Educational Technology in Higher Education, 16(1), 1-18. https://doi.org/10.1186/s41239-019-0149-y

Zinshteyn, M. (2019, February 14). California's new 'free college' law for community colleges covers more than tuition. EdSource. https://edsource.org/2019/californias-new-freecollege-law-for-community-colleges-covers-more-than-tuition/608612 